\title{
DINÂMICA DO FÓSFORO EM SOLO SUBMETIDO A SISTEMAS DE PREPARO ALTERNATIVOS AO DE CORTE E QUEIMA NO NORDESTE PARAENSE
}

\author{
MARCOS ANDRÉ PIEDADE GAMA
}

\begin{abstract}
Tese apresentada à Escola Superior de Agricultura "Luiz de Queiroz", Universidade de São Paulo, para obtenção do título de Doutor em Agronomia, Área de concentração: Solos e Nutrição de Plantas.
\end{abstract}

PIRACICABA

Estado de São Paulo - Brasil

Abril - 2002 


\title{
DINÂMICA DO FÓSFORO EM SOLO SUBMETIDO A SISTEMAS DE PREPARO ALTERNATIVOS AO DE CORTE E QUEIMA NO NORDESTE PARAENSE
}

\author{
MARCOS ANDRÉ PIEDADE GAMA \\ Engenheiro Agrônomo
}

Orientador: Prof. Dr. JORGE DE CASTRO KIEHL

Tese apresentada à Escola Superior de Agricultura "Luiz de Queiroz", Universidade de São Paulo, para obtenção do título de Doutor em Agronomia, Área de concentração: Solos e Nutrição de Plantas.

PIRACICABA

Estado de São Paulo - Brasil

Abril - 2002 
Dados Internacionais de Catalogação na Publicação (CIP)
DIVISÃO DE BIBLIOTECA E DOCUMENTACC̃O - ESALQ/USP

Gama, MarcosAndré Piedade

Dinâmica do fósforo em solo submetido a sistemas de preparo a ltemativos a o corte e queima no nordeste paraense / Marcos André Piedade Gama. - - Piracicaba, 2002.

$96 \mathrm{p}$.

Tese (doutorado) - Escola Superior de Agric ultura Luiz de Queiroz, 2002. Bibliografia.

1. Corte 2. Fertilida de do solo 3. Fertiliza ntes fosfata dos 4. Prepa ro do solo I. Título

CDD 631.42

"Permitida a cópia total ou parcial deste documento, desde que citada a fonte - O autor" 
À minha esposa e grande amor, Dênmora Araujo, pelo carinho, compreensão e companhe rismo;

Aos meus pais (Raimunda e Eládio);

Aos meus irmãos (Luis, Mauro e Simone) e ao meu querido sobrinho Maurício;

Ao tio Francisco Piedade (In memorian)

DEDICO. 


\section{AGRADECIMENTOS}

A Deus, pela força e presença divina em todas as fases de nossas vidas;

Ao Prof. Dr. Jorge de Castro Kiehl pela orientação, manifestada pela compreensão e liberdade.

À Coordenação do Curso de Solos e Nutrição de Plantas pelo apoio e oportunidade;

À Escola Superior de Agricultura "Luiz de Queiroz" e seus professores pela oportunidade de aprendizagem;

Ao Programa SHIFT (Studies on Human Impact on forests and Floodplains in the Tropics), acordo CNPq/IBAMA/DLR, em execução na Embrapa Amazônia Oriental

A Dra. Maria do Socorro A. Kato, pesquisadora da Embrapa Amazônia Oriental pelo inestimável apoio durante a execução deste trabalho;

Aos amigos da comunidade paraense de Piracicaba: Rainério e Rita, Nagib e Alice Melém, Michelle e Michell Costa, Edson Vidal e Gerlane, Oriel e Nely Lemos, Rosângela e família, Joelson e Betânia, Cláudia e Marcelino, Antônio, Patrícia e Hudson, pelos bons momentos de descontração;

Aos companheiros e amigos das horas extras: Tadeu e Cristina, Silvino, Marcia Simonete, Luis Timm, José Fernandes e Tilma, Reinaldo e Marli, Fábio Prata, Adriana, Belisa Ramos, Norberto; Genelício;

Aos amigos que contribuíram com o desenvolvimento do trabalho: Marcelo Alves, Edson Madruga, José Maria, José Luis e Júnior;

Às outras pessoas, que de forma não menos importante, contribuíram direta ou indiretamente para a realização desse trabalho. 


\section{SUMÁRIO}

\begin{tabular}{|c|c|}
\hline \multicolumn{2}{|l|}{ 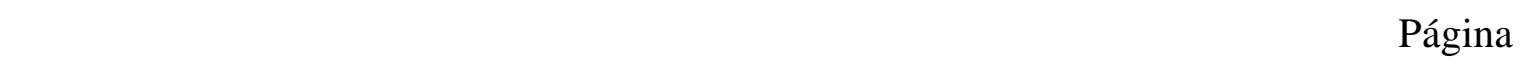 } \\
\hline RESUMO... & vii \\
\hline SUMMARY.. & ix \\
\hline 1 INTRODUÇÃO.... & 1 \\
\hline 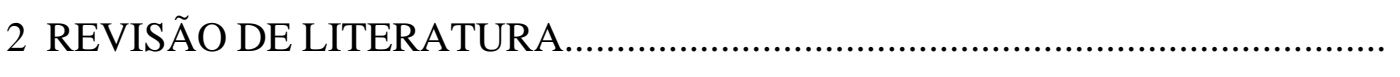 & 4 \\
\hline 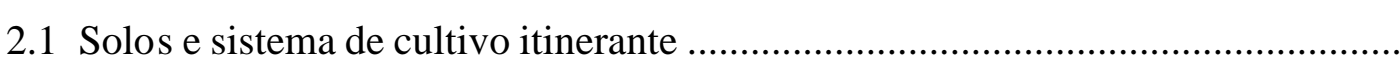 & 4 \\
\hline 2.2 Alternativas para sustentabilidade da agricultura familiar na Amazônia.............. & 9 \\
\hline 2.3 Dinâmica do fósforo nos solos......................... & 11 \\
\hline 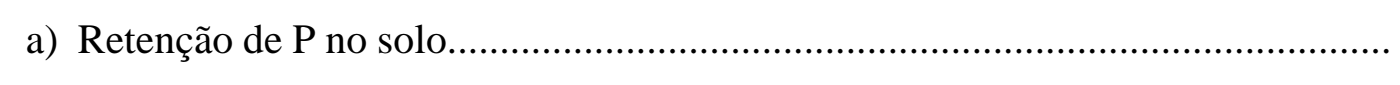 & 12 \\
\hline 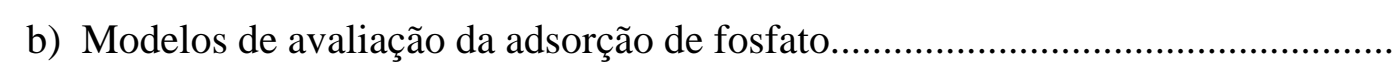 & 14 \\
\hline c) Formas de P no solo...................................... & 17 \\
\hline d) Métodos para estudo & 18 \\
\hline
\end{tabular}

3 MATERIAL E MÉTODOS ........................................................................... 21

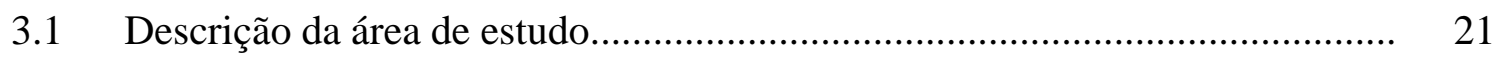

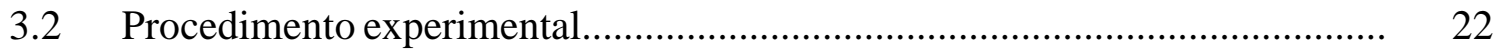

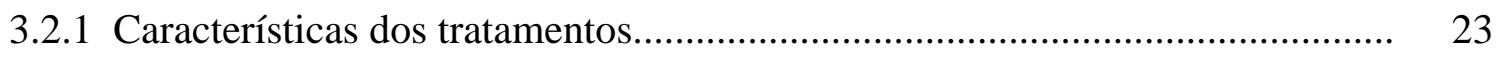

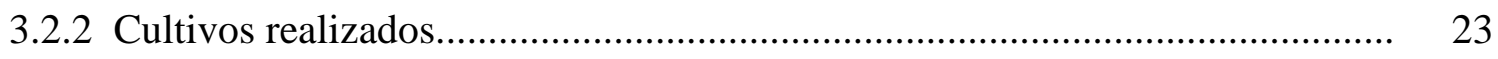

3.3 Amostras de solo e análises....................................................................... 24

3.3.1 Análises físicas e químicas do solo........................................................... 25

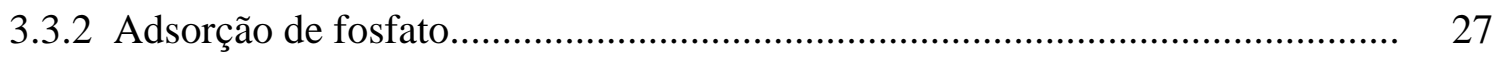

3.3.3 Fração de fósforo orgânico....................................................................... 29

4 RESULTADOS E DISCUSSÃO................................................................. 30 
4.1 Avaliação da fertilidade do solo nas áreas experimentais............................... 30

4.1.1 Caracterização química inicial do solo..................................................... 30

4.1.2 Avaliação da fertilidade do solo ao longo das épocas de amostragem............. 32

4.2 Adsorção de fósforo................................................................................... 43

4.2.1 As isotermas de Langmuir e Freundlich.................................................... 43

4.2.2 Representação gráfica e comparação dos ajustes das equações de Langmuir e

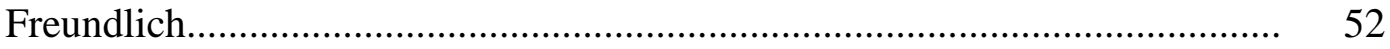

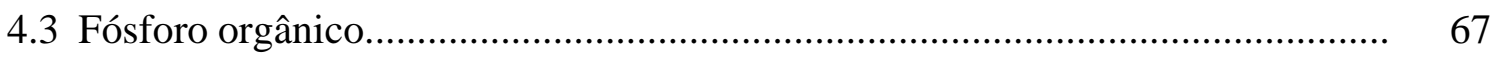

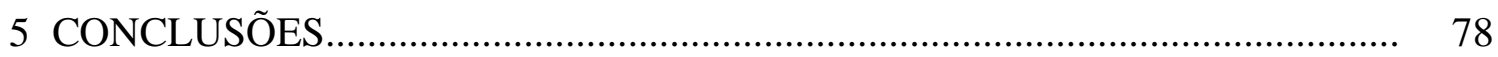

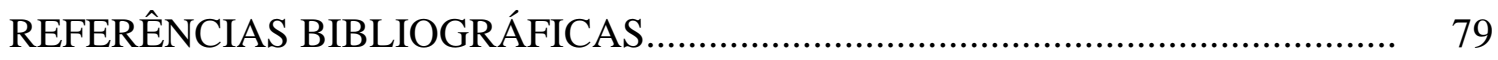




\title{
DINÂMICA DO FÓSFORO EM SOLO SUBMETIDO A SISTEMAS DE PREPARO ALTERNATIVOS AO DE CORTE E QUEIMA NO NORDESTE PARAENSE
}

\author{
Autor: MARCOS ANDRÉ PIEDADE GAMA \\ Orientador: Prof. Dr. JORGE DE CASTRO KIEHL
}

\section{RESUMO}

Na Amazônia, o sistema de cultivo predominante é o da agricultura de corte-queima, desenvolvido pelos pequenos agricultores que trabalham exclusivamente com mão-de-obra familiar e que são responsáveis pela maior parte da produção agrícola regional. Esse sistema, no entanto, deixa de ser sustentável quando desenvolvido em áreas como a do nordeste paraense, onde a densidade populacional é crescente e a disponibilidade de terra aos agricultores é pequena, sendo por isso, considerado como uma das causas do crescente desmatamento florestal e degradação dos solos. Além disso, outros fatores contribuem para o insucesso da agricultura de corte-queima, como por exemplo, a generalizada deficiência de fósforo (P), comum nos solos da região tropical e que possuem alta capacidade de retenção desse elemento. Esta pesquisa foi realizada na região nordeste paraense com o objetivo de avaliar as alterações na fertilidade do solo, no teor de $\mathrm{P}$ orgânico (Po) e na adsorção de fósforo em duas áreas submetidas a diferentes tempos de pousio (quatro anos- VS4a; e dez anos-VS10a) e a diferentes métodos de 
preparo do solo. Os tratamentos, em número de cinco, consistiram de duas formas de preparo da terra (1- corte e queima da vegetação; e 2- Corte, trituração e deposição da vegetação de pousio sobre o solo, como cobertura morta ou "mulching") combinadas com aplicação ou não de fertilizante NPK. O quinto tratamento (testemunha) consistiu de uma área na qual se manteve a vegetação de pousio. Amostras de solo foram coletadas em quatro períodos: antes do preparo inicial da área (outubro de 1994); no início (janeiro de 1997) e no final do segundo ciclo de cultivo (julho de 1998); e próximo ao final do segundo período de pousio (julho de 2000). Para todos os métodos de preparo do solo houve manutenção ou aumentos no nível de fertilidade do solo, avaliada pela matéria orgânica, P-resina, $\mathrm{pH}$ em $\mathrm{CaCl}_{2}$, saturação por bases e por alumínio trocável, bem como redução da capacidade de adsorção de P. O método de preparo do solo que não utiliza a queima da vegetação (mulching) mostrou-se superior ao método tradicional de corte-queima, uma vez que não degradou a fertilidade do solo, reduziu a capacidade de adsorção de $\mathrm{P}$ e aumentou a quantidade de $\mathrm{P}$ orgânico total. A utilização do fertilizante NPK contribuiu para manter o teor de P-resina e de P orgânico total do solo ao longo dos seis anos de estudo, independentemente da utilização ou não do fogo no preparo do solo. A sustentabilidade do sistema foi maior na área com tempo de pousio de 10 anos e com maior quantidade de biomassa vegetal do que na área com 4 anos de po usio. 


\section{PHOSPHORUS DYNAMICS IN A SOIL SUBJECTED TO CLEARING SYSTEMS ALTERNATIVE TO SLASH AND BURN IN NORTHEASTERN OF PARÁ}

Author: MARCOS ANDRÉ PIEDADE GAMA

Adviser: Prof. Dr. JORGE DE CASTRO KIEHL

\section{SUMMARY}

In Amazonia, Brazil, the most important cultivation system is the slash and burn agriculture or shifting agriculture. This system was developed by small farmers that use exclusively family labor and are responsible for most of the agricultural production in the region. However, this system is unsustainable when developed in areas such as the northeast of the State of Pará, where population is growing and land availability to farmers is small; such facts have been considered to be among the causes of the increasing deforested areas and degraded soils. In addition, other factors contribute to the failure of the shifting agriculture, as the widespread phosphorus deficiency $(\mathrm{P})$, common in the tropical soils with high capacity of phosphorus retention. This research was carried out in the northeast of the State of Pará, Brazil, to study alterations in the soil fertility, in the organic $\mathrm{P}(\mathrm{Po})$ content and in the phosphorus adsorption in two areas submitted to different fallow periods (four years - VS4a; ten years - VS10a) and different methods of soil preparation. Treatments, in a number of five, consisted of two methods of soil preparation (1- slash and burn of the vegetation; 
and 2- slash, chop and deposition of the fallow vegetation on the ground to act as a mulch), combined with application or not of NPK fertilizer. The fifth treatment (control) consisted of an area in which the fallow vegetation was maintained. Soil samples were collected in four periods: before the preparation of the area (October of 1994); at the beginning (January of 1997) and end of the second cultivation cycle (July of 1998); and almost at the end of the second fallow period (July of 2000). All soil preparation methods maintained or increased the soil fertility, evaluated by the content of organic matter and resin- $\mathrm{P}, \mathrm{pH}$ in $\mathrm{CaCl}_{2}$, soil base saturation and exchangeable $\mathrm{Al}$ content, as well as decreased phosphorus adsorption in the soil. Clearing the soil without burning was superior to the traditional slash and burn method, since soil fertility was not affected, phosphorous adsorption decreased and the amount of organic P increased. The application of NPK fertilizer helped in maintaining the content of resin-P and total organic $\mathrm{P}$ in the soil during the study period of six years, whether or not fire was used in the soil clearing process. System sustainability was higher in the area submitted to a fallow period of 10 years and containing a larger amount of plant biomass than in the area where the fallow period was only 4 years. 


\section{INTRODUÇÃ̃o}

O desenvolvimento de atividades agrícolas em algumas áreas da região tropical, como a Amazônia, vem sendo prejudicado por vários fatores. Entre esses fatores, destacam-se a situação econômica do agricultor, o acesso a crédito agrícola, assistência técnica adequada, a elevada acidez dos solos, o sistema de manejo da terra e a generalizada deficiência de fósforo $(\mathrm{P})$ nos solos.

Para os dois primeiros fatores, as soluções passam por melhorias na formação educacional e técnica dos agricultores e pela participação e apoio governamental nas atividades agrícolas. A questão da acidez dos solos na Amazônia vem sendo tratada nos últimos anos de forma mais adequada e ampla, tanto por pesquisadores quanto pelos agricultores, embora ainda sejam necessários vários estudos para o melhor entendimento da questão.

Há décadas que a deficiência de fósforo nos solos da região tropical vem sendo alvo de estudos. As pesquisas têm demonstrado que uma das principais causas dessa deficiência está relacionada aos processos de retenção de $\mathrm{P}$ (adsorção e precipitação) nos solos. Diante disso, os estudos têm procurado avaliar vários aspectos

que podem estar inter-relacionados com esses processos, tais como: extração e disponibilidade do elemento e os efeitos das propriedades do solo, das formas de manejo e do tipo de cultivo.

Na Amazônia, esses estudos ainda são incipientes e geralmente restritos à disponibilidade do fósforo em sistema de cultivo intensivo, o qual, embora importante, não é o mais utilizado na região. São poucas as pesquisas que buscam entender a dinâmica do P de maneira mais detalhada, como por exemplo realizando estudos de adsorção e de fracionamento do elemento no solo em função dos sistemas de manejo. 
A retenção de $\mathrm{P}$ ocorre através de processos nos quais fosfatos solúveis, geralmente aplicados como fertilizantes, se tornam menos disponíveis às plantas devido às reações com partículas orgânicas e inorgânicas do solo. Em decorrência disso, e da predominância de solos intemperizados na região amazônica, grandes quantidades de fertilizantes fosfatados são requeridas para suprir as necessidades das plantas.

Na Amazônia, o sistema de manejo do solo de grande importância ainda é o da agricultura de corte-queima, também chamado de itinerante. É a agricultura tradicional na região, desenvolvida em áreas pequenas (máximo de 1 ha) pelos pequenos agricultores, que trabalham exclusivamente com mão-de-obra familiar e que são responsáveis pela maior parte da produção agrícola regional.

É um sistema baseado no preparo da área através do corte e da queima da vegetação primária ou secundária, após o que é feito o plantio de culturas como arroz, milho, caupi (Vigna unguiculata) e mandioca por um período de um a dois anos. Ao final do cultivo, a área é deixada em pousio por um período, que em algumas microregiões da Amazônia, como a região nordeste paraense, tem se tornado cada vez menor (em média três anos de pousio) e mais dependente da disponibilidade de terra em cada propriedade. A sustentabilidade desse sistema é diretamente relacionada à regeneração da vegetação secundária (capoeira) e à recuperação da fertilidade do solo durante a fase de pousio.

O sistema corte-queima pode ser sustentável quando há disponibilidade de terra, pois nesse caso o tempo de pousio torna-se mais longo e suficiente para o acúmulo de nutrientes durante a regeneração da vegetação. No entanto, em áreas como as do nordeste paraense, onde a densidade populacional é crescente e a disponibilidade de terra aos agricultores é menor, essa atividade deixa de ser sustentável, sendo considerada como uma das responsáveis pelo crescente desmatamento florestal e degradação dos solos. Por esse motivo, nos últimos anos algumas pesquisas vêm sendo realizadas com o objetivo de aumentar a sustentabilidade desse sistema ou de delinear alternativas de preparo de área sem utilização de fogo.

Entre essas pesquisas, citam-se as que estão sendo desenvolvidas na região nordeste paraense, como por exemplo: i) corte da biomassa da capoeira para ser 
utilizada como cobertura morta e como fonte de matéria orgânica (M.O.) para o sistema sem a utilização de fogo; ii) enriquecimento da capoeira com espécies leguminosas de rápido crescimento e que fixam nitrogênio durante o período de pousio; iii) utilização de fertilizantes de forma isolada ou conjugada com a M.O.

$\mathrm{Na}$ avaliação desses sistemas, vários aspectos têm sido levados em consideração, tais como produção de biomassa proveniente da capoeira e das culturas agrícolas, alterações na composição química do solo, seleção de cultivares adaptadas, viabilidade econômica das alternativas, viabilidade do uso de fertilizantes inorgânicos e doses mais adequadas, adaptação de leguminosas no enriquecimento das capoeiras, etc. No entanto, nesses trabalhos, raramente tenta-se avaliar a dinâmica do fósforo durante a utilização desses sistemas alternativos de uso do solo, principalmente em experimentos de longa duração.

Os aspectos observados anteriormente levam à necessidade de estudos de sistemas alternativos que visem a sustentabilidade da agricultur a desenvolvida com mão de-obra familiar por um longo período em uma mesma área e que procurem entender a dinâmica do fósforo dentro dos mesmos. Esses estudos auxiliariam no entendimento dos processos de retenção, formas e manejo de fósforo no solo.

A hipótese desta pesquisa é a de que o preparo do solo sem a utilização da queima da vegetação e com o uso mínimo de fertilizante conduz a uma redução na adsorção de fósforo, a um aumento na fração de fósforo orgânico (Po) e a uma manutenção da fertilidade do solo por um longo período de tempo.

Diante disso, esta pesquisa teve como objetivo avaliar a adsorção de fósforo e as alterações no teor de $\mathrm{P}$ orgânico e na fertilidade do solo em duas áreas com diferentes idades de pousio submetidas a diferentes métodos de preparo do solo. 


\section{REVISÃO DE LITERATURA}

\subsection{Solos e Sistema de Cultivo Itinerante}

Os solos ácidos e inférteis, classificados como oxissolos e ultissolos, podem ocupar entre $75 \%$ e $80 \%$ da Bacia Amazônia, sendo profundos, e apresentando coloração vermelha ou amarelada. A principal limitação desses solos está relacionada às suas propriedades químicas, pois as físicas são adequadas. Deficiências de fósforo podem ser encontradas em grande parte dos solos dessa região, e seus efeitos dependem do cultivo realizado (Sanchez \& Buol, 1975; Sanchez et al., 1982; Vieira \& Santos, 1987).

Dentre os sistemas de manejo do solo para fins agrícolas, o que predomina na região amazônica é a agricultura de corte-queima ou itinerante. Esse sistema, segundo Sanchez (1976), é o mais amplamente utilizado na região tropical, sendo conhecido por vários nomes como "milpa" no México e América Central, e "roza", "monte" e "chaco" em outras partes da América do Sul. Em países de idoma inglês é chamado de "slash and burning agriculture", "bush following", "shifting cultivation" e swidden farming".

Myers (1991) relata que no trópico úmido cerca de 300 milhões de pessoas seriam dependentes de alguma forma do cultivo itinerante, e que essa prática contribuiria com cerca de $60 \%$ de todo o desmatamento. Brady (1996), numa revisão sobre o tema, relata que cerca de 240 milhões de hectares de floresta fechada e 170 milhões de hectares de floresta aberta podem estar envolvidas em alguma forma desse sistema, o que representaria cerca de $30 \%$ da terra arável global.

Outra importância desse sistema reside no fato de ser praticado pelos agricultores que trabalham exclusivamente com mão-de-obra familiar, 
pequenos agricultores, mas que são responsáveis pela maior parte da produção agrícola na Amazônia. Kato et al. (1992), trabalhando com sistemas de produção, citam que essa forma de uso do solo tem grande importância para a região nordeste do Estado do Pará. Serrão (1995) relata que pelo menos 500.000 pequenos produtores trabalham nessa forma de agricultura e são responsáveis por pelo menos $80 \%$ da produção total de alimentos da região amazônica.

É um sistema agrícola no qual o preparo do solo é feito com o corte e queima da vegetação primária ou secundária para o cultivo de culturas anuais (milho, arroz, feijão, caupi, mandioca) por um período curto de um a dois anos. Após isso, a área é deixada em pousio para regeneração da vegetação por período que é sempre maior que o de cultivo, enquanto nova área é utilizada.

Kanashiro \& Denich (1998) consideram que as pincipais funções do pousio são: o aumento do estoque de nutrientes através do acúmulo de biomassa das plantas (depende da capacidade de crescimento e vitalidade) e o controle das ervas daninhas que invadem a área no período de cultivo (ocorre em função da densidade da vegetação e do tempo).

Os pequenos agricultores da Amazônia preferem utilizar o sistema de corte-queima em áreas de vegetação secundária (capoeira) devido à facilidade de limpeza da terra. A sustentabilidade desse sistema é diretamente associada à vitalidade da capoeira. De uma forma geral, a principal função da capoeira é a acumulação de nutrientes que são liberados após a queima. O fogo, por sua vez, é utilizado por diversos motivos, entre os quais: controla as ervas daninhas, tem efeito fitossanitário (evitando problemas com pragas e doenças) e promove aumentos no $\mathrm{pH}$, nas bases trocáveis, na capacidade de troca de cátions (T) e na saturação por bases do solo (Brinkmann \& Nascimento, 1973; Hernani et al., 1987; Martins et al., 1990; Kato et al., 1999).

No entanto, a prática de corte e de queima da vegetação, antes da utilização do solo, é uma das principais causas de desmatamento na Amazônia (Fearsinde, 1996), além de ser também foco de queimadas nessa região.

A queima da vegetação pode gerar problemas sérios para o sistema agrícola e meio ambiente. Brinkmann \& Nascimento (1973), trabalhando com o sistema 
de corte-queima na Amazônia brasileira, observaram que durante a aplicação do fogo ocorre perda considerável de nutrientes por volatilização e, posteriormente, perdas por lixiviação, já que na fase inicial de cultivo as plantas ainda não tinham suficiente capacidade de absorção.

Resultados semelhantes foram obtidos por Mackensen et al. (1996), que trabalhando no nordeste paraense, verificaram grandes perdas de nutrientes para a atmosfera. Hölscher ${ }^{1}$, citado por Mackensen et al. (1996), relata que durante o período de pousio, a entrada de nutrientes ( $\mathrm{N}, \mathrm{Ca}$ e $\mathrm{Mg}$ ) via deposição é distintamente menor que as perdas estimadas devido à queima.

Além disso, outros problemas como declínio de rendimentos, erosão, degradação do solo, incêndios acidentais, emissões de carbono para a atmosfera e perda da biodiversidade, têm tornado a utilização do sistema corte-queima uma das grandes questões ambientais (Mapa \& Gunasena, 1995; Fujisaka \& White, 1998, Schroeder, 1995).

Esses problemas surgem ou são acelerados quando modificações, como redução na disponibilidade de terra e no tempo de regeneração da vegetação de pousio, proporcionam desempenho não satisfatório do sistema de corte-queima (Juo \& Manu, 1996). Essa situação demonstra que a adequada utilização dessa forma de agricultura exige dois importantes fatores: disponibilidade de terra e período de pousio longo.

Kleinman et al. (1996), trabalhando em Kembera, na Indonésia, verificaram correlações positivas entre alguns indicadores de fertilidade do solo (matéria orgânica, capacidade de troca de cátions, nitrato, $\mathrm{P}$ total e cátions básicos extraíveis) e a duração do período de pousio. Os autores concluíram que não havia evidência de que a agricultura de corte-queima conduziria à degradação da fertilidade do solo.

Produtores que trabalham com o sistema de corte-queima têm obtido produtividades agrícolas menores ao longo do tempo em áreas, como a do nordeste paraense, onde a densidade populacional chega a ser superior a 20 habitantes $/ \mathrm{km}^{2}$ e que têm, na sua maior parte, solos de fertilidade baixa (Homma, 1981).

\footnotetext{
${ }^{1}$ HÖLSCHER, D. Wasser- und Stoffhaushlt eines Agrarökosystems mit Waldbrache im östlichen Amazonasgebiet. Ph.D. Thesis, Göttinger Beiträge zur Land- und Forstwirtschaft in den Tropen und Subtropen, Bd. 106, 134 p. 1995.
} 
Juo \& Manu (1996) relatam que, idealmente, a agricultura de cortequeima é ecologicamente estável quando realizada em áreas sob baixa densidade populacional, condição que raramente existe, exceto em algumas regiões remotas das bacias do Congo e da Amazônia. Em termos de dinâmica de nutrientes, os autores consideram que a estabilidade do sistema itinerante ocorre mais em função do estoque total de nutrientes do sistema inteiro do que do ganho líquido do solo após o corte e a queima da vegetação.

Considerando os problemas relatados anteriormente e as crescentes idéias de proteção ambiental e utilização sustentável da terra, é que sistemas alternativos têm sido avaliados para substituir e/ou aumentar a sustentabilidade do sistema de cortequeima e, consequentemente, o tempo de cultivo numa mesma área. Essas alternativas, por sua vez, devem levar em consideração aspectos econômicos e produtivos. Sá et al. (1998) relatam que modificações do sistema itinerante envolvem a consideração e o manejo da capoeira como um componente importante desse sistema.

Lal (1986) e Tiessen et al. (1992) consideram que, para a realização de cultivo contínuo num sistema itinerante é essencial o suprimento contínuo de matéria orgânica na superfície do solo, sendo essa alternativa viável em áreas onde os longos períodos de pousios não são possíveis. Essa é uma situação típica do nordeste paraense, onde a densidade populacional é crescente e a disponibilidade de terra para os agricultores que trabalham com mão-de-obra familiar tende a diminuir.

Com a finalidade de substituir o sistema itinerante por outro mais eficiente, Sanchez et al. (1982), Nicholaides et al. (1985) e outros, trabalhando em Yurimaguas no Peru, aplicaram a tecnologia de produção agrícola contínua nos solos da Amazônia. Os autores concluíram que pelo menos três culturas de grãos poderiam ser cultivadas anualmente com apropriada utilização de fertilizantes, e que algumas propriedades do solo foram melhoradas ao longo dos anos com essa tecnologia. Além disso, estimou-se que essa tecnologia seria adequada para áreas de grande pressão demográfica e para reduzir o desmatamento florestal causado pela demanda de alimentos na região. 
Essa tecnologia utilizada em Yurimaguas, no entanto, não pode ser encarada como adequada para toda a região amazônica, pois entre outros fatores, a condição sócio econômica da maioria dos produtores não permitiria isso.

Fearnside (1987), fazendo uma análise sobre a tecnologia de Yurimaguas, indica que a avaliação da viabilidade e rentabilidade foram super-otimistas, e que a estimativa de redução do desmatamento é questionável. Suas observações críticas foram baseadas em seis fatores importantes: manutenção da fertilidade do solo, erosão, problemas econômicos, implicações políticas, pragas nas culturas, ervas daninhas e limites para a tecnologia (incluindo aí a questão da utilização de fertilizantes fosfatados).

Botschek et al. (1996), analisando uma toposequência na Amazônia, com características de solo, clima e vegetação típicas dessa região, concluíram que, considerando a condição sócio-econômica na bacia amazônica, os sistemas de baixo insumo ou "low-input" (Sanchez \& Salinas, 1981; Sanchez \& Benites, 1987) parecem ser os mais apropriados para essa região. No entanto, tais sistemas requerem conhecimentos adequados das propriedades dos solos.

Quando as condições iniciais são favoráveis em termos de nutrientes provenientes da cinza e de baixa pressão de ervas daninhas, o que ocorre em florestas secundárias de 10 anos de idade, o cultivo de baixo-insumo é viável. No entanto, esse sistema deixa de ter uma boa performance em solos nutricionalmente pobres, compactados e cheios de ervas daninhas (Sanchez \& Benites, 1987). As condições iniciais adequadas no primeiro caso determinam a duração do período de cultivo. Os autores relatam ainda que a instalação desses sistemas em várias partes do trópico úmido e com as devidas adaptações locais serviria de base para averiguar a aplicabilidade dessa tecnologia transitória entre os cultivos itinerantes e contínuos.

Outra opção que vem sendo amplamente avaliada como alternativa para substituir a agricultura itinerante são os sistemas agroflorestais (Raintree \& Warner, 1986; Wiersum, 1983; Padoch et al., 1985; Mapa \& Gunasena, 1995; Schroeder, 1995). Esses sistemas são modelos intermediários entre os ecossistemas florestais e agrícolas, caracterizados pela deposição de material orgânico ao solo e possibilidade de cultivo contínuo com pouco uso de fertilizante. 
Brasil (1992), objetivando a substituição da prática de corte-queima na Amazônia, avaliou o sistema de "alley cropping"- que é um sistema agroflorestal no qual faixas de culturas anuais são intercaladas com faixas de leguminosas para produção de material orgânico no próprio lugar. Nesse trabalho, foi verificado que a aplicação do material orgânico aumentou o teor de MO e proporcionou maior controle de ervas daninhas. Essa tecnologia não proporcionou aumentos significativos nos rendimentos das culturas, mas esse resultado pode ser considerado como positivo, já que os cultivos foram realizados anualmente, sem a necessidade de novas queimadas.

Martins (1992), numa revisão sobre a utilização de leguminosas para cultivo contínuo de culturas alimentares, relata a importância dessas plantas para a melhoria da fertilidade em áreas onde se deseja o utilização contínua do solo, principalmente através de técnicas de cobertura morta, adubação verde, cobertura viva ou cultivo em faixas.

A utilização de material orgânico para recuperação ou manutenção da fertilidade do solo pode ser viável na região tropical, mas vários estudos ainda são necessários. Ayanaba (1982) considera que essa técnica é suficiente apenas para reduzir as taxas de declínio do conteúdo de matéria orgânica do solo, mas ressalta que ainda não há evidência de que a mesma mantêm, ao longo tempo, os níveis de MO similares aos que ocorrem em solos com períodos de pousios longos.

Por outro lado, Kleinmann et al. (1995) relatam que em sistemas de corte e queima, cultivados continuamente, a utilização do "mulch" pode ser de grande importância para limitação da degradação do solo, pois há proteção da superfície do solo contra a radiação solar, precipitação e vento, reduzindo assim a suscetibilidade à erosão e mantendo constante a temperatura na superfície do solo.

\subsection{Alternativas para Sustentabilidade da Agricultura Familiar na Amazônia}

Os problemas relacionados com a agricultura itinerante, levam ao desenvolvimento de várias pesquisas com o objetivo de garantir a sustentabilidade do uso do solo. Um exemplo disso é o projeto "Vegetação Secundária como Vegetação de 
Pousio na Paisagem Agrícola da Amazônia Oriental: Função e Possibilidades de Manipulação”, proposto no âmbito da cooperação bilateral Brasil-Alemanha, através do Programa SHIFT (Studies on Human Impact on Forests and Floodplains in the Tropics, BMBF/CNPq/MCT/IBAMA) que é executado em parceria com a Embrapa Amazônia Oriental desde o início dos anos 90.

Inseridos nesse projeto, Brienza Junior et al. (1999) avaliaram a utilização de leguminosas para o enriquecimento da capoeira durante o período de pousio. Os autores observaram que esse sistema (um ano de cultivo + dois anos de pousio enriquecido) proporcionou um acúmulo de biomassa equivalente a 4 ou 5 anos de pousio tradicional. Os resultados demonstram a possibilidade de acumulação de biomassa na capoeira em períodos curtos.

Sommer et al. (1999) relatam que uma alternativa de preparo de área sem fogo, utilizando-se do corte e trituração da biomassa da vegetação para uso como cobertura morta (mulch), pode melhorar o balanço de nutrientes em relação ao sistema tradicional de corte-queima, pois evita perdas de nutrientes através da volatilização sem aumento de perdas por lixiviação.

Kato et al. (1999), trabalhando com três métodos de preparo do solo (queima, mulch e incorporação do material triturado) e utilizando ou não fertilizantes durante dois ciclos de cultivo, verificaram que, para obtenção de rendimentos aceitáveis das culturas (milho e caupi) no sistema de preparo do solo sem fogo, é essencial a utilização de fertilizante. Os efeitos residuais desse insumo duplicaram a produção de mandioca. Relataram, ainda, que o risco de degradação do solo pelo cultivo intensivo e período de pousio curto é considerado baixo, contanto que o material vegetal e os nutrientes sejam aplicados ao solo pela técnica de preparo do solo sem queima e pela adubação.

Kanashiro e Denich (1998), resumindo os principais resultados obtidos nos primeiros 4 anos do projeto, relatam entre outras coisas que: i) tecnologias de manejo da matéria orgânica em substituição à queima no preparo de área são umas das principais medidas para promover a sustentabilidade da agricultura tradicional na Amazônia; ii) a carência de P e N é o principal fator limitante da produção agrícola; iii) 
no sistema que utiliza o corte e trituração da capoeira para cobertura morta do solo, é necessária a aplicação de fertilizantes para obtenção de produção satisfatória de milho, arroz e caupi.

Szott \& Palm (1996), trabalhando com leguminosas para o manejo da vegetação por ocasião do período de pousio, na Amazônia peruana, verificaram que o estoque de $\mathrm{N}, \mathrm{P}$ e potássio em solos ácidos e inférteis durante o período de pousio pode ser acelerado pelo enriquecimento da vegetação de pousio, através da utilização de árvores leguminosas que tenham crescimento rápido. Os autores sugeriram algumas medidas que poderiam ser realizadas para melhorar o manejo da vegetação de pousio: identificação e seleção de leguminosas de crescimento rápido e que tenham sistema radicular profundo; utilização de culturas de cobertura por um curto período, mas que tenham crescimento mais rápido; utilizar técnicas de custo baixo.

\subsection{Dinâmica do Fósforo nos Solos}

O fósforo é um dos principais fatores limitantes para a produção de alimentos, principalmente na região tropical, onde predominam solos altamente intemperizados. Esse fato, ao longo dos anos, vem sendo amplamente divulgado na literatura (Leal \& Velloso, 1973; Lopez \& Cox, 1979; Sanchez et al., 1982; Fearnside, 1987; Botschek et al., 1996; Iyamuremye et al., 1996; Kanashiro e Denich, 1998; entre outros ).

Nos solos da região tropical, grande parte do P total está indisponível para utilização imediata pelas plantas. Vários trabalhos têm sido desenvolvidos para entender as causas das deficiências, assim como as relações existentes entre formas disponíveis e indisponíveis de $\mathrm{P}$ em diversas condições de solo. Em geral, os estudos que têm sido conduzidos buscam o entendimento e a quantificação dos processos de retenção e das formas de ocorrência de P nos solos. 


\section{a) Retenção de P nos solos}

De forma geral, vários pesquisadores têm considerado que os processos de retenção de fósforo englobam os mecanismos de adsorção e precipitação. Os óxidoshidróxidos de alumínio e ferro, componentes da fração coloidal, são os principais responsáveis por esses processos (Parfitt, 1978; Sample et al., 1980).

Com base na literatura, pode-se dizer que a adsorção é um termo que indica as reações químicas que ocorrem na superfície de separação de duas fases (interface), na qual a superfície é chamada de adsorvente, e a substância, de adsorvato. A precipitação é uma reação entre íons, com formação de uma nova fase ou novo composto definido.

A adsorção ocorre em duas fases: na primeira, há adsorção do $\mathrm{P}$ ao solo por processo rápido e através de atração eletrostática. Em seguida, já na segunda fase e num processo mais lento, o fosfato é adsorvido à superfície dos óxidos por meio de troca de ligantes, com $\mathrm{OH}^{-}$e $\mathrm{OH}_{2}{ }^{+}$. É uma reação com ligação predominantemente covalente, sendo chamada de adsorção específica (Parfitt et al., 1975; Parfitt, 1978; Sanchez \& Uehara, 1980; Barrow, 1985).

A precipitação ocorre geralmente com a formação de compostos pouco solúveis de $\mathrm{P}$ com as formas iônicas de $\mathrm{Al}$ e Fe. Esses precipitados variam na composição química e têm um produto da solubilidade mais alto que a variscita $\left(\mathrm{AlPO}_{4} \cdot 2 \mathrm{H}_{2} \mathrm{O}\right)$ e a estrengita $\left(\mathrm{FePO}_{4} \cdot 2 \mathrm{H}_{2} \mathrm{O}\right)$. Esses compostos, ao longo dos anos, podem liberar lentamente os íons $\mathrm{H}_{2} \mathrm{PO}_{4}{ }^{-}$para a solução do solo (Lindsay et al., 1962; Sanchez e Uehara, 1980).

Na literatura, verificam-se que as distinções entre adsorção e precipitação não são simples de serem identificadas, mas Hsu (1964) relata que, se as atividades de $\mathrm{Fe}^{3+}$ e $\mathrm{Al}^{3+}$ forem muito baixas na solução, a precipitação é menos importante que a adsorção. Sample et al. (1980) citam que o mecanismo de adsorção de P ao Fe e Al parece ser mais importante porque normalmente a quantidade de Fe e Al na solução do solo não é suficiente para precipitar todo o fósforo imobilizado. No entanto, esses autores relatam que não há consenso quanto às contribuições relativas de cada 
mecanismo de retenção de fósforo. Thomas e Peaslee (1973) consideram que do ponto de vista de resposta pelas plantas, a natureza dos dois mecanismos não difere tanto.

A formação de compostos de fósforo com ferro, alumínio e cálcio é dependente do $\mathrm{pH}$ e da natureza e quantidade dos minerais presentes na fração argila. Em solos ácidos e com predominância de caulinita e óxidos de $\mathrm{Fe}$ e Al, típicos de regiões tropicais, os compostos mais importantes são os de fósforo com Fe e Al. Em solos neutros ou calcáreos predominam os compostos de $\mathrm{P}$ com cálcio, como a hidroxiapatita (Parfitt, 1978).

Alguns trabalhos têm demonstrado que os óxidos de Al se correlacionam mais com a adsorção do que os óxidos de Fe. Isso também serve para as relações com Fe e Al trocáveis. Uma das justificativas é a de que os compostos de Al são mais ativos na adsorção que os de Fe (Udo \& Uzu, 1972).

Na maior parte do Brasil e de outros países, vários estudos a cerca dos processos de retenção de fósforo já foram realizados e têm demonstrado que, além das propriedades dos solos já citadas anteriormente, outras influem nesses processos, como por exemplo, matéria orgânica, superfície específica, $\mathrm{pH}$, cátions trocáveis, temperatura e cor do solo (Fox \& Kamprath, 1971; Leal \& Velloso, 1973; Rajan \& Fox, 1975; Munns \& Fox, 1976; Almeida Neto \& Brasil Sobrinho, 1977; Bigham et al., 1978; Lopes \& Cox, 1979; Nakos, 1987; Mehadi e Taylor, 1988; Brennan et al., 1994; Ker et al., 1996; Fontes \& Weed, 1996). No entanto, poucos são os trabalhos sobre retenção de fósforo nos solos da Amazônia brasileira, Essas publicações têm demonstrado haver correlações entre adsorção máxima e algumas propriedades dos solos como conteúdo de argila e de óxidos-hidróxidos de Fe e Al (Singh et al., 1983; Moller \& Klant, 1984; Brasil \& Muraoka, 1995). Em nenhum desses trabalhos avaliou-se o comportamento dos solos quando submetidos a diferentes formas ou práticas de manejo.

Existem na literatura pesquisas sobre o efeito de algumas práticas de manejo do solo sobre a retenção de P. Entre essas tem-se: comparações de áreas virgens com cultivadas (Mehadi et al., 1990); efeito da rotação de culturas (Hedley et al., 1982a; Silva et al., 1997); efeito da utilização de materiais orgânicos (Lemare et al., 1987; O'Reilly \& Sims, 1995; Nziguheba et al., 1998); efeito da queima de palha no campo 
(Kwari e Batey, 1991). Em geral, esses trabalhos têm demonstrado que o uso de materiais orgânicos e a queima da vegetação no campo geram efeitos opostos na adsorção e disponibilidade de fósforo no solo. A primeira prática tende a reduzir a adsorção e a aumentar a disponibilidade.

\section{b) Modelos de Avaliação da Adsorção de Fosfato.}

A adsorção de fosfatos pelos solos é experimentalmente determinada pela seguinte maneira: a uma sequência de amostras do solo são adicionadas soluções com concentrações crescentes de $\mathrm{P}$, e após um certo tempo de agitação, determinam-se as concentrações de equilíbrio para cada amostra. O P adsorvido pelo solo é obtido pelo cálculo da diferença entre a concentração de $\mathrm{P}$ adicionada e a de equilíbrio. Esse procedimento vem sendo citado e utilizado em vários trabalhos relacionados com adsorção (Rajan \& Fox, 1975; Parfitt, 1978; Mehadi \& Taylor, 1988; Barrow et al., 1998; Casa Grande 1993; Brasil \& Muraoka, 1995).

Para determinação da amplitude de concentrações de $\mathrm{P}$ a serem utilizadas no procedimento citado anteriormente, Alvarez V. et al. (2000) sugerem a determinação prévia do $\mathrm{P}$ remanescente (P-rem), que é a quantidade de $\mathrm{P}$ adicionada que fica na solução de equilíbrio após concluído o contato com o solo. Os autores, nesse trabalho, citam uma metodologia simples e rápida que pode ser empregada para a determinação do P-rem. A utilização do P-rem é baseda na sua estreita correlação com a capacidade tampão de fosfatos e com a capacidade máxima de adsorção de fósforo.

Os resultados de $\mathrm{P}$ adsorvido e $\mathrm{P}$ na concentração de equilíbrio obtidos experimentalmente são usualmente avaliados através das isotermas de adsorção. Isotermas são equações matemáticas utilizadas para representar quantitativamente os mecanismos de adsorção e precipitação. Entre essas equações, as mais utilizadas são as de Langmuir e de Freundlich (Olsen \& Watanabe, 1957; Larsen, 1967; Leal \& Velloso, 1973; Singh et al., 1983). 
A isoterma de Langmuir foi desenvolvida inicialmente para representar a adsorção de gases em sólidos, e Olsen \& Watanabe (1957) foram os primeiros a utilizar essa equação para descrever a adsorção de $\mathrm{P}$ em solos. Essa equação baseia-se em duas pressuposições: a) a adsorção ocorre em uma camada, e b) a constante de energia de adsorção não varia com o aumento da quantidade do elemento adsorvido.

O modelo ajustado pela equação de Langmuir é hiperbólico, e sua forma mais simples é:

$$
x / m=\frac{K C b}{1+K C}
$$

Na qual: $\mathbf{x} / \mathbf{m}$ é a quantidade do elemento adsorvido ao solo; b é a capacidade máxima de adsorção do elemento; K é a constante relacionada com a energia de ligação do elemento ao solo; C é a concentração do elemento na solução de equilíbrio.

Para obtenção das estimativas das constantes $\mathrm{K}$ e b deve-se utilizar a forma linearizada da equação de Langmuir:

$$
C / x / m=\frac{1}{K b}+\frac{C}{b}
$$

A grande vantagem da utilização da equação de Langmuir em relação às demais é que através dela se tem a estimativa da capacidade máxima de adsorção (b) e da constante relacionada com a energia de ligação (K). Almeida Neto \& Brasil Sobrinho (1977) verificaram que solos que apresentam maior valor de adsorção máxima exigem maiores quantidades de fertilizantes fosfatados para que as culturas alcancem produção máxima. Quanto a constante K, Mehadi \& Taylor (1988), por exemplo, verificaram que quanto maior o valor dessa constante maior a energia da adsorção de P`a superfície do solo. Esses autores observaram menores valores de $\mathrm{K}$ em solos cultivados, o que foi 
justificado pelo fato de que nessas condições a quantidade de $\mathrm{P}$ disponível é maior, ou seja, o P disponível não permite que os sítios de adsorção fiquem mais ativos e tenham maior capacidade de adsorção.

Além da capacidade de adsorção máxima e da constante $\mathrm{K}$, outra informação que pode ser obtida a partir dessa isoterma está relacionada à capacidade tampão máxima (CTM), a qual pode ser determinada pelo produto das constantes K e b (Holford \& Mattingly, 1976; Laverdière \& Karan, 1984).

De maneira simples pode-se dizer que CTM é a resistência do solo a mudanças do P lábil como consequência de alterações no P da solução. A limitação da CTM como um parâmetro para entendimento do $\mathrm{P}$ no sistema solo é que podem ocorrer alterações significativas quando o fósforo é adicionado ou retirado do sistema. Além disso, quanto maiores os valores de CTM maiores as quantidades de P que devem ser utilizadas para se alcançar determinadas concentrações desse elemento na solução do solo (Fox \& Kamprath, 1970; Holford \& Mattingly, 1976; Laverdière \& Karan, 1984).

Um dos problemas com utilização da isoterma de Langmuir está relacionado com erros de cerca de $50 \%$ ou mais na estimativa da capacidade máxima de adsorção (b) obtidas a partir de uma curva ajustada com dados que não se aproximam dessa estimativa (Harter, 1984; Taylor et al.,1996). No entanto, esse problema pode ser minimizado pela utilização do valor do $\mathrm{P}$ remanescente para encontrar a melhor amplitude de concentração de $\mathrm{P}$ a ser utilizada na agitação com as amostras de solo.

A equação de Langmuir também pode ser encontrada com outras variações, mas Harter (1984) considera que a utilização dessa isoterma com duas ou mais regiões de estudo não tem sido.

A isoterma de Freundlich é empírica e as constantes da equação não têm significado físico. Indica que a energia de ligação decresce exponencialmente com a saturação da superfície de adsorção. Pesquisas têm demonstrado ajustes satisfatórios com a utilização dessa equação (Larsen, 1967; Bache \& Williams, 1971; Barrow, 1978, Mead, 1981; entre outros).

A represent ação exponencial segue a seguinte equação: 


$$
x / m=K \cdot C^{1 / n}
$$

Na qual: $\mathbf{K}$ e $\mathbf{n}$ são as constantes; $\mathbf{x} / \mathbf{m}$ e $\mathbf{C}$ têm o mesmo significado da equação de Langmuir.

A forma linearizada da equação é:

\section{$\log \mathbf{x} / \mathbf{m}=\log K+(1 / n) \log C$}

\section{c) Formas de P no Solo}

No solo o P ocorre basicamente nas formas orgânicas $(\mathrm{Po})$ e inorgânicas (Pi), com diferentes graus de solubilidade (Dalal, 1977). A manutenção do P orgânico ocorre em função da manutenção da matéria orgânica do solo, e as formas inorgânicas dependem do estágio químico de intemperização do solo, pois a proporção de fosfatos de cálcio diminui com a intemperização, ocorrendo o inverso com a de fosfatos de alumínio que são menos solúveis que os primeiros (Sanchez, 1976).

Os processos geoquímicos, em vários ecossistemas naturais, podem determinar a distribuição do $\mathrm{P}$ a longo prazo, mas a curto prazo os processos biológicos influenciam essa distribuição, porque muito do fósforo disponível às plantas é proveniente da matéria orgânica (Smeck, 1985; Walbridge, 1991). Processos biológicos regulam o movimento e distribuição de formas lábeis de $\mathrm{P}$, e a reciclagem da forma orgânica é importante para disponibilidade desse elemento (Stewart \& Tiessen, 1987). Ainda sobre distribuição de P no solo, Walker \& Syers (1976) sugerem que a proporção de P nas frações lábil, não lábil, oclusa e não oclusa podem variar nos solos em função do grau de intemperização dos mesmos.

Os métodos usuais de determinação de $\mathrm{P}$ do solo fornecem um índice do Pi disponível às plantas e são utilizados para estimar a necessidade de fertilizantes fosfatados. No entanto, as plantas são capazes de utilizar quantidades substanciais de P de compartimentos (pools) menos lábeis (Hedley et al., 1982a; Tiessen et al., 1984; 
Oberson et al., 1993). Compartimentos de P, como o Po, não são quantificados pelas análises de rotina de solos, embora já se tenha demonstrado haver correlação entre os vários compartimentos de fósforo (Tiessen et al., 1984; Beck e Sanchez, 1994). Beck e Sanchez (1994) e Linquist et al (1997) verificaram que em sistemas não fertilizados o Po é a principal fonte de fósforo disponível.

Nesse sentido, vários trabalhos têm demonstrado a importância da fração de $\mathrm{P}$ orgânico na ciclagem e na nutrição desse elemento às plantas, tanto em solos da região temperada como tropical (Acquaye, 1963; Adeptu \& Corey, 1976; Harrison, 1982; Stewart \& Tiessen, 1987). Outro aspecto importante e que tem sido alvo de estudos é que a natureza e a dinâmica da matéria orgânica e dos nutrientes associados (inclusive P), apresentam comportamentos diferentes sob diferentes sistemas de uso do solo (Turrión, 2000), ou seja, as práticas de cultivo influenciam o comportamento da MO e, consequentemente, das formas de fósforo no solo.

Por essas razões, vários são os trabalhos que têm sido desenvolvidos com o intuito de quantificar e entender a dinâmica de formas ou frações de P (orgânico e inorgânico) em função de diferentes práticas ou sistemas de uso do solo (Thompson \& Black, 1970; Hedley et al., 1982a; O’Halloran et al., 1987; Pavan \& Leal, 1995; Pavan \& Filho, 1995; Iyamuremye et al., 1996; Beck \& Sanchez, 1996; Nziguheba et al., 1998). Entre as práticas avaliadas nesses trabalhos tem-se: utilização de diferentes fontes de matéria orgânica, de sistemas de cultivo com aplicação ou não de fertilizantes em longa duração, e de sistemas que envolvem utilização conjugada de fertilizantes e materiais orgânicos em períodos de curta e longa duração.

Na Amazônia, no entanto, os trabalhos anteriormente citados são raros, principalmente da questão de avaliação das relações entre formas de fósforo orgânico e os sistemas de cultivos desenvolvidos na região.

\section{d) Métodos para estudo de formas de Fósforo}

Métodos de fracionamentos têm sido desenvolvidos e adaptados para o estudo de formas de $\mathrm{P}$ no solo, em várias partes do mundo. O fracionamento ou extração 
sequencial tem sido utilizado para avaliação do fósforo removido de transformações de longa duração, os quais removem primeiro formas de $\mathrm{P}$ lábeis, e então as formas mais estáveis (Tiessen \& Moir, 1993).

Beck e Sanchez (1994) relatam que o fracionamento proposto por Chang e Jackson (1957) extrai várias formas de P inorgânico e é amplamente utilizado para estudos de transformações de fosfatos aplicados e formas nativas. No entanto, esse método extrai o $\mathrm{P}$ fortemente retido e não é apropriado para estudos de dinâmica de $\mathrm{P}$ do solo que influencia a absorção pelas plantas. Os autores verificaram ainda que o método proposto por Hedley et al. (1982b) fraciona o P em cinco formas de Pi, três de Po, além do $\mathrm{P}$ residual. Os tratamentos crescentemente severos extraem frações de $\mathrm{P}$ que são tidas como menos disponíveis às plantas.

O método proposto por Hedley et al. (1982b), com ou sem modificações, tem sido amplamente utilizado nas últimas décadas, pois possibilita o entendimento da dinâmica do $\mathrm{P}$ quanto às formas inorgânicas e orgânicas, e pode ser empregado em experimentos que envolvam utilização de matéria orgânica ou diferentes práticas ou sistemas de manejo do solo (ex: cultivos convencional, mínimo, de baixo insumo) de curta e longa duração (Hedley et al., 1982a; O’Halloran et al., 1987; Tiessen \& Moir, 1993; Beck e Sanchez, 1994 e 1996; Pavan \& Leal, 1995; Pavan \& Filho, 1995; Iyamuremye et al., 1996; Nziguheba et al., 1998).

Para determinação do fósforo orgânico dos solos também podem ser utilizados alguns procedimentos indiretos que fornecem uma estimativa do $\mathrm{P}$ orgânico total. Um desses é o método de extração (Mehta et al., 1954), que envolve o tratamento dos solos com ácidos, bases ou ambos, seguido pela determinação do $\mathrm{P}$ no extrato, antes e depois da oxidação da matéria orgânica. O outro é o método de ignição (Saunders \& Williams, 1955), no qual são utilizadas temperaturas altas ou baixas para oxidação da MO antes da extração ácida do P total. Uma amostra que não passa pela ignição é utilizada para a extração ácida do $\mathrm{P}$ inorgânico. Nos dois métodos o Po é obtido pela diferença entre o P total e o Pi.

O método de ignição é menos trabalhoso que o de extração. O’Halloran (1993) relata que, em geral, para muitos solos os dois procedimentos proporcionam 
valores de Po comparáveis, embora o método de ignição apresente tendência para indicar valores mais altos de Po para solos mais intemperizados.

Bowman (1989) relata que o método de extração é mais adaptado para comparações dos níveis de Po entre diferentes tipos de solos, enquanto que o método de ignição é mais satisfatório para comparação de tratamentos dentro de um mesmo tipo de solo. Esse autor apresentou ainda um terceiro método, que envolve extração sequencial de Po com a utilização de $\mathrm{H}_{2} \mathrm{SO}_{4}$ e $\mathrm{NaOH}$. Esse procedimento é mais rápido que os outros dois, além disso fornece resultados similares aos obtidos com o método de Mehta et al. (1954). O método de Bowman (1989), no entanto, foi avaliado para solos pouco intemperizados.

Condron et al. (1990) compararam os métodos de ignição e extração na determinação de fósforo orgânico total de solos de várias partes do mundo e verificaram que para os dois métodos de extração os resultados foram similares, enquanto que pelo método de ignição foram obtidos os maiores valores de Po. Os autores também observaram que os resultados com o método de ignição apresentaram um menor coeficiente de variação. 


\section{MATERIAL E MÉTODOS}

\subsection{Descrição da Área de Estudo}

$\mathrm{O}$ experimento foi instalado em área de pequeno produtor na comunidade de Cumaru, no Município de Igarapé-Açu, localizado na região nordeste do Estado do Pará (Figura 1). O Município possui uma área de $797 \mathrm{~km}^{2} \mathrm{e}$ tem uma população de 32.361 habitantes, com uma densidade demográfica de 40,6 habitantes $/ \mathrm{km}^{2}$ (IBGE, 2000). Apresenta uma precipitação média anual de $2500 \mathrm{~mm}$ e temperatura média anual variando entre 25 e $26^{\circ} \mathrm{C}$. É uma região com relevo plano a suave ondulado.

Os solos predominantes da região eram classificados como Latossolos Amarelos álicos com horizonte A moderado, sendo Oxisol pela USDA Soil Taxonomy. No entanto, com o decorrer do uso intensivo pelo cultivo itinerante e com a erosão laminar principalmente do horizonte superficial, grande parte desses solos começou a apresentar uma relação textural do horizonte B sob o A bastante elevada (abrúptica).

Diante disso, em estudos mais recentes e detalhados, esses solos estão sendo classificados como Podzólico Amarelo álico, ou Ultissol pela USDA Soil Taxonomy (Kanashiro e Denich, 1998). Pela atual classificação brasileira esses solos são denominados de Argissolo Amarelo distróficos.

Nas áreas experimentais os solos são classificados como Argissolos Amarelos distróficos (Embrapa, 1999), com textura variando de arenosa a média. Pela USDA Soil Taxonomy o solo é classificado como Typic Kandiudults. 




Figura 1 - Localização do área experimental na região do nordeste paraense.

\subsection{Procedimento Experimental}

Os estudos foram conduzidos em duas áreas que estavam em pousio e com vegetação secundária em idades de 4 e 10 anos. Por esse motivo as áreas foram identificadas como área VS4a e área VS10a. Foi quantificada a biomassa aérea total da vegetação nas duas áreas, encontrando-se valores de 24 e $59 \mathrm{t} \mathrm{ha}^{-1}$ de matéria seca, nas áreas VS4a e VS10a, respectivamente. A metodologia para determinação dessa biomassa bem como da análise de nutrientes estão apresentados em Kato et al. (1999).

Foram avaliadas duas formas de preparo da terra (1 - corte e queima da vegetação; 2- Corte e trituração da vegetação de pousio para cobertura morta mulching) com e sem o utilização de fertilizante NPK. Como testemunha foi utilizada parcela com a capoeira original, o que totaliza cinco tratamentos arranjados em blocos ao acaso. Cada parcela experimental possui uma área de $120 \mathrm{~m}^{2}(10 \mathrm{x} 12 \mathrm{~m})$. 


\subsubsection{Características dos tratamentos}

a) Preparo da terra com queima - é o sistema tradicional dos agricultores da região e consistiu da broca, corte e queima da vegetação de pousio.

b) Preparo da terra sem queima (mulching) - a vegetação de pousio foi cortada e triturada com uma ensiladeira de forragem acoplada à um trator de roda. Toda vegetação triturada foi distribuída uniformemente sobre o solo. Isso foi realizado no primeiro corte da capoeira. Atualmente estão sendo utilizados dois equipamentos agrícolas que trituram a capoeira, também atrelados ao trator de rodas, sendo um desenvolvido no Instituto de Engenharia Agrícola da Universidade de Göttigem TRITUCAP $^{2}$ (Figura 2a) e outro que já existe no mercado - Fresador AHWI-600 3 (Figura 2b)

\subsubsection{Cultivos realizados}

O sistema de cultivo foi o plantio de arroz seguido de caupi (Vigna unguiculata) associado com mandioca. Até o momento já foram realizados dois ciclos de cultivos. Foram realizados dois ciclos de cultivos. Entre um cultivo e outro a área foi deixada em pousio por um período de seis meses, conforme mostra a Figura 3. Nas parcelas com fertilizantes foram utilizadas como fontes de NPK a uréia, o superfosfato triplo e o cloreto de potássio, respectivamente. Para a cultura do arroz foram utilizados 50,25 e $25 \mathrm{~kg} \mathrm{ha}^{-1}$ de $\mathrm{N}, \mathrm{P}_{2} \mathrm{O}_{5}$ e $\mathrm{K}_{2} \mathrm{O}$ respectivamente e para a cultura do caupi, 10, 22 e $42 \mathrm{~kg} \mathrm{ha}^{-1}$ de NPK.

\footnotetext{
2 Tritucap - trator com lâminas acopladas (Figura 1), que corta e tritura capoeira de cinco anos de idade numa só passada. A velocidade média de trabalho é de $1,5 \mathrm{~km} / \mathrm{h}$. A máquina corta e tritura cerca de 10 toneladas de massa verde por hora.

${ }^{3}$ Fresadora FM 600 - é capaz de triturar a capoeira de até doze anos de idade. Trabalha em duas passadas: na primeira, de marcha ré, ocorre a derrubada da vegetação e na segunda passada, indo de frente, ocorre a trituração do material. Em capoeira de oito anos de idade tem um desempenho 5 horas por hectare.
} 
(a)


Figura 2 - Área preparada com o tritucap e a lâmina de serra e facas helicoidais utilizadas na máquina (a); Preparo de área com a fresadora AHWI FM 600 e os dentes no rotor principal da máquina (b).

\subsection{Amostras de solo e Análises}

Para as análises de solo foram coletadas amostras nas profundidades de 0-10 cm e $10-20 \mathrm{~cm}$, nas duas áreas experimentais (VS4a e VS10a). Neste trabalho foram utilizadas as amostras coletadas em quatro períodos: $1^{\circ}$ ) antes do preparo inicial da área - outubro de $1994 ; 2^{\circ}$ ) no início do segundo ciclo de cultivo - janeiro de 1997; $3^{\circ}$ ) no final do segundo ciclo de cultivo - julho de 1998 ; e $4^{\circ}$ ) próximo ao final do segundo período de pousio - julho de 2000 (Figura 3). 


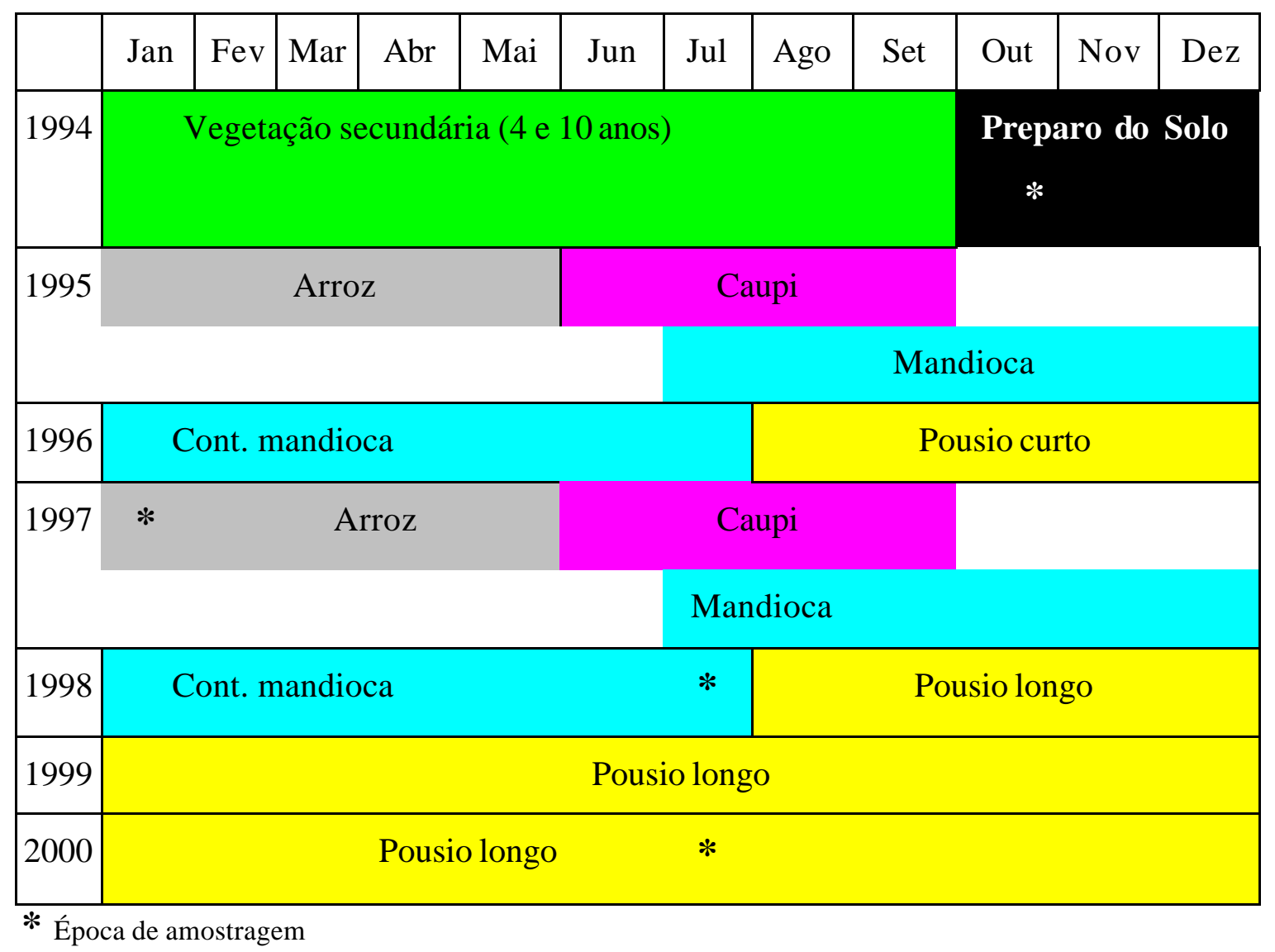

Figura 3 - Ciclos de cultivo e épocas de amostragem na área experimental no período de $1994-2000$.

\subsubsection{Análises Físicas e Químicas do Solo}

As análises físicas foram utilizadas para caracterização das áreas experimentais. Foram obtidas pela equipe do projeto SHIFT por ocasião da instalação do experimento e estão apresentadas nas Tabelas 1 e 2. Entre os parâmetros apresentados estão: areia grossa e fina, silte, argila total e dispersa em água, densidade do solo e porosidade (macro, micro e total).

Pela Tabela 1 verifica-se que o solo da área VS10a possui conteúdos de argila total maior do que o solo da área VS4a, principalmente nas camadas mais profundas. As diferenças entre as duas áreas quanto à densidade e porosidade são mais 
evidentes a partir da profundidade 10-20 (Tabela 2), quando foram observados os valores de densidade e microporosidade maiores para a área VS10a.

As análises químicas foram realizadas tanto para caracterização inicial nas duas áreas experimentais (Tabela 3) quanto para atender os objetivos de avaliação da fertilidade do solo em função dos tratamentos aplicados e das quatro épocas de amostragens.

Entre as determinações foram realizadas as seguintes: $\mathrm{pH}$ em solução $\mathrm{CaCl}_{2}$ 0,01 mol L ${ }^{-1}$, pH em água, $\mathrm{pH}$ em $\mathrm{KCl} 1 \mathrm{~mol} \mathrm{~L}^{-1}$, fósforo, cálcio, magnésio e teores de matéria orgânica segundo as metodologias citadas em Raij et al. (1987). Após isso foram calculadas a soma de bases, capacidade de troca de cátions $(\mathrm{T})$, saturação por bases (V\%) e saturação por alumínio (m\%). Os resultados dessas análises estão apresentadas na tabela 2 .

Tabela 1. Conteúdos de areia, silte e argila (total e dispersa em água) nos solos das duas áreas experimentais (VS4a e VS10a).

\begin{tabular}{|c|c|c|c|c|c|}
\hline Profundidade & Areia Grossa & $\begin{array}{c}\text { Areia } \\
\text { Fina }\end{array}$ & Silte & Argila Total & $\begin{array}{c}\text { Argila dispersa em } \\
\text { água }\end{array}$ \\
\hline \multirow[t]{2}{*}{$(\mathrm{cm})$} & 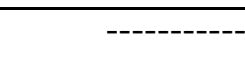 & ------ & - &  & 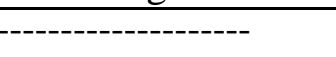 \\
\hline & \multicolumn{5}{|c|}{ VS4a } \\
\hline $0-7$ & 71 & 21 & 4 & 4 & 0 \\
\hline $7-15$ & 66 & 26 & 4 & 4 & 0 \\
\hline $15-29$ & 56 & 27 & 11 & 6 & 0 \\
\hline \multirow[t]{2}{*}{$29-61$} & 50 & 28 & 10 & 12 & 2 \\
\hline & \multicolumn{5}{|c|}{ VS10a } \\
\hline $0-7$ & 71 & 18 & 7 & 4 & 0 \\
\hline $7-19$ & 65 & 17 & 10 & 8 & 0 \\
\hline $19-45$ & 55 & 16 & 11 & 18 & 10 \\
\hline $45-70$ & 49 & 14 & 9 & 28 & 14 \\
\hline
\end{tabular}


Tabela 2. Densidade e porosidade do solo nas duas áreas experimentais (VS4a e VS10a).

\begin{tabular}{ccccc}
\hline Profundidade & Densidade do solo & \multicolumn{3}{c}{ Porosidade } \\
\cline { 3 - 5 }$(\mathrm{cm})$ & $\left(\mathrm{kg} \mathrm{dm}^{-3}\right)$ & Total & Macro & Micro \\
\hline & & ---1 & \\
$0-10$ & 1,26 & 53 & 39 & 14 \\
$10-20$ & 1,38 & 47 & 30 & 17 \\
$20-30$ & 1,47 & 44 & 25 & 19 \\
$30-50$ & 1,43 & 45 & 26 & 19 \\
$0-10$ & 1,21 & & & 16 \\
$10-20$ & 1,46 & 52 & 36 & 21 \\
$20-30$ & 1,55 & 43 & 22 & 24 \\
$30-50$ & 1,50 & 40 & 16 & 27 \\
\hline
\end{tabular}

\subsubsection{Adsorção de Fosfato}

Para definição da amplitude dos níveis ou doses de fósforo que foram utilizadas no estudo de adsorção, realizou-se inicialmente uma avaliação do $\mathrm{P}$ remanescente (P-rem), seguindo metodologia sugerida por Alvarez V. et al. (2000). O método é rápido e consiste em: colocar $5 \mathrm{~cm}^{3}$ de TFSA em Erlenmeyer de $125 \mathrm{~mL}$ e adicionar $50 \mathrm{~mL}$ de solução de $\mathrm{CaCl}_{2} 0,01 \mathrm{~mol} \mathrm{~L}^{-1}$ contendo $60 \mathrm{mg} \mathrm{L}^{-1}$ de $\mathrm{P}$, na forma de $\mathrm{KH}_{2} \mathrm{PO}_{4}$. Agitar por 1 hora e, após, centrifugar, filtrar e determinar o teor de $\mathrm{P}$ em solução.

A partir do teor de P-rem e de uma tabela fornecida por Alvarez V. et al. (2000), determinou-se que a amplitude da dose de P a ser utilizada seria de 0 a 80 ug $\mathrm{mL}^{-1}$, dividida em dez doses dentro desse intervalo. 
No estudo de adsorção foi empregada a metodologia utilizada por Casagrande (1993). Por tratamento foram utilizadas três amostras de solo (três repetições). A 2,5 g de TFSA de cada amostra, colocados em Erlenmeyer, foram adicionadas soluções com doses de $\mathrm{P}$ de $0,4,8,16,28,36,44,56,68$ e $80 \mu \mathrm{g} \mathrm{mL}^{-1}$, na forma de $\mathrm{KH}_{2} \mathrm{PO}_{4}$, contendo $\mathrm{CaCl}_{2}$ a $0,01 \mathrm{~mol} \mathrm{~L}^{-1}$ (eletrólito suporte). Após isso, procedeu-se agitação por $24 \mathrm{~h}$ seguida de filtragem lenta. No sobrenadante foi determinado o teor de $\mathrm{P}$ da solução de equilíbrio. A diferença entre a quantidade de $\mathrm{P}$ adicionado e o presente na solução de equilíbrio indicou a quantidade de $\mathrm{P}$ adsorvido. Para determinação do $\mathrm{P}$ nesse estudo de adsorção foi utilizado o método colorimétrico do azul de molibdênio, que é baseado no emprego do reativo sulfobismutomolíbdico e ácido ascórbico como redutor.

Os resultados de $\mathrm{P}$ na solução de equilíbrio e $\mathrm{P}$ adsorvido foram utilizados para a avaliação da adsorção pelo ajuste das equações de Langmuir e Freundlich, através da utilização do programa SAS. Primeiramente, utilizaram-se as equações linearizadas para obtenção das estimativas das constantes envolvidas nas duas isotermas, $\mathbf{K}$ e b para Langmuir e k e $\mathbf{n}$ para Freundlich. A partir daí os dados foram ajustados com as equações não-linear (Langmuir) e exponencial (Freundlich).

Pelo produto entre a capacidade de adsorção máxima de $\mathrm{P}$ (b) e a constante relacionada com a energia de ligação $(K)$ foram obtidos os valores da capacidade tampão máxima de $\mathrm{P}$ (CTM). Neste trabalho a capacidade de adsorção máxima de $\mathrm{P}$ será representada por Cmax.

A comparação das duas isotermas foi realizada de acordo com Mead (1981), Raven \& Hossner (1994) e Chen et al. (1999), que utilizaram alguns critérios para definição da melhor isoterma em termos de ajuste aos dados experimentais. Entre esses critérios podemos citar: o quadrado médio residual (QMR), obtido com o ajuste das equações aos dados; o coeficiente de determinação $\left(\mathrm{R}^{2}\right)$ e os coeficientes linear e angular da equação de regressão entre os dados experimentais e estimados de $\mathrm{P}$ adsorvido. 


\subsubsection{Fração de Fósforo Orgânico}

Foi utilizado o método de ignição de Saunders and Williams (1955), modificado por Walker \& Adams (1958). Esse método foi citado também por O’Halloran (1993). Na determinação do P orgânico, a quantidade da amostra de solo utilizada foi de $2 \mathrm{~g}$ em vez de $1 \mathrm{~g}$ como proposto originalmente. Em resumo, para cada amostra analisada, o método foi desenvolvido da seguinte maneira:

- Foram colocados $2 \mathrm{~g}$ de terra finamente moída em um Erlenmeyer de $125 \mathrm{~mL}$, e este introduzido em mufla. A temperatura foi elevada lentamente até os $550{ }^{\circ} \mathrm{C}$, mantendo-a assim por duas horas. Após isso, o material foi removido da mufla para esfriar à temperatura ambiente. Esse material foi utilizado para extração do $\mathrm{P}$ total $(\mathrm{Pt})$;

- Em outro Erlenmeyer foram colocados $2 \mathrm{~g}$ de terra da mesma amostra, que não foi calcinada, para extração do P inorgânico (Pi);

- A ambos os Erlenmeyers foram adicionados $50 \mathrm{~mL}$ de $\mathrm{H}_{2} \mathrm{SO}_{4} 1 \mathrm{~mol} \mathrm{~L}{ }^{-1}$, agitando-os em seguida. Após isso, foram colocados em mesa agitadora por 16 horas. A prova em branco, contendo apenas $\mathrm{H}_{2} \mathrm{SO}_{4} 1 \mathrm{~mol} \mathrm{~L}^{-1}$, também foi incluída;

- As amostras foram centrifugadas e o sobrenadante utilizado para as determinações de P; A estimativa do Po foi obtida pela diferença entre o P proveniente da amostra calcinada e o da não calcinada.

Nessa metodologia os teores de $\mathrm{P}$ foram determinados pelo método de Murphy-Riley ${ }^{4}$, citados por Tiessen \& Moir (1993). Esse método foi utilizado porque os extratos obtidos deveriam passar por um processo de neutralização antes da determinação do P.

Os resultados de Po foram submetidos à análise de variância (teste F), e as médias comparadas pelo teste de Tukey ao nível de 5\%, com utilização do programa SAS.

${ }^{4}$ MURPHY, J.; RILEY, J.P. A modified single solution method for the determination of phosphate in natural waters. Anal. Chim. Acta, v.27, p.31-36, 1962. 


\section{RESULTADOS E DISCUSSÃO}

\subsection{Avaliação da fertilidade do solo nas áreas experimentais}

\subsubsection{Caracterização química inicial do solo}

A caracterização química inicial do solo nas áreas experimentais está apresentada na Tabela 3. Verificou-se que no início das atividades não havia grande diferença em termos de fertilidade do solo entre as duas áreas, embora fossem observados valores maiores de $\mathrm{pH}, \mathrm{MO}, \mathrm{Pe} \mathrm{V} \%$ para a área VS4a.

Esses resultados podem ser justificados pelo fato de que vegetações secundárias jovens, caso da área VS4a, acumulam menos nutrientes que vegetações mais antigas, no entanto, os solos apresentam melhor nível de fertilidade. Essas diferenças de acúmulo de nutrientes são confirmadas pela Tabela 4, que apresenta os resultados da análise da biomassa vegetal existente nas duas áreas experimentais. Szott \& Palm (1996), trabalhando com vegetação secundária na Amazônia Peruana, observaram um decréscimo no nível de fertilidade do solo com o aumento do tempo de desenvolvimento dessa vegetação.

Os resultados da caracterização química do solo nas duas áreas de estudo são similares aos obtidos por Kleinman et al. (1996), que não observaram diferenças significativas na fertilidade dos solos que estavam sob vegetações secundárias com tempos de pousio variando entre três e onze anos, na Indonésia. Apesar disso, ainda observaram uma tendência de a acidez e os teores de Al trocável serem maiores nos solos com tempo de pousio maior. Esses autores destacaram que após esse período de 
três a onze anos, que permite a acumulação de biomassa vegetal, é que iniciou-se o processo de restauração da fertilidade do solo.

As diferentes quantidades de biomassa vegetal de 24 e $59 \mathrm{t} \mathrm{ha}^{-1}$ estimadas no início do experimento nas respectivas áreas VS4a e VS10a tornam-se justificáveis quando se leva em consideração que os primeiros dez anos de pousio servem para o acúmulo desse material.

Tabela 3. Caracterização química inicial do solo nas duas áreas experimentais (VS4a e VS10a), localizadas no Município de Igarapé-Açu, Pará.

\begin{tabular}{|c|c|c|c|c|c|c|c|c|c|c|c|}
\hline & $\mathrm{PH}$ & & & & & & & & & & \\
\hline Profundidade & $\mathrm{CaCl}_{2}$ & $\mathrm{MO}$ & $\mathrm{P}$ & $\mathrm{K}$ & $\mathrm{Ca}$ & $\mathrm{Mg}$ & $\mathrm{Al}$ & $\mathrm{SB}$ & $\mathrm{T}$ & $\mathrm{V}$ & $\mathrm{m}$ \\
\hline
\end{tabular}

VS4a

$\begin{array}{llllllllllll}0-10 & 4,2 & 34,88 & 5,7 & 0,95 & 14,0 & 3,5 & 2,5 & 18,45 & 60,45 & 30,50 & 11,81 \\ 10-20 & 3,8 & 22,79 & 5,0 & 0,50 & 5,0 & 1,5 & 5,5 & 7,00 & 45,00 & 15,46 & 44,46\end{array}$

VS10a

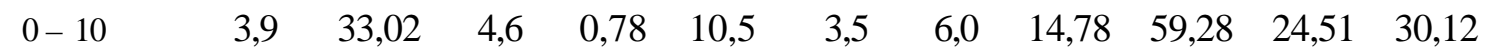

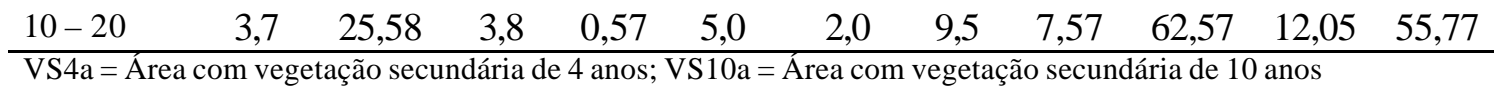

Tabela 4. Biomassa e estoque de nutriente total da vegetação de pousio de 4 anos de idade (VS4a) e de 10 anos (VS10a).

\begin{tabular}{ccccccc}
\hline Vegetação & Biomassa & $\mathrm{N}$ & $\mathrm{P}$ & $\mathrm{K}$ & $\mathrm{Ca}$ & $\mathrm{Mg}$ \\
\hline VS4a & 24 & 143 & 9 & 72 & 150 & 42 \\
t ha & & & & \\
VS10a & 59 & 332 & 9 & 186 & 430 & 87 \\
\hline
\end{tabular}

Fonte: Kato et al. (1999). 


\subsubsection{Avaliações da fertilidade do solo ao longo das épocas de amostragem}

A avaliação da fertilidade do solo, durante o período de estudo nas duas áreas experimentais desta pesquisa, foi baseada no estudo de seis indicadores: o pH em solução de $\mathrm{CaCl}_{2}$ 0,01 mol L-1, a saturação por alumínio (m\%), a saturação por bases (V\%), a CTC (T), o teor de fósforo disponível e a matéria orgânica.

Nas Figuras 4 e 5 estão apresentadas as variações nos valores de $\mathrm{pHCaCl}_{2}$, de $\mathrm{m} \%$, de $\mathrm{V} \%$ e de $\mathrm{T}$, que ocorreram em função dos tratamentos aplicados nas duas áreas experimentais (VS10a e VS4a). Na área VS10a foram observados aumentos nos valores de $\mathrm{pHCaCl}_{2}$ nas duas profundidades analisadas durante as quatro épocas de amostragem. Esses aumentos foram mais evidentes na camada superficial do solo e ocorreram em todas as áreas submetidas ao preparo do solo; nas áreas não preparadas. Na profundidade $10-20 \mathrm{~cm}$ a amplitude de aumento foi bem menor do que na camada superficial e só passaram a ser mais evidentes a partir da terceira época. $\mathrm{Na}$ área VS4a observou-se que os resultados finais foram semelhantes aos valores iniciais de $\mathrm{pHCaCl}_{2}$ para profundidade $0-10 \mathrm{~cm}$; no entanto, os resultados da camada subsuperficial foram similares aos da área VS10a (Figura 4).

A capacidade de troca de cátions manteve-se constante até a terceira época de amostragem em todas as profundidades e áreas analisadas, mas houve redução na quarta amostragem (Figura 5). Esse declínio pode ser relacionado com o decréscimo nos teores de matéria orgânica (a ser detalhado mais adiante), que também ocorreu na última amostragem.

As variações dos valores de V\% nas profundidades e nas áreas estudadas (Figura 5) foram similares aos observados para os resultados de $\mathrm{pHCaCl}_{2}$. No caso da saturação por alumínio (m\%), contudo, os valores diminuíram ao longo do tempo (Figura 4). As relações observadas entre $\mathrm{pHCaCl}_{2}, \mathrm{~V} \%$ e $\mathrm{m} \%$ eram esperadas, já que existe uma relação diretamente proporcional entre $\mathrm{pHCaCl}_{2}$ e $\mathrm{V} \%$, e inversamente entre esses dois parâmetros e m\% (Catani \& Gallo, 1955; Raij \& Sacchetto, 1968; Castro et al., 1972; Raij, 1991; Gama, 1998). 

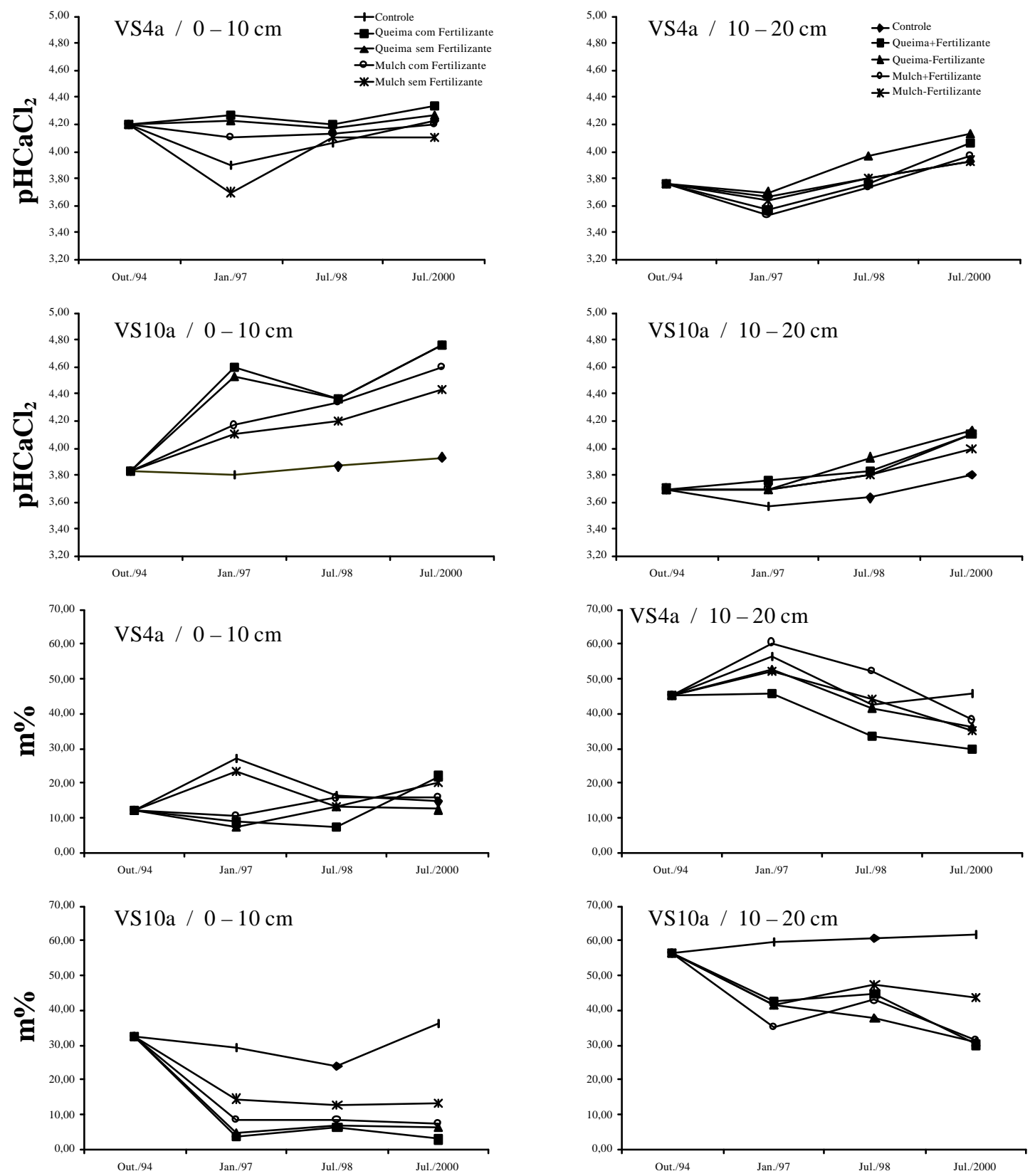

Épocas de amostragem

Figura 4 - Variação de $\mathrm{pHCaCl}_{2}$ e m\% em função dos métodos de preparo de solo e da utilização de fertilizante durante as quatro épocas de amostragem, nas áreas experimentais VS10a e VS4a e nas profundidades 0-10 e 10-20 cm estudadas. 

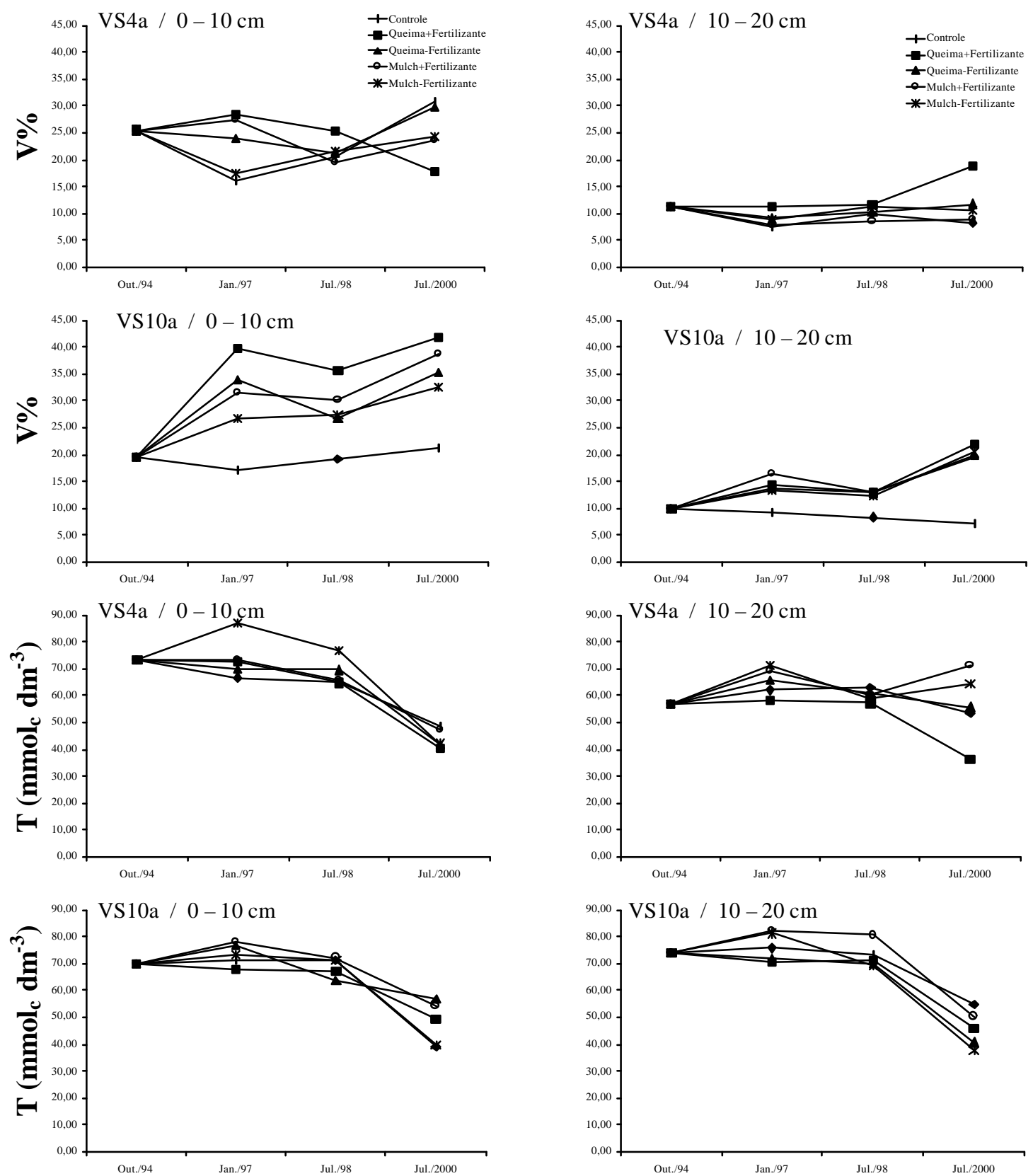

\section{Épocas de amostragem}

Figura 5 - Variação de V\% e T em função dos métodos de preparo de solo e da utilização de fertilizante durante as quatro épocas de amostragem, nas áreas experimentais VS10a e VS4a e nas profundidades 0-10 e 10-20 cm estudadas. 
Os melhores resultados para esses três indicadores de fertilidade do solo $\left(\mathrm{pHCaCl}_{2}, \mathrm{~V} \%\right.$ e m\%) na área VS10a, em relação à VS4a, podem ser justificados pelo fato de que antes da instalação do experimento houve maior acúmulo de biomassa vegetal na VS10a e, consequentemente maior acúmulo de nutrientes, como $\mathrm{Ca}, \mathrm{Mg}$ e $\mathrm{K}$ nesse material (Tabela 4). Com a queima, esses elementos retornam ao solo e melhoram sua fertilidade.

A acumulação de nutrientes na vegetação é umas das principais funções do pousio, pois o estoque de nutrientes na biomassa vegetal é diretamente relacionado com o tempo de pousio, ou seja, vegetações secundárias jovens tendem a acumular menos nutrientes que as maduras (Juo \& Manu, 1996; Kanashiro \& Denich (1998). No entanto, o solo sob vegetação secundária jovem tende a apresentar melhor fertilidade. De certa forma isso foi verificado neste trabalho, já que inicialmente a fertilidade do solo era ligeiramente melhor na área VS4a (Tabela 3).

Para os resultados de P-resina e matéria orgânica serão apresentadas as análises estatísticas, pelo fato de que esses parâmetros são diretamente relacionados com os estudos de $\mathrm{P}$ orgânico e adsorção de $\mathrm{P}$ apresentados mais adiante.

Dessa forma, para os resultados referentes ao teor de fósforo determinado com a resina (P-resina) houve interação entre tratamentos e épocas de amostragem somente na camada superficial das duas áreas experimentais (VS10a e VS4a). Os resultados médios de P-resina dessas interações e dos efeitos isolados de tratamentos e épocas de amostragem estão apresentados nas Tabelas 5, 6, 7, 8, 9 e 10.

Pelas Tabelas 5 e 8 observa-se que os efeitos da interação entre tratamentos e épocas de amostragem sobre os teores de P-resina são similares nas camadas superficiais das duas áreas experimentais. No segundo período de amostragem realizado nessas áreas, observou-se um efeito positivo e significativo dos tratamentos que envolveram a utilização de fertilizantes $(Q+F$ e $M+F)$ em relação aos demais. Esses efeitos ocorreram também em relação aos teores de P-resina obtidos na primeira amostragem. 
Outro fato observado nas Tabelas 5 e 8 é que os efeitos de tratamentos sobre os teores médios de P-resina, embora não significativos na terceira e quarta amostragem, foram sempre maiores que os apresentados no início do experimento.

Nas camadas subsupe rficiais das duas áreas experimentais as melhores médias de P-resina durante as quatro épocas de amostragem foram obtidas com a aplicação dos tratamentos Q + F e M + F (Tabelas 6 e 9). Para o fator época notou-se um aumento significativo do teores médios de P-resina após a primeira amostragem na área VS10a (Tabela 7). Na área VS4a esse efeito significativo só foi obtido para a terceira amostragem (Tabela 10).

Tabela 5. Valores médios de P-resina, na profundidade $010 \mathrm{~cm}$, em função dos tratamentos e épocas de amostragem da área experimental VS10a ${ }^{1}$.

\begin{tabular}{|c|c|c|c|c|}
\hline \multirow[t]{2}{*}{ Tratamentos } & \multicolumn{4}{|c|}{ Épocas de Amostragem } \\
\hline & Outubro/94 & Janeiro/97 & Julho/98 & Julho/00 \\
\hline & \multicolumn{4}{|c|}{------------------------------mg dm"3 } \\
\hline Controle & $4,32 \mathrm{Aa}$ & $5,04 \mathrm{Aa}$ & $6,84 \mathrm{Aa}$ & 4,92 Аа \\
\hline Queima + Fertilizante & $4,32 \mathrm{Aa}$ & $13,08 \mathrm{Bb}$ & $7,20 \mathrm{Aa}$ & 6,36 Aa \\
\hline Queima-Fertilizante & $4,32 \mathrm{Aa}$ & $6,36 \mathrm{Aa}$ & $5,16 \mathrm{Aa}$ & $5,04 \mathrm{Aa}$ \\
\hline Mulching + Fertilizante & $4,32 \mathrm{Aa}$ & $13,20 \mathrm{Bb}$ & $9,00 \mathrm{Aab}$ & $6,72 \mathrm{Aa}$ \\
\hline Mulching - Fertilizante & 4,32 Aa & $6,24 \mathrm{Aa}$ & $6,24 \mathrm{Aa}$ & 5,04 Aa \\
\hline
\end{tabular}

Tabela 6. Médias de P-resina, durante as 4 épocas de amostragem da profundidade 10-20 cm em função dos tratamentos aplicados na área experimental VS10a .

\begin{tabular}{cc}
\hline Tratamentos & P-resina \\
\hline Controle & $\mathrm{mg} \mathrm{dm}^{-3}$ \\
Queima + Fertilizante & $4,32 \mathrm{a}$ \\
Queima - Fertilizante & $5,49 \mathrm{~b}$ \\
Mulching + Fertilizante & $4,47 \mathrm{a}$ \\
Mulching - Fertilizante & $5,40 \mathrm{~b}$ \\
\hline
\end{tabular}

\footnotetext{
* Médias seguidas por mesma letra não diferem entre sí, ao nível de 5\%, pelo teste de Tukey; DMS=0,89 $\mathrm{mg} \mathrm{dm}^{-3}$
} 
Tabela 7. Médias de P-resina nas 4 épocas de amostragens da profundidade $10-20 \mathrm{~cm}$, na área experimental VS10a.

\begin{tabular}{cc}
\hline Épocas de Amostragem & P-resina \\
\hline Out./94 & $3,48 \mathrm{a}$ \\
Jan./97 & $5,59 \mathrm{~b}$ \\
Jul./98 & $5,66 \mathrm{~b}$ \\
Jul./00 & $4,77 \mathrm{~b}$ \\
\hline
\end{tabular}

* Área que no início do experimento estava sob pousio de 10 anos.

* Médias seguidas por mesma letra não diferem entre sí, ao nível de 5\%, pelo teste de Tukey; DMS=1,039 $\mathrm{mg} \mathrm{dm}^{-3}$

Tabela 8. Valores médios de P-resina, na profundidade $010 \mathrm{~cm}$, em função dos tratamentos e épocas de amostragens da área experimental VS4a ${ }^{1}$.

\begin{tabular}{|c|c|c|c|c|}
\hline \multirow[t]{2}{*}{ Tratamentos } & \multicolumn{4}{|c|}{ Épocas de Amostragem } \\
\hline & Outubro/94 & Janeiro/97 & Julho/98 & Julho/00 \\
\hline & --------------- & -----mg d & -------- & ------- \\
\hline Controle & $5,16 \mathrm{Aa}$ & $4,68 \mathrm{Aa}$ & 7,08 Aa & $5,52 \mathrm{Aa}$ \\
\hline Queima + Fertilizante & $5,16 \mathrm{Aa}$ & $12,72 \mathrm{Ba}$ & 7,32 Aa & $5,28 \mathrm{Aa}$ \\
\hline Queima - Fertilizante & $5,16 \mathrm{Aa}$ & $4,56 \mathrm{Aa}$ & 6,36 Aa & $4,80 \mathrm{Aa}$ \\
\hline Mulching + Fertilizante & $5,16 \mathrm{Aa}$ & $13,44 \mathrm{Bb}$ & $8,40 \mathrm{Aab}$ & $5,76 \mathrm{Aa}$ \\
\hline Mulching - Fertilizante & $5,16 \mathrm{Aa}$ & $8,76 \mathrm{AB}$ & $8,16 \mathrm{Aac}$ & 4,80 Aa \\
\hline
\end{tabular}


Tabela 9. Médias de P-resina, durante as 4 épocas de amostragens da profundidade 10$20 \mathrm{~cm}$ em função dos tratamentos aplicados na área experimental VS4a.

\begin{tabular}{cc}
\hline Tratamentos & P resina \\
\hline Controle & $\mathrm{mg} \mathrm{dm}^{-3}$ \\
& $3,81 \mathrm{a}$ \\
Queima + Fertilizante & $5,73 \mathrm{~b}$ \\
Queima - Fertilizante & $4,68 \mathrm{ab}$ \\
Mulching + Fertilizante & $5,34 \mathrm{~b}$ \\
Mulching - Fertilizante & $4,59 \mathrm{a}$ \\
\hline * Área que no início do experimento estava sob pousio de 4 anos. \\
* Médias seguidas por mesma letra não diferem entre sí, ao nível de 5\%, pelo teste de Tukey; DMS $=1,32 \mathrm{mg} \mathrm{dm}^{-3}$
\end{tabular}

Tabela 10. Médias de P-resina nas 4 épocas de amostragens da profundidade $10-20 \mathrm{~cm}$, na área experimental VS4a.

\begin{tabular}{|c|c|}
\hline Épocas de Amostragem & P-resina \\
\hline & $\mathrm{mg} \mathrm{dm}^{-3}$ \\
\hline Out./94 & $4,68 \mathrm{a}$ \\
\hline Jan./97 & $4,51 \mathrm{a}$ \\
\hline Jul./98 & $6,00 \mathrm{~b}$ \\
\hline Jul./00 & $4,13 \mathrm{a}$ \\
\hline
\end{tabular}

A análise de variância dos teores de matéria orgânica não evidenciou efeito significativo das interações entre tratamentos e épocas de amostragem para nenhuma das profundidades e áreas estudadas. A comparação dos teores médios de MO 
pelo teste de Tukey para os efeitos dos tratamentos e épocas estão apresentados nas Tabelas 11, 12, 13 e 14 .

O efeito dos tratamentos só foi significativo para a profundidade $0-10 \mathrm{~cm}$ da área VS10a, mas os teores médios de MO de todas as profundidades e áreas estudadas Tabelas 11 e 13. Por esse teste evidenciou-se que o teor de MO no tratamento que utilizou cobertura morta e fertilizante $(\mathrm{M}+\mathrm{F})$ foi significativamente superior aos demais, na camada superficial da área VS10a (Tabela 11).

No caso do efeito das épocas de amostragem verificaram-se reduções significativas nos teores de MO na quarta época, o que ocorreu para as duas profundidades analisadas na área VS10a (Tabela 11). Para a área VS4a foram observados efeitos significativos somente para a camada superficial (Tabela 13), tendo os resultados sido similares aos citados anteriormente para a área VS10a.

Tabela 11. Teores médios de matéria orgânica $\left(\mathrm{g} \mathrm{dm}^{-3}\right)$, durante as 4 épocas de amostragens das profundidades 0-10 e 10-20 cm em função dos tratamentos aplicados na área VS10a.

\begin{tabular}{ccc}
\hline Tratamentos & \multicolumn{1}{c}{ Profundidades (cm) } \\
\cline { 2 - 3 } Controle & $0-10$ & $10-20$ \\
Queima + Fertilizante & $29,14 \mathrm{a}$ & $22,94 \mathrm{a}$ \\
Queima - Fertilizante & $28,60 \mathrm{a}$ & $23,64 \mathrm{a}$ \\
Mulching + Fertilizante & $28,68 \mathrm{a}$ & $24,03 \mathrm{a}$ \\
Mulching - Fertilizante & $32,16 \mathrm{~b}$ & $25,42 \mathrm{a}$ \\
\hline
\end{tabular}

* Médias seguidas por mesma letra não diferem entre sí, ao nível de 5\%, pelo teste de Tukey;

DMS $=2,81 \mathrm{~g} \mathrm{dm}^{-3}$ (profundidade $0-10 \mathrm{~cm}$ ); DMS $=2,59 \mathrm{~g} \mathrm{dm}^{-3}$ (profundidade $10-20 \mathrm{~cm}$ ). 
Tabela 12. Teores médios de matéria orgânica $\left(\mathrm{g} \mathrm{dm}^{-3}\right)$ nas 4 épocas de amostragens das profundidades 0-10 e 10-20 cm, na área experimental VS10a.

\begin{tabular}{ccc}
\hline Épocas de Amostragem & \multicolumn{2}{c}{ Profundidades (cm) } \\
\cline { 2 - 3 } & $0-10$ & $10-20$ \\
\hline Out./94 & $30,38 \mathrm{~b}$ & $23,87 \mathrm{ab}$ \\
Jan./97 & $34,34 \mathrm{~b}$ & $27,09 \mathrm{~b}$ \\
Jul./98 & $29,76 \mathrm{~b}$ & $26,04 \mathrm{~b}$ \\
Jul./00 & $23,31 \mathrm{a}$ & $20,21 \mathrm{a}$ \\
\hline
\end{tabular}

* Médias seguidas por mesma letra não diferem entre sí, ao nível de 5\%, pelo teste de Tukey;

DMS $=4,98 \mathrm{~g} \mathrm{dm}^{-3}$ (profundidade $0-10 \mathrm{~cm}$ ); DMS $=4,29 \mathrm{~g} \mathrm{dm}^{-3}$ (profundidade $10-20 \mathrm{~cm}$ ).

Tabela 13. Teores médios de matéria orgânica $\left(\mathrm{g} \mathrm{dm}^{-3}\right)$, durante as 4 épocas de amostragens das profundidades 0-10 e 10-20 $\mathrm{cm}$ em função dos tratamentos aplicados na área experimental VS4a.

\begin{tabular}{ccc}
\hline Tratamentos & \multicolumn{2}{c}{ Profundidades $(\mathrm{cm})$} \\
\cline { 2 - 3 } Controle & $0-10$ & $10-20$ \\
\hline Queima + Fertilizante & $31,15 \mathrm{a}$ & $20,54 \mathrm{a}$ \\
Queima - Fertilizante & $34,41 \mathrm{a}$ & $21,39 \mathrm{a}$ \\
Mulching + Fertilizante & $29,76 \mathrm{a}$ & $20,69 \mathrm{a}$ \\
Mulching - Fertilizante & $29,92 \mathrm{a}$ & $22,55 \mathrm{a}$ \\
\hline
\end{tabular}

\footnotetext{
* Médias seguidas por mesma letra não diferem entre sí, ao nível de 5\%, pelo teste de Tukey;
} DMS $=11,73 \mathrm{~g} \mathrm{dm}^{-3}$ (profundidade $0-10 \mathrm{~cm}$ ); DMS $=2,45 \mathrm{~g} \mathrm{dm}^{-3}$ (profundidade $10-20 \mathrm{~cm}$ ). 
Tabela 14. Teores médios de matéria orgânica $\left(\mathrm{g} \mathrm{dm}^{-3}\right)$ nas 4 épocas de amostragens das profundidades 0-10 e 10-20 cm, na área experimental que inicialmente apresentava vegetação secundária com 4 anos de idade.

\begin{tabular}{ccc}
\hline \multirow{2}{*}{ Épocas de Amostragem } & \multicolumn{2}{c}{ Profundidades (cm) } \\
\cline { 2 - 3 } & $0-10$ & $10-20$ \\
\hline Out./94 & $31,93 \mathrm{a}$ & $21,08 \mathrm{a}$ \\
Jan./97 & $36,27 \mathrm{~b}$ & $22,32 \mathrm{a}$ \\
Jul./98 & $33,85 \mathrm{a}$ & $22,75 \mathrm{a}$ \\
Jul./90 & $24,24 \mathrm{a}$ & $19,03 \mathrm{a}$ \\
\hline
\end{tabular}

* Médias seguidas por mesma letra não diferem entresí, ao nível de 5\%, pelo teste de Tukey;

$\mathrm{DMS}=10,28 \mathrm{~g} \mathrm{dm}^{-3}$ (profundidade $0-10 \mathrm{~cm}$ ); DMS=4,47 $\mathrm{g} \mathrm{dm}^{-3}$ (profundidade $10-20 \mathrm{~cm}$ ).

Pesquisas anteriores têm demonstrado que a utilização do sistema de corte-queima da vegetação proporciona melhorias no nível de fertilidade do solo, principalmente devido aos aumentos de $\mathrm{pH}$, de saturação por bases e de $\mathrm{P}$ disponível. Além disso, observaram-se reduções nos teores de Al trocável (Brinkmann \& Nascimento, 1973; Seubert et al. 1977; Silva, 1981; Smyth \& Bastos, 1984; Hernani et al., 1987; Hölscher et al., 1997; Giardina et al., 2000).

No entanto, também tem sido demonstrado que essa melhoria da fertilidade do solo é de duração relativamente curta, o que leva à necessidade da utilização de pousios e/ou fertilizantes. Brinkmann \& Nascimento (1973), mesmo tendo verificado aumentos na fertilidade do solo após a queima, relatam que o retorno de nutrientes com essa forma de preparo do solo não é suficiente para garantir a atividade agrícola por um longo prazo, sendo necessária a correção e fertilização do solo. Roder et al. (1997) observaram um declínio do P-disponível e do carbono orgânico quando avaliaram um sistema de corte-queima por quatro anos, sendo 1 ano de cultivo e 3 de pousio.

Martins et al. (1991), avaliando uma áea cultivada continuamente por cinco anos no sistema de corte-queima, verificaram que a saturação por bases foi menor 
que o encontrado na área cultivada por um ano, mas as condições químicas ainda eram melhores que no solo sob floresta nativa. Esse tipo de resultado evidencia que a utilização da queima proporciona um efeito fertilizador a curto prazo, geralmente até o fim do primeiro ciclo de cultivo, sendo o motivo pelo qual os agricultores que adotam o sistema de corte-queima abandonam a terra após 1 ou 2 anos de uso.

Os resultados da avaliação da fertilidade do solo, durante os seis primeiros anos nas duas áreas experimentais, evidenciaram a manutenção e até aumentos dos níveis de fertilidade em relação ao início do experimento para todos os tratamentos, sendo os resultados mais expressivos quando houve utilização de fertilizantes.

Esses resultados demonstram que a utilização da técnica de cobertura morta a partir da capoeira apresenta um grande potencial para evitar que ocorra a degradação da fertilidade do solo. Para isso também é importante a quantidade da biomassa vegetal que pode ser utilizada para cobertura morta por ocasião da implantação dessa técnica, pois verificou-se que os melhores resultados foram obtidos na área em que o período de pousio era maior.

Outro fato a ser levado em consideração é que esses resultados são referentes a um período no qual foram realizados dois ciclos de cultivo (arroz - caupi mandioca) e mais um período de pousio curto de cerca de dois anos. 


\subsection{Adsorção de Fósforo}

Os resultados obtidos com adsorção de $\mathrm{P}$ mostraram que a utilização do P-remanescente proporcionou adequada definição das concentrações de fósforo utilizadas neste estudo. As estimativas de adsorção máxima de fósforo (Cmax) obtidas variaram sempre dentro da amplitude da dose de P utilizada no estudo experimental de adsorção, que foi de 0 a $800 \mathrm{mg} \mathrm{kg}^{-1}$.

Esse resultado está de acordo com o citado por Alvarez V. et al. (2000), os quais relatam que o $\mathrm{P}$-remanescente tem estreita relação com a capacidade máxima de adsorção de fosfatos, possibilitando assim a definição das doses de $\mathrm{P}$ adequadas em determinações fisico-químicas e em experimentos com esse nutriente.

Em vários trabalhos, entre os quais, os de Lopes \& Fox (1979), Nakos (1987), Anghinoni (1996), Eghball et al. (1996), Abekoe \& Sahrawa (2001), as estimativas de Cmax superaram da quantidade de $\mathrm{P}$ adicionada no estudo de adsorção, o que deve ocasionar erros nessas estimativas.

O P-remanescente, além de ser determinado por uma metodologia simples e rápida, evita que sejam utilizadas concentrações de $\mathrm{P}$ acima da capacidade adsortiva do solo, o que facilita o ajuste das isotermas de adsorção aos dados experimentais.

Quando se considera a isoterma de Langmuir, a utilização do Premanescente pode evitar erros de cerca de $50 \%$ na estimativa da adsorção máxima. Harter (1984) cita que isso pode ocorrer quando as concentrações das soluções utilizadas no estudo de adsorção ocasionam quantidades adsorvidas que se distanciam desse máximo. No presente trabalho, essa situação foi evitada pela utilização do P-rem.

\subsubsection{As isotermas de Langmuir e Freundlich}

Os valores da capacidade máxima de adsorção de $\mathrm{P}$ (Cmax), da constante de energia de ligação (K) e da capacidade tampão máxima de P (CTM) obtidas a partir da isoterma de Langmuir estão apresentadas nas Tabelas 15 e 16. Esses resultados estão apresentados em função dos tratamentos, das áreas experimentais e das profundidades de amostragem. 
Tabela 15. Valores da constante de energia de ligação (K), capacidade máxima de adsorção (b) e capacidade tampão máxima de P (CTM) obtidas a partir da isoterma de Langmuir para a área com vegetação secundária de 10 anos..

\begin{tabular}{|c|c|c|c|c|c|c|c|c|c|c|c|c|}
\hline & \multicolumn{3}{|c|}{ Outubro/94 } & \multicolumn{3}{|c|}{ Janeiro/97 } & \multicolumn{3}{|c|}{ Julho/98 } & \multicolumn{3}{|c|}{ Julho/00 } \\
\hline & $\begin{array}{c}\mathrm{K} \\
\mathrm{mL} \mathrm{ug}^{-1}\end{array}$ & $\begin{array}{l}\mathrm{Cmax} \\
\text { ug g }^{-1}\end{array}$ & $\begin{array}{l}\text { CTM } \\
\mathrm{mL} \mathrm{g}^{-1}\end{array}$ & $\begin{array}{c}\mathrm{K} \\
\mathrm{mL} \mathrm{ug}^{-1}\end{array}$ & $\begin{array}{l}\mathrm{Cmax} \\
\text { ug g }^{-1}\end{array}$ & $\begin{array}{l}\text { CTM } \\
\mathrm{mL} \mathrm{g}^{-1}\end{array}$ & $\begin{array}{c}\mathrm{K} \\
\mathrm{mL} \mathrm{ug}^{-1}\end{array}$ & $\begin{array}{l}\mathrm{Cmax} \\
\text { ug g }^{-1}\end{array}$ & $\begin{array}{l}\text { CTM } \\
\mathrm{mL} \mathrm{g}^{-1}\end{array}$ & $\begin{array}{c}\mathrm{K} \\
\mathrm{mL} \mathrm{ug}^{-1}\end{array}$ & $\begin{array}{l}\mathrm{Cmax} \\
\text { ug g }^{-1}\end{array}$ & $\begin{array}{l}\text { CTM } \\
\mathrm{mL} \mathrm{g}^{-1}\end{array}$ \\
\hline \multirow{3}{*}{$\begin{array}{c}\text { Controle } \\
\mathrm{Q}+\mathrm{F}\end{array}$} & \multicolumn{12}{|c|}{$0-10 \mathrm{~cm}$} \\
\hline & 0,74 & 249,98 & 185,98 & 1,34 & 114,74 & 153,63 & 1,52 & 125,26 & 190,15 & 0,35 & 104,79 & 36,26 \\
\hline & 0,74 & 249,98 & 185,98 & 1,46 & 130,32 & 189,87 & 0,13 & 187,59 & 25,14 & 0,78 & 150,23 & 117,24 \\
\hline Q-F & 0,74 & 249,98 & 185,98 & 0,72 & 183,88 & 132,95 & 1,23 & 140,82 & 173,07 & 0,73 & 172,40 & 124,99 \\
\hline $\mathrm{M}+\mathrm{F}$ & 0,74 & 249,98 & 185,98 & 0,36 & 123,12 & 44,08 & 0,42 & 120,57 & 50,28 & 0,49 & 140,34 & 69,05 \\
\hline $\mathrm{M}-\mathrm{F}$ & 0,74 & 249,98 & 185,98 & 0,74 & 146,49 & 107,82 & 0,73 & 127,26 & 93,02 & 0,51 & 108,83 & 55,94 \\
\hline \multirow{2}{*}{ Controle } & \multicolumn{12}{|c|}{$10-20 \mathrm{~cm}$} \\
\hline & 0,27 & 327,72 & 86,85 & 0,66 & 260,62 & 172,79 & 0,61 & 260,95 & 159,96 & 2,71 & 169,91 & 461,09 \\
\hline $\mathrm{Q}+\mathrm{F}$ & 0,27 & 327,72 & 86,85 & 0,61 & 307,57 & 186,39 & 0,98 & 243,31 & 238,93 & 0,64 & 232,26 & 148,41 \\
\hline Q-F & 0,27 & 327,72 & 86,85 & 1,21 & 285,22 & 345,97 & 1,79 & 319,22 & 570,45 & 0,78 & 224,22 & 174,22 \\
\hline $\mathrm{M}+\mathrm{F}$ & 0,27 & 327,72 & 86,85 & 0,85 & 251,16 & 212,94 & 7,74 & 273,33 & 2115,61 & 1,02 & 189,77 & 192,80 \\
\hline $\mathrm{M}-\mathrm{F}$ & 0,27 & 327,72 & 86,85 & 0,60 & 278,42 & 167,89 & 0,56 & 235,20 & 131,48 & 1,09 & 206,89 & 225,93 \\
\hline
\end{tabular}

(1) Tratamentos: Controle; Queima+fertilizante (Q+F); Queima-fertilizante (Q-F); Mulch+Fertilizante (M+F); Mulch-Fertilizante (M-F). 
Tabela 16. Valores da constante de energia de ligação (K), capacidade máxima de adsorção (b) e capacidade tampão máxima de P (CTM) obtidas a partir da isoterma de Langmuir para a área com vegetação secundária de 4 anos..

\begin{tabular}{|c|c|c|c|c|c|c|c|c|c|c|c|c|}
\hline & \multicolumn{3}{|c|}{ Outubro/94 } & \multicolumn{3}{|c|}{ Janeiro/97 } & \multicolumn{3}{|c|}{ Julho/98 } & \multicolumn{3}{|c|}{ Julho/00 } \\
\hline & $\mathrm{K}$ & Cmax & CTM & $\mathrm{K}$ & Cmax & CTM & $\mathrm{K}$ & Cmax & CTM & $\mathrm{K}$ & Cmax & CTM \\
\hline & $\mathrm{mL} \mathrm{ug}^{-1}$ & $\operatorname{ug~g}^{-1}$ & $\mathrm{~mL} \mathrm{~g}^{-1}$ & $\mathrm{~mL} \mathrm{ug}^{-1}$ & $\mathrm{ug} \mathrm{g}^{-1}$ & $\mathrm{~mL} \mathrm{~g}^{-1}$ & $\mathrm{~mL} \mathrm{ug}^{-1}$ & $\mathrm{ug} \mathrm{g}^{-1}$ & $\mathrm{~mL} \mathrm{~g}^{-1}$ & $\mathrm{~mL} \mathrm{ug}^{-1}$ & $\operatorname{ug~g}^{-1}$ & $\mathrm{~mL} \mathrm{~g}^{-1}$ \\
\hline \multirow{3}{*}{$\begin{array}{c}\text { Controle } \\
\text { Q+F }\end{array}$} & \multicolumn{12}{|c|}{$0-10 \mathrm{~cm}$} \\
\hline & 0,08 & 94,19 & 7,16 & 0,18 & 103,46 & 18,42 & & & & 0,06 & 95,89 & 5,95 \\
\hline & 0,08 & 94,19 & 7,16 & 0,44 & 110,48 & 48,72 & 0,17 & 70,02 & 12,04 & 0,15 & 102,89 & 15,33 \\
\hline Q-F & 0,08 & 94,19 & 7,16 & 0,31 & 103,06 & 31,84 & 0,23 & 86,54 & 19,64 & 0,40 & 162,94 & 65,83 \\
\hline $\mathrm{M}+\mathrm{F}$ & 0,08 & 94,19 & 7,16 & 0,10 & 111,71 & 10,95 & 0,12 & 76,76 & 9,13 & 0,12 & 98,42 & 12,20 \\
\hline $\mathrm{M}-\mathrm{F}$ & 0,08 & 94,19 & 7,16 & 0,29 & 64,68 & 18,56 & 0,26 & 82,43 & 21,43 & 0,01 & 251,39 & 3,27 \\
\hline \multirow[b]{2}{*}{ Controle } & \multicolumn{12}{|c|}{$10-20 \mathrm{~cm}$} \\
\hline & 0,06 & 307,67 & 19,32 & 0,47 & 224,13 & 105,79 & 8,39 & 99,96 & 838,58 & 2,16 & 134,35 & 289,79 \\
\hline $\mathrm{Q}+\mathrm{F}$ & 0,06 & 307,67 & 19,32 & 0,35 & 236,91 & 83,87 & 1,25 & 111,20 & 138,56 & 0,59 & 141,38 & 83,84 \\
\hline Q-F & 0,06 & 307,67 & 19,32 & 0,93 & 211,69 & 196,70 & 1,04 & 168,29 & 174,52 & 2,14 & 106,05 & 226,58 \\
\hline $\mathrm{M}+\mathrm{F}$ & 0,06 & 307,67 & 19,32 & 0,72 & 227,03 & 163,69 & 2,86 & 139,71 & 398,86 & 1,47 & 113,02 & 166,00 \\
\hline $\mathrm{M}-\mathrm{F}$ & 0,06 & 307,67 & 19,32 & 0,64 & 193,34 & 123,74 & 15,27 & 105,08 & 1605,04 & 1,08 & 131,87 & 141,93 \\
\hline
\end{tabular}

(1) Tratamentos: Controle; Queima+fertilizante (Q+F); Queima-fertilizante (Q-F); Mulch+Fertilizante (M+F); Mulch-Fertilizante (M-F). 
O valor da Cmax na área VS10a variou entre 104,79 e $249,98 \mu \mathrm{g} \mathrm{g}^{-1}$ na profundidade $0-10 \mathrm{~cm}$ e entre 169,91 e $327,72 \mu \mathrm{g} \mathrm{g}^{-1}$ na profundidade $10-20 \mathrm{~cm}$. Na área VS4a a Cmax variou entre 64,68 e $251,39 \mu \mathrm{g} \mathrm{g}^{-1}$ na profundidade 0-10 $\mathrm{cm}$ e entre 99,96 e 307,67 $\mu \mathrm{g} \mathrm{g}^{-1}$ na profundidade $10-20 \mathrm{~cm}$. Esses resultados, nas duas áreas experimentais e durante as quatro épocas de amostragens, evidenciam que os maiores valores de Cmax foram obtidos para a profundidade de $10-20 \mathrm{~cm}$, no entanto, quando se compara as duas áreas verifica-se que, independentemente da profundidade, a Cmax do solo tendeu a ser maior na área que inicialmente apresentava vegetação secundária de 10 anos (VS10a) (Tabelas 15 e 16).

$\mathrm{Na}$ área com VS10a observou-se que nas duas profundidades (0-10 e 10$20 \mathrm{~cm}$ ) ocorreram reduções na Cmax do solo da primeira amostragem (outubro de 1994) para a última (julho de 2000), para todos os tratamentos aplicados. Essas reduções foram mais evidentes nos dois tratamentos que não envolveram a queima da vegetação, acompanhando os resultados obtidos nas parcelas controle, onde houve manutenção da vegetação secundária (Tabela 15).

Na camada superficial da área com VS4a observou-se que a Cmax inicial $\left(94,19 \mu \mathrm{g} \mathrm{g}^{-1}\right)$ foi praticamente mantida em todas as épocas de amostragem (Julho de 2000), embora tenham sido observados aumentos na Cmax do solo submetido aos tratamentos Q-F (queima sem fertilizante) e M-F (mulch sem fertilizante). Na camada subsuperficial (10-20 cm) verificaram-se reduções na Cmax após a primeira amostragem do solo e em todos os tratamentos (Tabela 16).

Com relação à capacidade tampão máxima de fósforo (CTM) os resultados apresentaram tendência tendência diferente que ocorreu para Cmax (Tabelas 15 e 16). Isso ocorreu porque para a determinação da CTM também é levado em consideração os valores da constante de energia de ligação $(\mathrm{K})$, que variaram entre as amostras.

Na primeira amostragem para as duas áreas experimentais observaram-se resultados opostos quanto aos valores de CTM. Na área com VS10a a constante K exerceu maior influência sobre os resultados de CTM. Isso foi evidenciado pelo fato de que a camada subsuperficial, mesmo com uma Cmax maior, acabou apresentando menor 
valor de CTM em relação à camada superficial, a qual apresentou as maiores estimativas da constante K. Na área com VS4a a estimativa de Cmax exerceu maior influência sobre os resultados de CTM, pois os valores de $\mathrm{K}$ foram semelhantes nas duas profundidades (Tabelas 15 e 16).

Para os demais períodos de amostragens realizados nas duas áreas experimentais (VS10a e VS4a) os resultados de CTM foram condicionados pelo valores de $\mathrm{K}$, obtidos nos diferentes tratamentos e profundidades. Isso foi evidenciado, por exemplo, pelos valores de CTM para o tratamento $\mathrm{Q}+\mathrm{F}$, na profundidade $0-10 \mathrm{~cm}$, que variaram entre esses períodos justamente por terem sido encontrados valores de $\mathrm{K}$ diferentes para cada época de amostragem.

Em relação à constante $\mathrm{k}$ da isoterma de Freundlich, observaram-se comportamentos diferenciados entre as duas áreas experimentais (Tabelas 17 e 18). Na área com VS10a os resultados obtidos com essa constante acompanharam os resultados de Cmax estimados pela isoterma de Langmuir (Tabela 15), ou seja, nas duas profundidades analisadas ocorreram reduções nos valores de k para todos os tratamentos (Tabela 16). Essa tendência também foi observada para a camada superficial da área com VS4a, no entanto, isso não ocorreu na camada subsuperficial, já que os valores de k não sofreram redução, como aconteceu para a Cmax estimada pela equação de Langmuir (Tabela 17).

A relação entre a constante $\mathrm{k}$ de Freundlich e os valores de Cmax de Langmuir tem sido encontrada em várias pesquisas (Mead, 1981; Anghinoni, 1996 ), demonstrando que essa constante de Freundlich proporciona medidas relativas da capacidade de adsorção de $\mathrm{P}$ dos solos. 
Tabela 17. Constantes k e $\mathrm{n}$ da isoterma de Freundlich obtidas a partir dos resultados de adsorção de P na área VS10a.

\begin{tabular}{|c|c|c|c|c|c|c|c|c|}
\hline \multirow[b]{2}{*}{ Tratamento $^{(1)}$} & \multicolumn{2}{|c|}{ Out./1994 } & \multicolumn{2}{|c|}{ Jan./1997 } & \multicolumn{2}{|c|}{ Jul./1998 } & \multicolumn{2}{|c|}{ Jul.2002 } \\
\hline & $\mathrm{k}$ & $\mathrm{n}$ & $\mathrm{k}$ & $\mathrm{n}$ & $\mathrm{k}$ & $\mathrm{n}$ & $\mathrm{k}$ & $\mathrm{n}$ \\
\hline & \multicolumn{8}{|c|}{0 a $10 \mathrm{~cm}$} \\
\hline Controle & 134,24 & 5,89 & 65,87 & 6,58 & 78,34 & 8,14 & 41,72 & 4,36 \\
\hline$Q+F$ & 134,24 & 5,89 & 67,50 & 5,36 & 57,71 & 3,71 & 81,13 & 6,16 \\
\hline $\mathrm{Q}-\mathrm{F}$ & 134,24 & 5,89 & 83,14 & 4,60 & 79,97 & 6,54 & 92,59 & 6,12 \\
\hline$M+F$ & 134,24 & 5,89 & 48,37 & 4,21 & 47,19 & 4,14 & 57,56 & 4,27 \\
\hline \multirow[t]{2}{*}{$\mathrm{M}-\mathrm{F}$} & 134,24 & 5,89 & 69,76 & 5,01 & 64,55 & 5,63 & 48,55 & 4,81 \\
\hline & \multicolumn{8}{|c|}{10 a $20 \mathrm{~cm}$} \\
\hline Controle & 132,70 & 4,34 & 137,01 & 5,68 & 120,07 & 4,64 & 111,06 & 8,23 \\
\hline $\mathrm{Q}+\mathrm{F}$ & 132,70 & 4,34 & 146,22 & 4,77 & 128,05 & 5,44 & 109,24 & 4,97 \\
\hline $\mathrm{Q}-\mathrm{F}$ & 132,70 & 4,34 & 156,73 & 5,61 & 176,37 & 5,33 & 103,20 & 4,60 \\
\hline$M+F$ & 132,70 & 4,34 & 132,37 & 5,50 & 201,75 & 10,98 & 105,49 & 6,24 \\
\hline $\mathrm{M}-\mathrm{F}$ & 132,70 & 4,34 & 142,20 & 5,45 & 104,15 & 4,50 & 108,81 & 5,63 \\
\hline
\end{tabular}

(1) Tratamentos: Contro le (testemunha); Q + F (Queima+fertilizante); Q - F (Queima-fertilizante); M + F (Mulch + Fertilizante); M - F (Mulch - Fertilizante)

Tabela 18. Constantes k e n da isoterma de Freundlich obtidas a partir dos resultados de adsorção de P na área VS4a.

\begin{tabular}{|c|c|c|c|c|c|c|c|c|}
\hline \multirow[b]{2}{*}{ Tratamento $^{(1)}$} & \multicolumn{2}{|c|}{ Out./1994 } & \multicolumn{2}{|c|}{ Jan./1997 } & \multicolumn{2}{|c|}{ Jul./1998 } & \multicolumn{2}{|c|}{ Jul.2002 } \\
\hline & $\mathrm{k}$ & $\mathrm{n}$ & $\mathrm{k}$ & $\mathrm{n}$ & $\mathrm{k}$ & $\mathrm{n}$ & $\mathrm{k}$ & $\mathrm{n}$ \\
\hline & \multicolumn{8}{|c|}{0 a $10 \mathrm{~cm}$} \\
\hline Controle & 16,74 & 2,62 & 34,57 & 3,88 & & & 15,23 & 2,53 \\
\hline$Q+F$ & 16,74 & 2,62 & 46,70 & 4,55 & 21,29 & 3,60 & 25,66 & 2,97 \\
\hline$Q-F$ & 16,74 & 2,62 & 41,82 & 4,53 & 29,86 & 3,92 & 82,12 & 6,21 \\
\hline$M+F$ & 16,74 & 2,62 & 22,80 & 2,73 & 18,24 & 3,03 & 23,17 & 2,92 \\
\hline \multirow[t]{2}{*}{$\mathrm{M}-\mathrm{F}$} & 16,74 & 2,62 & 25,47 & 4,43 & 34,62 & 4,98 & 6,88 & 1,46 \\
\hline & \multicolumn{8}{|c|}{10 a $20 \mathrm{~cm}$} \\
\hline Controle & 68,47 & 3,25 & 101,08 & 4,73 & 81,27 & 18,16 & 98,78 & 12,57 \\
\hline$Q+F$ & 68,47 & 3,25 & 91,78 & 4,01 & 74,26 & 9,63 & 65,91 & 5,00 \\
\hline $\mathrm{Q}-\mathrm{F}$ & 68,47 & 3,25 & 110,03 & 5,44 & 113,81 & 10,14 & 65,24 & 7,36 \\
\hline$M+F$ & 68,47 & 3,25 & 112,65 & 5,17 & 109,13 & 16,22 & 71,80 & 8,26 \\
\hline $\mathrm{M}-\mathrm{F}$ & 68,47 & 3,25 & 99,28 & 5,62 & 87,44 & 17,97 & 84,66 & 8,76 \\
\hline
\end{tabular}


Os valores iniciais de Cmax do solo nas duas áreas experimentais deste trabalho são similares aos obtidos por Brasil \& Muraoka (1995), que avaliaram a adsorção de fósforo na camada superficial de cinco amostras de solos de ocorrência na Amazônia Oriental e encontraram valores médios de Cmax de $239 \mu \mathrm{g} \mathrm{g}^{-1}$ para um Latossolo Amarelo de textura média. Embora trabalhando apenas com amostras da profundidade de 0-10 $\mathrm{cm}$, esses autores verificaram que as variações na capacidade de adsorção de fósforo ocorreram em função do conteúdo de argila e teor de matéria orgânica dos solos.

Os maiores valores de Cmax para as camadas subsuperficiais nas duas áreas experimentais (Tabelas 15 e 16) devem estar relacionados com o conteúdo de argila maior e teor de matéria orgânica menor nessa camada (Tabela 3). Trabalhos desenvolvidos por Mesquita Filho \& Torrent (1993) e Silva et al. (1997) demonstraram que os maiores valores de Cmax foram obtidos na camada mais profunda devido à menor quantidade de matéria orgânica, evidenciando a influência desse material no bloqueio dos sítios de adsorção.

No entanto, Leal \& Velloso (1973) e Lopes \& Cox (1979), trabalhando com solos sob vegetação de cerrado de Minas Gerais e Goiás, Nakos (1987), com solos sob florestas na Grécia, Singh et al. (1983) e Brasil \& Muraoka (1995), com solos da Amazônia, encontraram correlações positivas e significativas da Cmax com o conteúdo de argila e com o teor de matéria orgânica.

Os valores de Cmax da camada superficial da área VS10a foram maiores do que os da área VS4a (Tabelas 15 e 16). Isso pode ser explicado pelos mais altos valores de Al trocável na primeira área, já que o conteúdo de argila e o teor de MO eram similares na camada superficial de ambas as áreas.

Singh et al. (1983), caracterizando solos da Amazônia, e Silva et al. (1997), avaliando a rotação adubo verde - milho na região central do Brasil, observaram correlações positivas entre teores de alumínio trocável e capacidade de adsorção máxima de fósforo. Udo \& Uzu (1972) também observaram essa relação em alguns solos da Nigéria, mas consideram dois fatos nessa relação: o primeiro é que o Al é mais ativo na 
formação de compostos com $\mathrm{P}$ do que o $\mathrm{Fe}$, e segundo é que os teores de Al trocável aumentam com a diminuição do $\mathrm{pH}$.

A redução da capacidade máxima de adsorção de $\mathrm{P}$ estimada pela isoterma de Langmuir, que ocorreu da primeira para última época de amostragem nas duas áreas experimentais, VS10a e VS4a (Tabela 15 e 16) pode ser atribuída aos aumentos nos valores de $\mathrm{pHCaCl}_{2}$ e de saturação por bases, e aos decréscimos nos valores de $\mathrm{m} \%$ e de T, principalmente na área VS10a (Figuras 6 e 7) onde a amplitude de redução de adsorção tendeu a acompanhar o comportamento desses indicadores de fertilidade do solo.

$\mathrm{O}$ aumento no valor de $\mathrm{pH}$ pode afetar a adsorção de $\mathrm{P}$ de três maneiras. Uma delas é pela redução nos teores de Al trocável, ocasionando assim diminuição da Cmax. Outra maneira é pelo aumento de íons $\mathrm{OH}^{-}$, que por sua vez competem com íons fosfatos pelos sítios de adsorção. $\mathrm{O}$ aumento de $\mathrm{pH}$ ainda pode aumentar a quantidade de cargas negativas, aumentando a repulsão entre íons fosfato e a superfície de adsorção (Parfitt, 1978; Bar-Yosef et al., 1988; Haynes, 1984; Barrow, 1985; Iyamuremye et al., 1996).

Correlações positivas entre $\mathrm{Al}$ e Cmax têm sido observadas em diversos solos (Udo \& Uzu, 1972, Singh et al., 1983 e Silva et al., 1997). Além disso, Singh et al. (1983) observaram relações significativas entre Cmax e T para solos da Amazônia. Tais resultados servem de base às justificativas das reduções da adsorção de $\mathrm{P}$ durante as quatro épocas de amostragem realizadas na área VS10a.

As diferenças observadas nos comportamentos da adsorção de $\mathrm{P}$ e dos indicadores de fertilidade do solo entre as duas áreas experimentais podem ser atribuídas à quantidade e à qualidade da biomassa vegetal, queimada ou utilizada como cobertura morta no início do experimento, que foi maior na área VS10a (Tabela 4). Essas justificativas podem ser levadas em consideração principalmente quando se avalia que foram realizados dois ciclos de cultivos agrícolas e que por isso, os resultados deveriam ser similares nas duas áreas experimentais.

Resultados obtidos em função da quantidade e qualidade da biomassa vegetal neste trabalho também foram verificadas por Iyamuremye et al. (1996). Esses 
autores, trabalhando com diferentes materiais orgânicos e taxas de aplicação no solo, observaram que a utilização de maiores quantidades desses materiais propiciou os aumentos de $\mathrm{pH}$, de $\mathrm{P}$ disponível e decréscimos de $\mathrm{Al}$ trocável, ocorrendo ainda redução nos valores da Cmax e da constante de afinidade (K). Esses resultados, no entanto, foram condicionados à melhor qualidade dos materiais orgânicos.

Além das justificativas citadas anteriormente para a redução da capacidade de adsorção dos solos nas duas áreas experimentais, outras podem ser ainda levantadas com relação à utilização de fertilizantes e de materiais orgânicos. A redução da Cmax pode ser atribuída à aplicação prévia de fertilizantes, como foi citado por Smyth \& Sanchez (1980) e Barrow et al. (1998). Dynia \& Camargo (1997) concluíram que a aplicação continuada de $\mathrm{P}$ proporciona, com o passar do tempo, redução da capacidade de adsorção, o que levaria à diminuição das necessidades de adubação fosfatada. No entanto, essa não parece ser a justificativa adequada, pois foram observadas reduções de Cmax para todos os tratamentos envolvidos neste experimento, indiferentemente do utilização ou não de fertilizantes.

A outra justificativa para a redução da Cmax pode ser atribuída aos efeitos da aplicação de materiais orgânicos no solo. Trabalhos têm demonstrado que durante a decomposição desses materiais há a formação de vários ácidos orgânicos que tendem a competir com o P pelos mesmos sítios de adsorção. Além disso, pode ocorrer a complexação do Al trocável pelos ácidos orgânicos, diminuindo assim a adsorção de P (Singh \& Jones, 1976; Smyth \& Sanchez, 1980; Hue, 1990, Hue, 1991, Hue, 1992).

Hue (1991), avaliando o efeito de ácidos orgânicos em diferentes solos do Hawaii, observou que esses ácidos competiram com o $\mathrm{P}$ pelos sítios de adsorção, o que proporcionou a disponibilização de fósforo na solução do solo. O autor sugeriu ainda que a eficiência dos fertilizantes fosfatados pode aumentar significativamente se os mesmos forem aplicados juntamente com materiais que possam produzir esses ácidos, como adubos verdes e estercos. Resultados similares foram obtidos por Afif et al. (1995), quando trabalharam com solos do cerrado do Brasil.

Ohno \& Crannell (1996) avaliaram a qualidade do material orgânico quanto ao seu peso molecular e observaram que sistemas de manejo do solo que utilizam 
adubos verdes podem disponibilizar maior quantidade de $\mathrm{P}$, porque os ácidos orgânicos formados a partir desses materiais apresentam menor peso molecular. Hue (1991) também observou esses resultados quando avaliou a competição entre ácidos orgânicos e P pelos sítios de adsorção.

Quanto à capacidade tampão máxima de $\mathrm{P}$ (CTM), os resultados indicam que esse parâmetro não pode ser utilizado para se realizar qualquer tipo de avaliação da capacidade de adsorção e disponibilidade de $\mathrm{P}$ nas condições experimentais deste trabalho, principalmente na área VS4a.

De certa forma, esses resultados estão de acordo com Holford \& Mattingly (1976), que consideram que a limitação da CTM como um parâmetro para entendimento do P no sistema solo é que podem ocorrer alterações significativas quando o fósforo é adicionado ou retirado do sistema. Essa é uma situação típica dos experimentos analisados, já que ocorreram adições at ravés de adubações e saídas através da absorção pelas plantas cultivadas.

Em trabalhos de comparação entre diferentes solos, frenqüentemente são encontradas relações entre CTM e os valores de Cmax e de P disponível. Barrow et al. (1998) observaram decréscimos nos valores de CTM e Cmax com a aplicação prévia de fertilizantes.

\subsubsection{Representação gráfica e comparação dos ajustes das equações de Langmuir e Freundlich}

As representações gráficas da quantidade de fósforo adsorvido em função da concentração de $\mathrm{P}$ na solução de equilíbrio obtidas em laboratório, bem como as curvas obtidas a partir dos valores estimados pelos modelos de Langmuir e Freundlich estão apresentadas nas Figuras 6, 7, 8, 9, 10, 11, 12 e 13.

De forma geral, percebe-se que as duas isotermas descreveram adequadamente a adsorção de fósforo em todas as amostras de solo analisadas das duas 
áreas experimentais (Figuras 6 a 13). Com base nessas figuras notaram-se dois fatos importantes, sendo o primeiro relacionado com a quantidade de $\mathrm{P}$ adsorvido em função dos tratamentos e das épocas de amostragem, e o segundo com a variação dessas estimativas em função da concentração de equilíbrio.

No primeiro caso, as Figuras 6 a 13 demonstram que os resultados da capacidade máxima de adsorção de $\mathrm{P}$ (Cmax), já discutida anteriormente, estão de acordo com a representação gráfica dos estudos experimentais de adsorção. Um exemplo são os resultados da camada superficial da área VS10a, na qual percebeu-se acentuada redução na quantidade de $\mathrm{P}$ adsorvido, tanto pelos dados observados quanto pelas estimativas, para todos os tratamentos aplicados após a primeira amostragem, semelhante ao que aconteceu para a estimativa de Cmax obtida pela equação de Langmuir. Além disso, percebeu-se na representação gráfica da adsorção e nos valores de Cmax (Tabelas 15 e 16) que, de maneira geral, os melhores resultados quanto à redução de adsorção de $\mathrm{P}$ foram obtidos com os tratamentos que envolveram a utilização de cobertura morta.

No segundo caso, observou-se pela representação gráfica a existência de três faixas distintas de diferenciação dos resultados das estimativas das quantidades de $\mathrm{P}$ adsorvidas, obtidas pelas duas isotermas, em função da concentração desse elemento na solução de equilíbrio. Quando a concentração de equilíbrio variou de 0 a $5 \mu \mathrm{g} \mathrm{mL}^{-1}$ ou foi maior que $30 \mu \mathrm{g} \mathrm{mL} \mathrm{m}^{-1}$ as estimativas de $\mathrm{P}$ adsorvido obtidas pela equação de Freundlich foram maiores do que as obtidas pela de Langmuir. O inverso ocorreu quando a concentração de equilíbrio variou entre 5 e $30 \mu \mathrm{g} \mathrm{mL}^{-1}$ (Figuras 6, 7, 8, 9, 10, 11,12 e 13). 

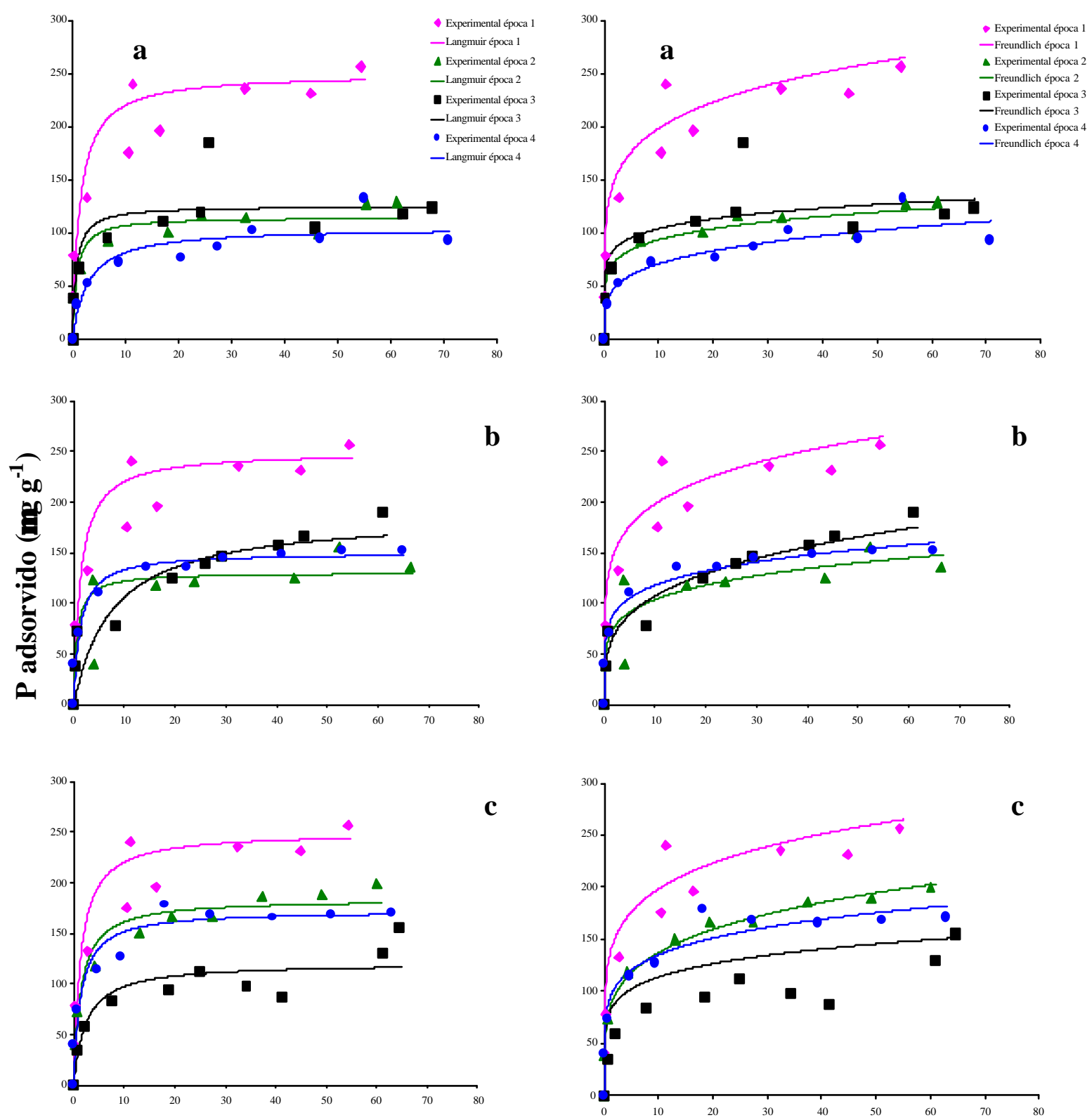

Concentração de equilíbrio ( $\mu \mathrm{g} \mathrm{mL}^{-1}$ )

Figura 6 - Adsorção de fósforo e curvas estimadas pelas isotermas de Langmuir e Freundlich, para a profundidade $0-10 \mathrm{~cm}$ da área VS10a durante as quatro épocas de amostragens. Tratamentos: a) controle, b) queima + fertilizante, c) queima - fertilizante. 

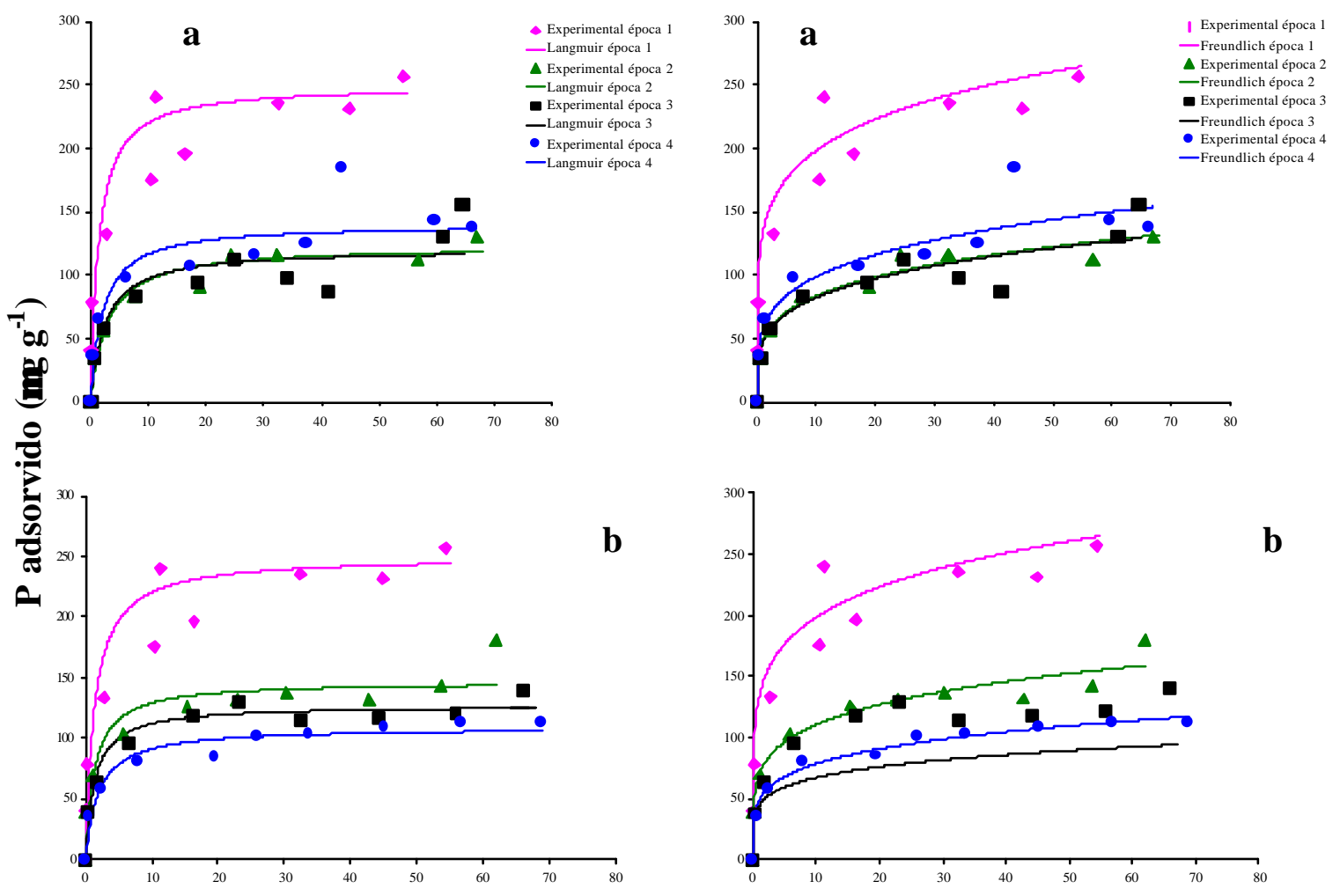

\section{Concentração de equilíbrio $\left(\mu \mathrm{g} \mathrm{mL} \mathrm{L}^{-1}\right)$}

Figura 7 - Adsorção de fósforo e curvas estimadas pelas isotermas de Langmuir e Freundlich, para a profundidade $0-10 \mathrm{~cm}$ da área VS10a durante as quatro épocas de amostragens. Tratamentos: a) mulch + fertilizante, b) mulch fertilizante. 



\section{Concentração de equilíbrio $\left(\mu \mathrm{g} \mathrm{mL}^{-1}\right)$}

Figura 8 - Adsorção de fósforo e curvas estimadas pelas isotermas de Langmuir e Freundlich, para a profundidade $10-20 \mathrm{~cm}$ da área VS10a durante as quatro épocas de amostragens. Tratamentos: a) controle, b) queima + fertilizante, c) queima - fertilizante. 

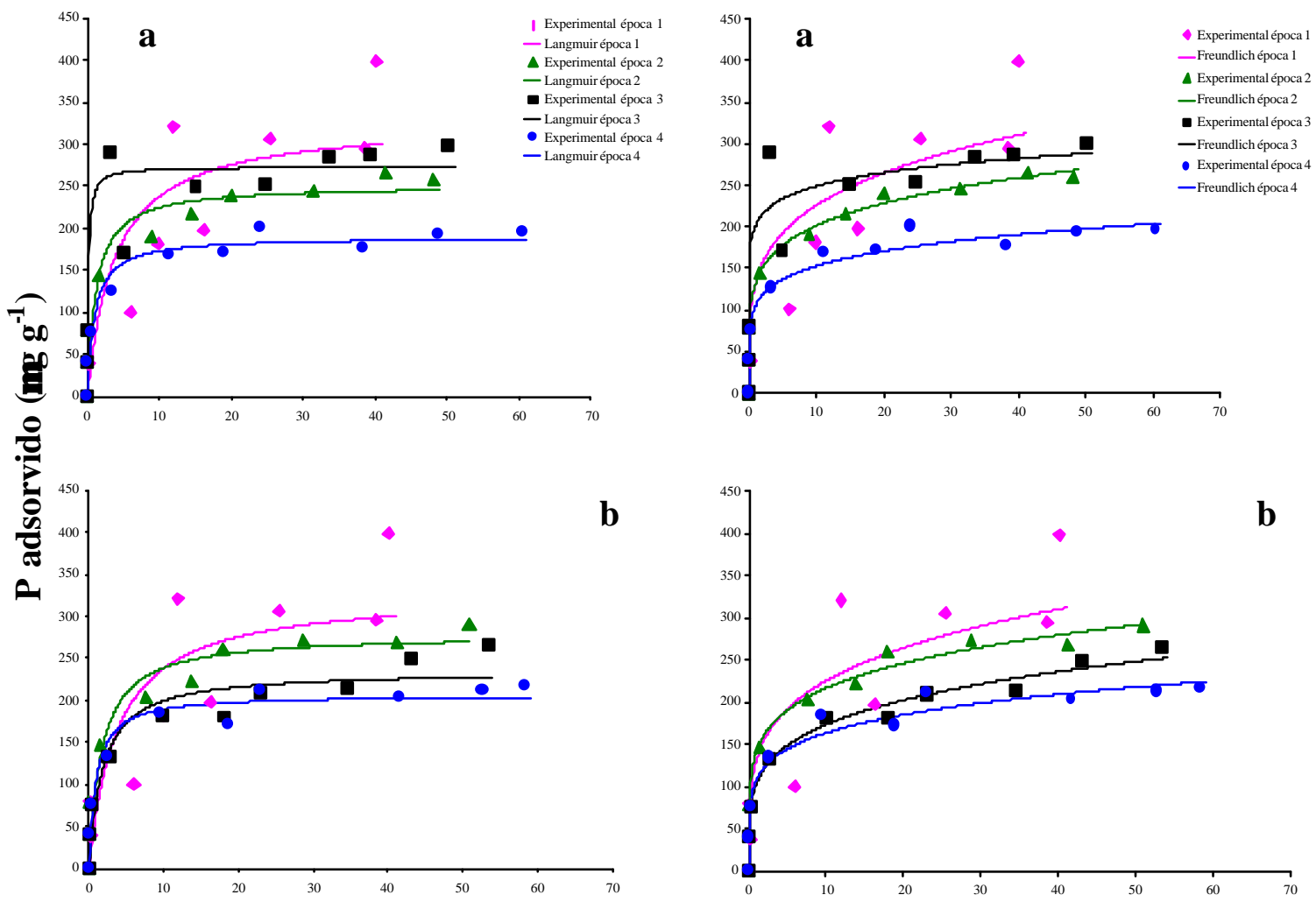

\section{Concentração de equilíbrio $\left(\mu \mathrm{g} \mathrm{mL} \mathrm{L}^{-1}\right)$}

Figura 9 - Adsorção de fósforo e curvas estimadas pelas isotermas de Langmuir e Freundlich, para a profundidade $10-20 \mathrm{~cm}$ da área VS10a durante as quatro épocas de amostragens. Tratamentos: a) mulch + fertilizante, b) mulch fertilizante. 

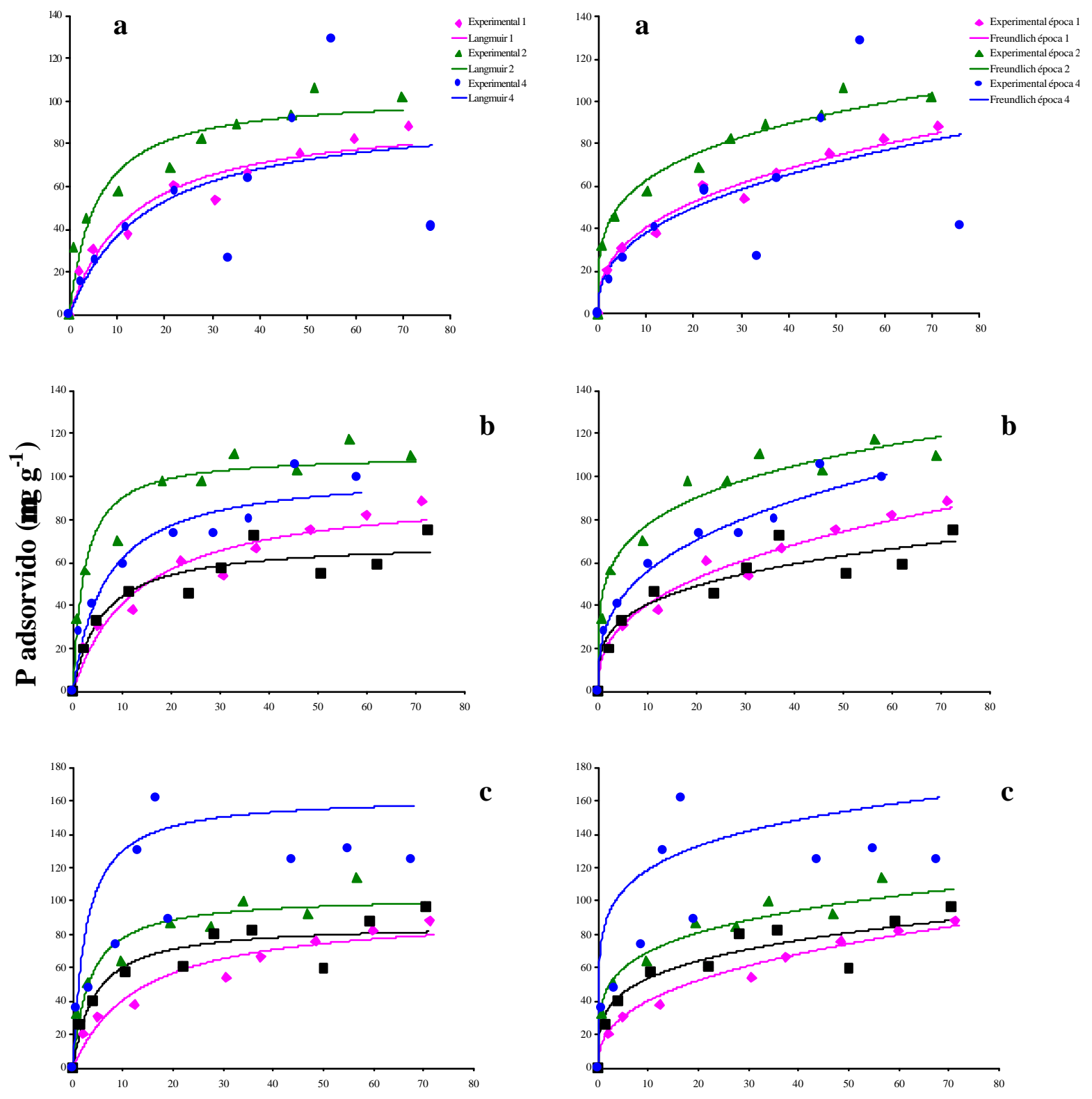

\section{Concentração de equilíbrio $\left(\mu \mathrm{g} \mathrm{mL}^{-1}\right)$}

Figura 10 - Adsorção de fósforo e curvas estimadas pelas isotermas de Langmuir e Freundlich, para a profundidade $0-10 \mathrm{~cm}$ da área VS4a durante as quatro épocas de amostragens. Tratamentos: a) controle, b) queima + fertilizante, c) queima - fertilizante. 

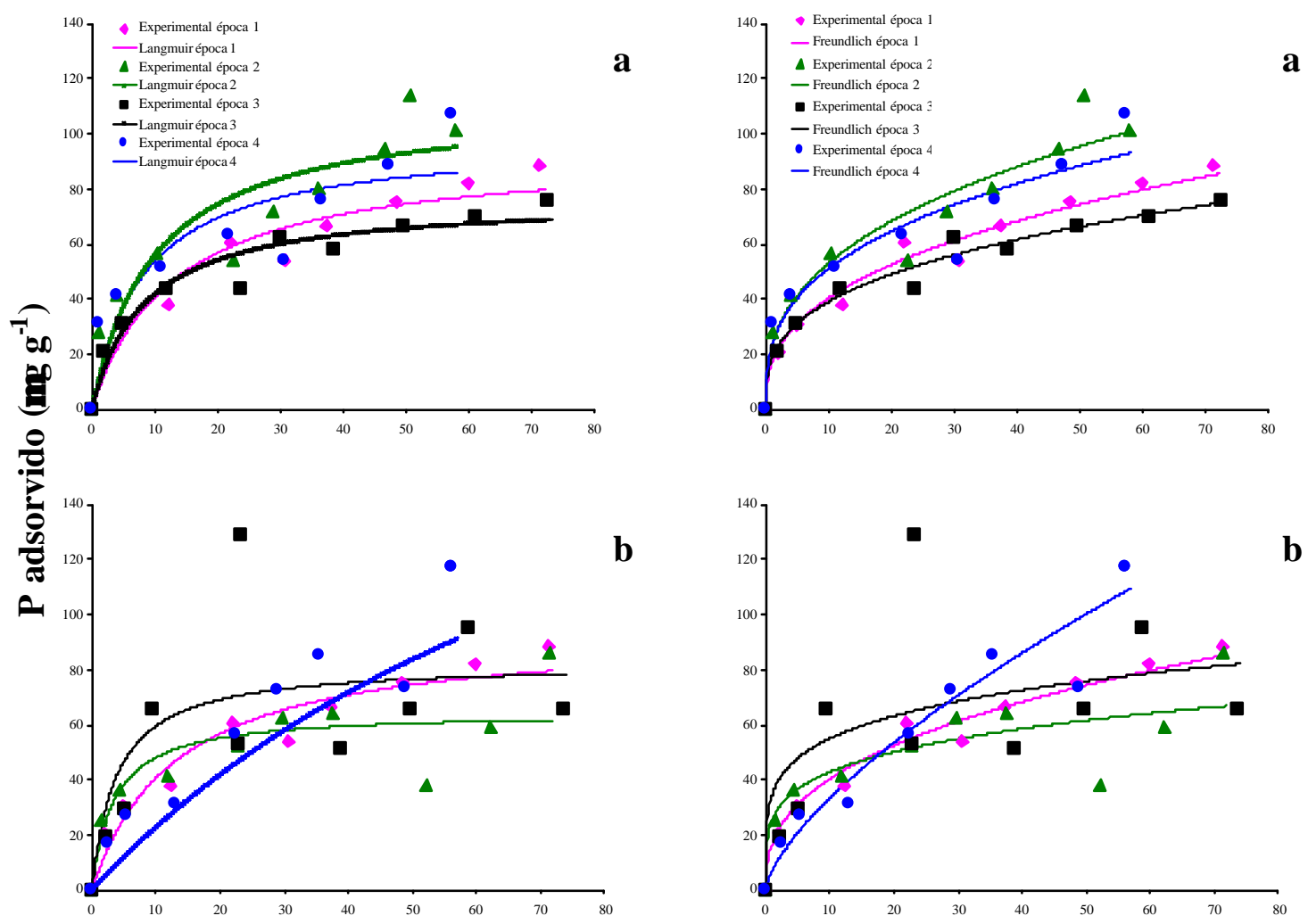

b

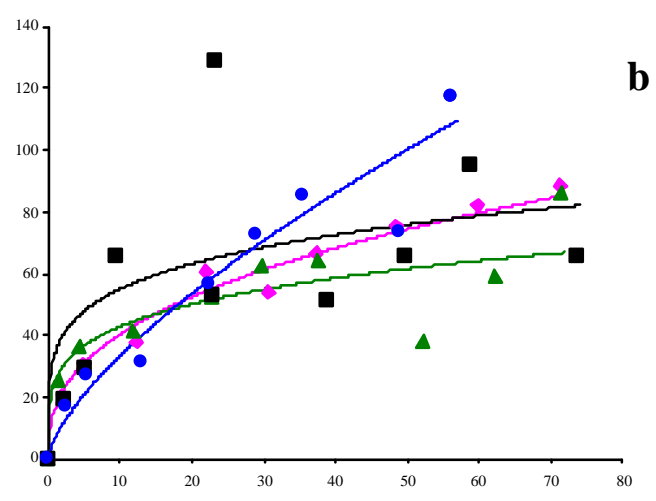

\section{Concentração de equilíbrio $\left(\mu \mathrm{g} \mathrm{mL}^{-1}\right)$}

Figura 11 - Adsorção de fósforo e curvas estimadas pelas isotermas de Langmuir e Freundlich, para a profundidade $0-10 \mathrm{~cm}$ da área VS4a durante as quatro épocas de amostragens. Tratamentos: a) mulch + fertilizante, b) mulch fertilizante. 

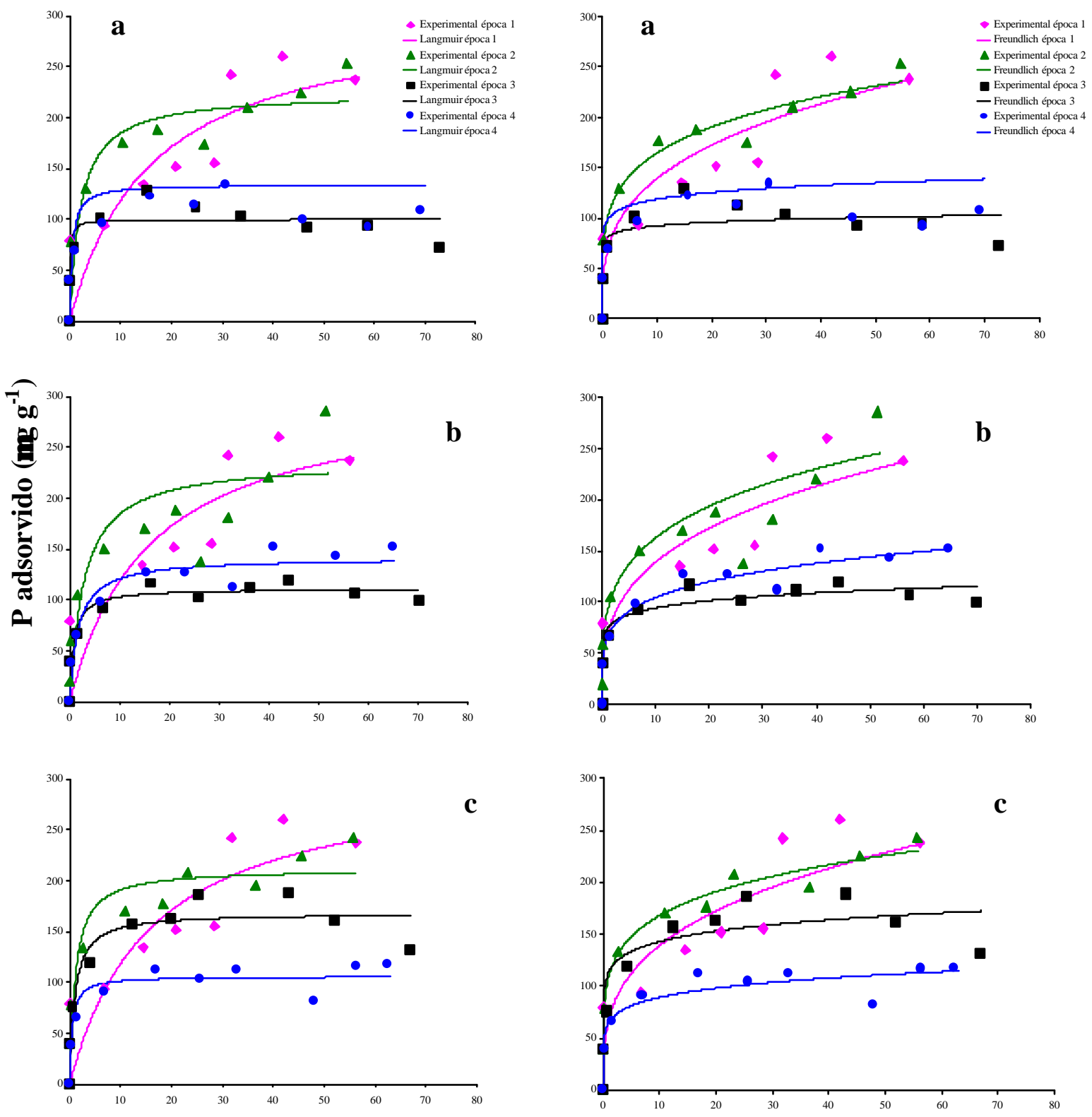

\section{Concentração de equilíbrio $\left(\mu \mathrm{g} \mathrm{mL} \mathbf{L}^{-1}\right)$}

Figura 12 - Adsorção de fósforo e curvas estimadas pelas isotermas de Langmuir e Freundlich, para a profundidade $10-20 \mathrm{~cm}$ da área VS4a durante as quatro épocas de amostragens. Tratamentos: a) controle, b) queima + fertilizante, c) queima - fertilizante. 

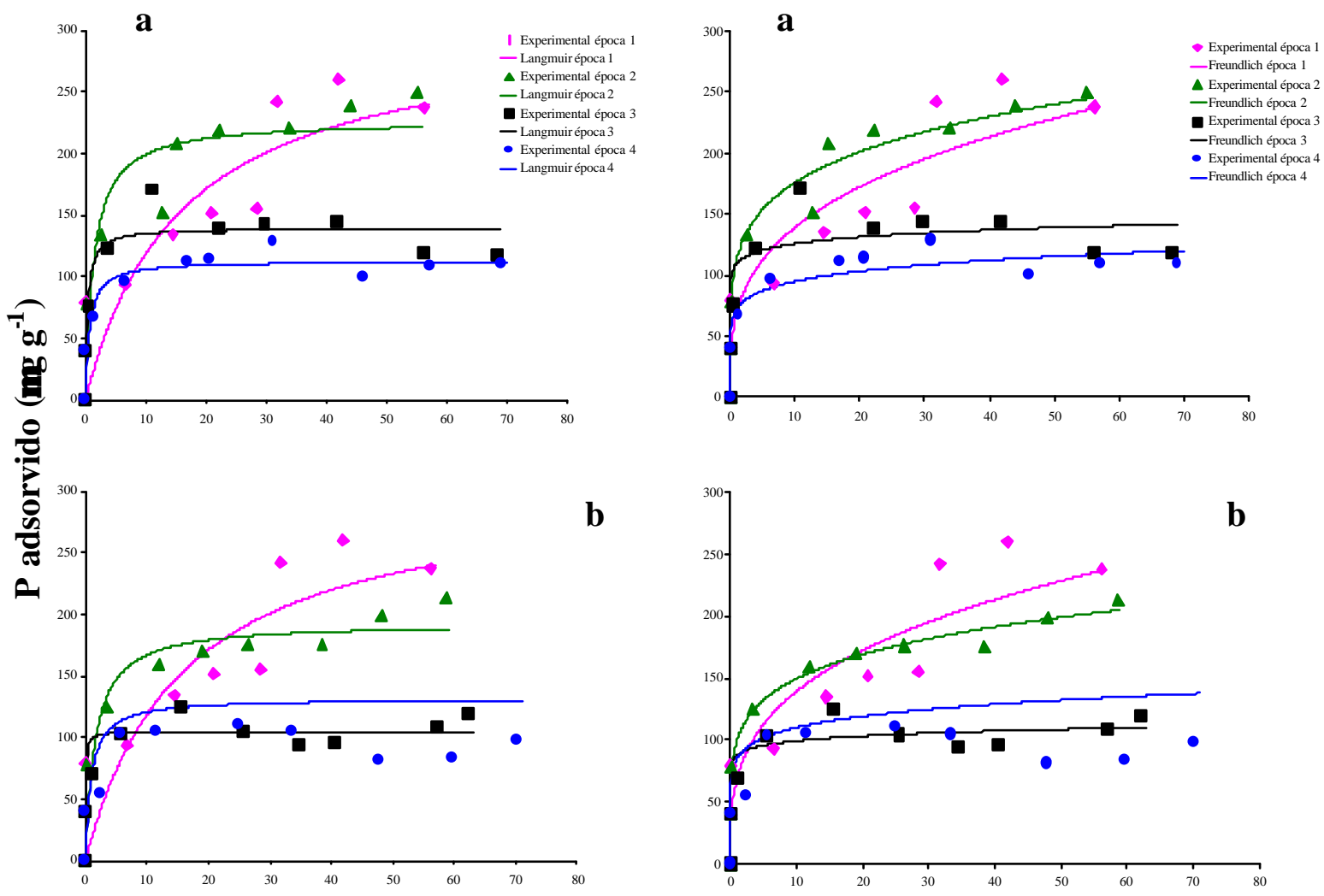

\section{Concentração de equilíbrio $\left(\mu \mathrm{g} \mathrm{mL} \mathrm{L}^{-1}\right)$}

Figura 13 - Adsorção de fósforo e curvas estimadas pelas isotermas de Langmuir e Freundlich, para a profundidade $10-20 \mathrm{~cm}$ da área VS4a durante as quatro épocas de amostragens. Tratamentos: a) mulch + fertilizante, b) mulch fertilizante. 
Os parâmetros estatísticos para comparação dos ajustes das equações não lineares de Langmuir e Freundlich aos resultados experimentais de adsorção de fósforo estão apresentados nas Tabelas 19, 20, 21 e 22, de acordo com áreas experimentais e profundidades analisadas.

A equação de melhor ajuste, definida pela utilização de critérios citados por Mead (1981), Sparks e Jardine (1984) e Raven \& Hossner (1994), é aquela à qual está associado o menor quadrado médio residual (QMR) e o menor erro padrão das estimativas (EP). Também foi levado em consideração que o modelo seria mais adequado quando a equação linear ajustada entre os valores observados e estimados apresentasse: um coeficiente linear (a) mais próximo de zero, um coeficiente angular (b) mais próximo da unidade e um coeficiente de determinação também próximo da unidade.

Considerando os cinco parâmetros apresentados nas Tabela 18, 19, 20, 21 e 22 verificourse que o modelo não linear de Freundlich foi o que melhor se ajustou aos dados experimentais de adsorção de $\mathrm{P}$, independentemente do tratamento aplicado e da profundidade analisada. No entanto, é possível notar que a diferença nos valores dos parâmetros de comparação de ajuste entre os dois modelos (Langmuir e Freundlich) é geralmente pequena, principalmente para o coeficiente de determinação. 
Tabela 19. Parâmetros estatísticos utilizados na comparação dos ajustes das equações de Langmuir e Freundlich aos resultados experimentais de adsorção de $\mathrm{P}$, na profundidade $0-10 \mathrm{~cm}$ da área com vegetação secundária de 10 anos.

\begin{tabular}{|c|c|c|c|c|c|c|c|c|c|c|c|}
\hline \multirow[b]{2}{*}{ Tratamento $^{(1)}$} & \multirow[b]{2}{*}{ Época } & \multicolumn{5}{|c|}{ Langmuir } & \multicolumn{5}{|c|}{ Freundlich } \\
\hline & & $\mathrm{QMR}^{(2)}$ & $\mathrm{EP}^{(3)}$ & $a^{(4)}$ & $b^{(4)}$ & $\mathrm{R}^{2(4)}$ & QMR & $\mathrm{EP}$ & $\mathrm{a}$ & $\mathrm{b}$ & $\overline{\mathrm{R}^{2}}$ \\
\hline \multirow[t]{4}{*}{ Controle } & Out./94 & 9294,62 & 96,41 & 39,452 & 0,851 & 0,57 & 8545,12 & 93,65 & 14,281 & 0,944 & 0,57 \\
\hline & Jan./97 & 1249,79 & 35,35 & 37,547 & 0,839 & 0,93 & 698,42 & 26,43 & 27,593 & 0,880 & 0,96 \\
\hline & Jul./98 & 2087,59 & 45,69 & 29,993 & 0,870 & 0,84 & 1874,14 & 43,29 & 19,988 & 0,912 & 0,84 \\
\hline & Jul./00 & 983,08 & 31,35 & 18,803 & 0,883 & 0,82 & 1020,77 & 31,95 & 16,895 & 0,894 & 0,81 \\
\hline \multirow{3}{*}{$\mathrm{Q}+\mathrm{F}$} & Jan./97 & 1571,62 & 39,64 & 38,743 & 0,857 & 0,93 & 1131,82 & 33,64 & 36,103 & 0,867 & 0,95 \\
\hline & Jul./98 & 2337,01 & 48,34 & 28,306 & 0,872 & 0,80 & 1849,88 & 43,01 & 14,856 & 0,932 & 0,83 \\
\hline & Jul./00 & 512,42 & 22,64 & 21,794 & 0,894 & 0,95 & 339,27 & 18,42 & 14,665 & 0,928 & 0,96 \\
\hline \multirow[t]{3}{*}{$\mathrm{Q}-\mathrm{F}$} & Out./94 & 9294,62 & 96,41 & 39,452 & 0,851 & 0,57 & 8545,12 & 93,65 & 14,281 & 0,944 & 0,57 \\
\hline & Jan./97 & 1078,49 & 32,85 & 33,671 & 0,870 & 0,95 & 720,43 & 26,84 & 26,089 & 0,899 & 0,96 \\
\hline & Jul./98 & 2519,94 & 50,19 & 32,071 & 0,890 & 0,88 & 1893,05 & 43,51 & 25,208 & 0,913 & 0,91 \\
\hline \multirow[t]{4}{*}{$M+F$} & Out./94 & 9294,62 & 96,41 & 39,452 & 0,851 & 0,57 & 8545,12 & 93,65 & 14,281 & 0,944 & 0,57 \\
\hline & Jan./97 & 925,83 & 30,43 & 32,803 & 0,856 & 0,94 & 238,22 & 15,43 & 15,087 & 0,932 & 0,98 \\
\hline & Jul./98 & 2775,40 & 52,68 & 28,497 & 0,891 & 0,83 & 3422,64 & 58,50 & 28,713 & 0,888 & 0,79 \\
\hline & Jul./00 & 803,91 & 28,35 & 18,881 & 0,891 & 0,87 & 855,67 & 29,25 & 15,902 & 0,907 & 0,86 \\
\hline \multirow[t]{4}{*}{$\mathrm{M}-\mathrm{F}$} & Out./94 & 9294,62 & 96,41 & 39,452 & 0,851 & 0,57 & 8545,12 & 93,65 & 14,281 & 0,944 & 0,57 \\
\hline & Jan./97 & 1239,59 & 35,21 & 38,486 & 0,844 & 0,94 & 1059,80 & 32,55 & 36,859 & 0,850 & 0,95 \\
\hline & Jul./98 & 1293,91 & 35,97 & 23,187 & 0,888 & 0,87 & 945,38 & 30,74 & 14,975 & 0,927 & 0,90 \\
\hline & Jul./00 & 382,39 & 19,55 & 18,127 & 0,904 & 0,95 & 281,96 & 16,79 & 6,949 & 0,962 & 0,96 \\
\hline
\end{tabular}

(1) Tratamentos: Controle; Queima+fertilizante (Q+F); Queima-fertilizante (Q-F); Mulch+Fertilizante (M+F); Mulch - Fertilizante (M-F).

(2) Quadrado médio residual da análise de variância da regressão não-linear empregada no estudo de adsorção de $P$

(3) Erro Padrão da estimativa calculado da seguinte maneira: $\mathrm{EP}=[$ (Xmed-Xest) $2 /(\mathrm{n}-2)] 1 / 2$, na qual Xmed=Adsorção medida, Xest= Adsorção estimada, e n= número de pares experimentais utilizados para ajuste da equação de adsorção.

(4) Coeficientes (linear, angular e de determinação) da equação de regressão entre dados experimentais e os estimados. 
Tabela 20. Parâmetros estatísticos utilizados na comparação dos ajustes das equações de Langmuir e Freundlich aos resultados experimentais de adsorção de $\mathrm{P}$, na profundidade $10-20 \mathrm{~cm}$ da área com vegetação secundária de 10 anos.

\begin{tabular}{|c|c|c|c|c|c|c|c|c|c|c|c|}
\hline \multirow[b]{2}{*}{ Tratamento $^{(1)}$} & \multirow[b]{2}{*}{ Época } & \multicolumn{5}{|c|}{ Langmuir } & \multicolumn{5}{|c|}{ Freundlich } \\
\hline & & $\mathrm{QMR}^{(2)}$ & $\mathrm{EP}^{(3)}$ & $a^{(4)}$ & $b^{(4)}$ & $\mathrm{R}^{2(4)}$ & QMR & $\mathrm{EP}$ & $\mathrm{a}$ & $\mathrm{b}$ & $\mathrm{R}^{2}$ \\
\hline \multirow[t]{4}{*}{ Controle } & Out./94 & 9294,62 & 96,41 & 39,452 & 0,851 & 0,57 & 8545,12 & 93,65 & 14,281 & 0,944 & 0,57 \\
\hline & Jan./97 & 1249,79 & 35,35 & 37,547 & 0,839 & 0,93 & 698,42 & 26,43 & 27,593 & 0,880 & 0,96 \\
\hline & Jul./98 & 2087,59 & 45,69 & 29,993 & 0,870 & 0,84 & 1874,14 & 43,29 & 19,988 & 0,912 & 0,84 \\
\hline & Jul./00 & 983,08 & 31,35 & 18,803 & 0,883 & 0,82 & 1020,77 & 31,95 & 16,895 & 0,894 & 0,81 \\
\hline \multirow[t]{4}{*}{$\mathrm{Q}+\mathrm{F}$} & Out./94 & 9294,62 & 96,41 & 39,452 & 0,851 & 0,57 & 8545,12 & 93,65 & 14,281 & 0,944 & 0,57 \\
\hline & Jan./97 & 1571,62 & 39,64 & 38,743 & 0,857 & 0,93 & 1131,82 & 33,64 & 36,103 & 0,867 & 0,95 \\
\hline & Jul./98 & 2337,01 & 48,34 & 28,306 & 0,872 & 0,80 & 1849,88 & 43,01 & 14,856 & 0,932 & 0,83 \\
\hline & Jul./00 & 512,42 & 22,64 & 21,794 & 0,894 & 0,95 & 339,27 & 18,42 & 14,665 & 0,928 & 0,96 \\
\hline \multirow[t]{3}{*}{$Q-F$} & Out./94 & 9294,62 & 96,41 & 39,452 & 0,851 & 0,57 & 8545,12 & 93,65 & 14,281 & 0,944 & 0,57 \\
\hline & Jan./97 & 1078,49 & 32,85 & 33,671 & 0,870 & 0,95 & 720,43 & 26,84 & 26,089 & 0,899 & 0,96 \\
\hline & Jul./98 & 2519,94 & 50,19 & 32,071 & 0,890 & 0,88 & 1893,05 & 43,51 & 25,208 & 0,913 & 0,91 \\
\hline \multirow[t]{4}{*}{$M+F$} & Out./94 & 9294,62 & 96,41 & 39,452 & 0,851 & 0,57 & 8545,12 & 93,65 & 14,281 & 0,944 & 0,57 \\
\hline & Jan./97 & 925,83 & 30,43 & 32,803 & 0,856 & 0,94 & 238,22 & 15,43 & 15,087 & 0,932 & 0,98 \\
\hline & Jul./98 & 2775,40 & 52,68 & 28,497 & 0,891 & 0,83 & 3422,64 & 58,50 & 28,713 & 0,888 & 0,79 \\
\hline & Jul./00 & 803,91 & 28,35 & 18,881 & 0,891 & 0,87 & 855,67 & 29,25 & 15,902 & 0,907 & 0,86 \\
\hline \multirow[t]{4}{*}{$M-F$} & Out./94 & 9294,62 & 96,41 & 39,452 & 0,851 & 0,57 & 8545,12 & 93,65 & 14,281 & 0,944 & 0,57 \\
\hline & Jan./97 & 1239,59 & 35,21 & 38,486 & 0,844 & 0,94 & 1059,80 & 32,55 & 36,859 & 0,850 & 0,95 \\
\hline & Jul./98 & 1293,91 & 35,97 & 23,187 & 0,888 & 0,87 & 945,38 & 30,74 & 14,975 & 0,927 & 0,90 \\
\hline & Jul./00 & 382,39 & 19,55 & 18,127 & 0,904 & 0,95 & 281,96 & 16,79 & 6,949 & 0,962 & 0,96 \\
\hline
\end{tabular}

(2) Quadrado médio residual da análise de variância da regressão não-linear empregada no estudo de adsorção de $P$

(3) Erro Padrão da estimativa calculado da seguinte maneira: EP=[ (Xmed-Xest)2/(n-2)]1/2, na qual Xmed=Adsorção medida, Xest= Adsorção estimada, e n= número de pares experimentais utilizados para ajuste da equação de adsorção.

(4) Coeficientes (linear, angular e de determinação) da equação de regressão entre dados experimentais e os estimados. 
Tabela 21. Parâmetros estatísticos utilizados na comparação dos ajustes das equações de Langmuir e Freundlich aos resultados experimentais de adsorção de $\mathrm{P}$, na profundidade $0-10 \mathrm{~cm}$ da área com vegetação secundária de 4 anos.

\begin{tabular}{|c|c|c|c|c|c|c|c|c|c|c|c|}
\hline \multirow[b]{2}{*}{ Tratamento $^{(1)}$} & \multirow[b]{2}{*}{ Época } & \multicolumn{5}{|c|}{ Langmuir } & \multicolumn{5}{|c|}{ Freundlich } \\
\hline & & $\mathrm{QMR}^{(2)}$ & $\mathrm{EP}^{(3)}$ & $a^{(4)}$ & $b^{(4)}$ & $\mathrm{R}^{2(4)}$ & QMR & EP & $\mathrm{a}$ & $\mathrm{b}$ & $\overline{\mathrm{R}^{2}}$ \\
\hline \multirow[t]{3}{*}{ Controle } & Out./94 & 445,95 & 21,12 & 3,345 & 0,949 & 0,63 & 429,52 & 20,72 & $-0,215$ & 1,003 & 0,63 \\
\hline & Jul./98 & & & & & & & & & & \\
\hline & Jul./00 & 790,48 & 28,11 & 0,942 & 0,985 & 0,52 & 824,23 & 28,71 & $-1,749$ & 1,028 & 0,50 \\
\hline \multirow[t]{4}{*}{$\mathrm{Q}+\mathrm{F}$} & Out./94 & 445,95 & 21,12 & 3,345 & 0,949 & 0,63 & 429,52 & 20,72 & $-0,215$ & 1,003 & 0,63 \\
\hline & Jan./97 & 252,03 & 15,88 & 5,363 & 0,944 & 0,85 & 196,25 & 14,01 & $-0,599$ & 1,006 & 0,88 \\
\hline & Jul./98 & 189,73 & 13,77 & 0,743 & 0,987 & 0,72 & 194,58 & 13,94 & $-0,639$ & 1,011 & 0,71 \\
\hline & Jul./00 & 83,94 & 9,16 & 4,220 & 0,947 & 0,93 & 35,15 & 5,93 & 0,187 & 0,998 & 0,97 \\
\hline \multirow[t]{4}{*}{$\mathrm{Q}-\mathrm{F}$} & Out./94 & 445,95 & 21,12 & 3,345 & 0,949 & 0,63 & 429,52 & 20,72 & $-0,215$ & 1,003 & 0,63 \\
\hline & Jan./97 & 420,91 & 20,52 & 6,727 & 0,923 & 0,73 & 390,96 & 19,77 & $-0,503$ & 1,006 & 0,74 \\
\hline & Jul./98 & 438,75 & 20,95 & 3,245 & 0,955 & 0,64 & 420,53 & 20,50 & $-0,306$ & 1,004 & 0,65 \\
\hline & Jul./00 & 4668,71 & 68,32 & $-0,083$ & 1,001 & 0,44 & 5427,48 & 73,67 & $-5,651$ & 1,043 & 0,35 \\
\hline \multirow[t]{4}{*}{$\mathrm{M}+\mathrm{F}$} & Out./94 & 445,95 & 21,12 & 3,345 & 0,949 & 0,63 & 429,52 & 20,72 & $-0,215$ & 1,003 & 0,63 \\
\hline & Jan./97 & 341,60 & 18,48 & 7,331 & 0,910 & 0,76 & 265,72 & 16,30 & 1,128 & 0,986 & 0,81 \\
\hline & Jul./98 & 109,18 & 10,44 & 2,630 & 0,955 & 0,84 & 89,36 & 9,45 & $-0,040$ & 1,001 & 0,86 \\
\hline & Jul./00 & 216,20 & 14,70 & 8,880 & 0,881 & 0,83 & 97,15 & 9,87 & 2,130 & 0,971 & 0,92 \\
\hline \multirow[t]{4}{*}{$M-F$} & Out./94 & 445,95 & 21,12 & 3,345 & 0,949 & 0,63 & 429,52 & 20,72 & $-0,215$ & 1,003 & 0,63 \\
\hline & Jan./97 & 451,63 & 21,25 & 2,059 & 0,963 & 0,48 & 440,31 & 20,98 & $-0,185$ & 1,003 & 0,50 \\
\hline & Jul./98 & 1005,39 & 31,71 & $-2,513$ & 1,037 & 0,42 & 1102,96 & 33,21 & $-1,739$ & 1,026 & 0,37 \\
\hline & Jul./00 & 136,80 & 11,69 & 4,344 & 0,949 & 0,93 & 118,49 & 10,88 & 1,351 & 0,984 & 0,94 \\
\hline
\end{tabular}

(1) Tratamentos: Controle, Queima+fertilizante (Q+F), Queima-fertilizante (Q-F); Mulch+Fertilizante (M+F), Mulch -

(2) Quadrado médio residual da análise de variância da regressão não-linear empregada no estudo de adsorção de $P$

(3) Erro Padrão da estimativa calculado da seguinte maneira: EP=[ (Xmed-Xest)2/(n-2)]1/2, na qual Xmed=Adsorção medida, Xest= Adsorção estimada, e n= número de pares experimentais utilizados para ajuste da equação de adsorção.

(4) Coeficientes (linear, an gular e de determinação) da equação de regressão entre dados experimentais e os estimados. 
Tabela 22. Parâmetros estatísticos utilizados na comparação dos ajustes das equações de Langmuir e Freundlich aos resultados experimentais de adsorção de P, na profundidade $10-20 \mathrm{~cm}$ da área com vegetação secundária de 4 anos.

\begin{tabular}{|c|c|c|c|c|c|c|c|c|c|c|c|}
\hline \multirow[b]{2}{*}{ Tratamento $^{(1)}$} & \multirow[b]{2}{*}{ Época } & \multicolumn{5}{|c|}{ Langmuir } & \multicolumn{5}{|c|}{ Freundlich } \\
\hline & & $\mathrm{QMR}^{(2)}$ & $\mathrm{EP}^{(3)}$ & $a^{(4)}$ & $b^{(4)}$ & $\mathrm{R}^{2(4)}$ & QMR & $\mathrm{EP}$ & $\mathrm{a}$ & $\mathrm{b}$ & $\mathrm{R}^{2}$ \\
\hline \multirow[t]{3}{*}{ Controle } & Out./94 & 2806,75 & 52,98 & 35,322 & 0,818 & 0,72 & $2.615,73$ & 51,14 & 25,378 & 0,866 & 0,71 \\
\hline & Jul./98 & 674,57 & 25,97 & 12,638 & 0,869 & 0,64 & 790,79 & 28,12 & 12,112 & 0,872 & 0,57 \\
\hline & Jul./00 & 594,04 & 24,37 & 18,328 & 0,855 & 0,83 & 748,21 & 27,35 & 18,670 & 0,851 & 0,78 \\
\hline \multirow[t]{4}{*}{$\mathrm{Q}+\mathrm{F}$} & Out./94 & 2806,75 & 52,98 & 35,322 & 0,818 & 0,72 & $2.615,73$ & 51,14 & 25,378 & 0,866 & 0,71 \\
\hline & Jan./97 & 3983,82 & 63,12 & 26,993 & 0,866 & 0,65 & $3.262,87$ & 57,12 & 10,246 & 0,948 & 0,70 \\
\hline & Jul./98 & 398,99 & 19,97 & 18,263 & 0,824 & 0,81 & 364,41 & 19,09 & 10,733 & 0,895 & 0,80 \\
\hline & Jul./00 & 446,64 & 21,13 & 11,317 & 0,910 & 0,85 & 343,78 & 18,54 & $-1,091$ & 1,009 & 0,88 \\
\hline \multirow[t]{3}{*}{$\mathrm{Q}-\mathrm{F}$} & Out./94 & 2806,75 & 52,98 & 35,322 & 0,818 & 0,72 & $2.615,73$ & 51,14 & 25,378 & 0,866 & 0,71 \\
\hline & Jan./97 & 1215,46 & 34,86 & 31,773 & 0,836 & 0,87 & 905,19 & 30,09 & 28,085 & 0,856 & 0,91 \\
\hline & Jul./98 & 1546,72 & 39,33 & 29,796 & 0,809 & 0,73 & $1.718,68$ & 41,46 & 30,456 & 0,803 & 0,69 \\
\hline \multirow[t]{4}{*}{$M+F$} & Out./94 & 2806,75 & 52,98 & 35,322 & 0,818 & 0,72 & $2.615,73$ & 51,14 & 25,378 & 0,866 & 0,71 \\
\hline & Jan./97 & 1914,59 & 43,76 & 30,618 & 0,850 & 0,81 & $1.707,38$ & 41,32 & 27,674 & 0,865 & 0,83 \\
\hline & Jul./98 & 761,55 & 27,59 & 18,222 & 0,862 & 0,78 & 964,05 & 31,05 & 19,002 & 0,854 & 0,72 \\
\hline & Jul./00 & 301,20 & 17,36 & 13,502 & 0,872 & 0,85 & 260,24 & 16,13 & $-1,186$ & 1,012 & 0,85 \\
\hline \multirow[t]{4}{*}{$\mathrm{M}-\mathrm{F}$} & Out./94 & 2806,75 & 52,98 & 35,322 & 0,818 & 0,72 & $2.615,73$ & 51,14 & 25,378 & 0,866 & 0,71 \\
\hline & Jan./97 & 781,84 & 27,96 & 32,309 & 0,816 & 0,91 & 588,32 & 24,26 & 28,509 & 0,837 & 0,93 \\
\hline & Jul./98 & 736,79 & 27,14 & 19,678 & 0,809 & 0,66 & 720,13 & 26,84 & 19,440 & 0,812 & 0,66 \\
\hline & Jul./00 & 268,88 & 16,40 & 18,071 & 0,852 & 0,92 & 350,08 & 18,71 & 18,244 & 0,849 & 0,90 \\
\hline
\end{tabular}

(1) Tratamentos: Controle, Queima+fertilizante (Q+F), Queima-fertilizante (Q-F), Mulch+Fertilizante (M+F), Mulch -

(2) Quadrado médio residual da análise de variância da regressão não-linear empregada no estudo de adsorção de P

(3) Erro Padrão da estimativa calculado da seguinte maneira: EP=[ (Xmed-Xest)2/(n-2)]1/2, na qual Xmed=Adsorção medida, Xest= Adsorção estimada, e n= número de pares experimentais utilizados para ajuste da equação de adsorção.

(4) Coeficientes (linear, angular e de determinação) da equação de regressão entre dados experimentais e os estimados 


\subsection{Fósforo Orgânico}

Nas Tabelas 23 e 24 estão apresentados os resultados de P-total (Pt), Pinorgânico (Pi) e P-orgânico (Po) obtidos pelo método de ignição. De maneira geral, observaram-se similaridades nas quantidades de Pt das camadas superficiais das duas áreas experimentais; no entanto, na camada subsuperficial a quantidade de Pt foi maior na área VS10a.

$\mathrm{Na}$ última amostragem realizada nas duas áreas (VS10A e VS4a) a quantidade de Pt manteve-se próxima dos valores encontrados no início do experimento. Durante as quatro épocas de amostragem, as quantidades de Po foram superiores às de Pi. Além disso, a quantidade de Pt encontrada nas duas áreas experimentais pode ser considerada muita baixa.

As quantidades de Po obtidas neste trabalho estão de acordo com as citados por Boernemisza \& Igue (1967), que verificaram que o Po representava mais de $50 \%$ do Pt; no entanto, esses resultados foram observados em solos mais jovens da Costa Rica. Vieira (1988) realizou uma avaliação das formas de fósforo em solos amazônicos e

encontrou quantidades baixas de $\mathrm{Pt}$, com média de $359 \mathrm{mg} \mathrm{kg}^{-1}$. Observou ainda que as quantidades de Po foram inferiores às de Pi e representavam cerca de $20 \%$ do fósforo total dos solos.

Fassbender \& Boernemisza (1994) relatam que o Po pode representar entre 25 e 75\% do Pt e que tem uma participação igual à do Pi; no entanto, isso depende de alguns fatores, como temperatura, precipitação pluvial, atividade biológica, acidez do solo e grau de desenvolvimento do solo. Em condições de acúmulo de matéria orgânica no solo há predominância de P orgânico.

A maior quantidade de Pt na camada subsuperficial da área VS10 pode ser explicada pelo maior de teor de argila nessa área. Trabalhos têm demonstrado uma correlação positiva entre textura do solo e Pt (Lópes-Hernández \& Nino, 1993; Fassbender \& Boernemisza,1994); no entanto, geralmente ocorre um decréscimo da quantidade de fósforo com a profundidade devido à diminuição da $\mathrm{MO}$, principalmente em solos da região tropical onde há uma relação direta entre Pt e MO. 
Para atender os objetivos desta pesquisa, foram realizadas análises estatísticas somente para os resultados de fósforo orgânico. A variação nos resultados da quantidade de fósforo orgânico total (Po) do solo, obtidos pelo método de ignição para as duas áreas experimentais (VS10a e VS4a), está apresentada nas Tabelas 25 e 26. Os valores mínimos e máximos foram obtidos em função dos tratamentos durante as quatro épocas de amostragem. De maneira geral, os valores médios de Po da área VS4a foram menores que os da área VS10a, no entanto, a amplitude de variação (diferença entre os valores mínimos e máximos) e o desvio padrão foram maiores para essa última área experimental. 
Tabela 23. Valores médios de P-total (Pt), P-inorgânico (Pi) e P-orgânico (Po), obtidos nas duas profundidades da área VS10a durante os quatro períodos de amostragem do solo.

\begin{tabular}{|c|c|c|c|c|c|c|c|c|c|c|c|c|}
\hline & \multicolumn{3}{|c|}{ Outubro/94 } & \multicolumn{3}{|c|}{ Janeiro/97 } & \multicolumn{3}{|c|}{ Julho/98 } & \multicolumn{3}{|c|}{ Julho/00 } \\
\hline Tratamentos $^{(1)}$ & $\mathrm{Pt}$ & $\mathrm{Pi}$ & Po & $\mathrm{Pt}$ & $\mathrm{Pi}$ & Po & $\mathrm{Pt}$ & $\mathrm{Pi}$ & $\mathrm{Po}$ & $\mathrm{Pt}$ & $\mathrm{Pi}$ & Po \\
\hline & \multicolumn{12}{|c|}{$0-10 \mathrm{~cm}$} \\
\hline Controle & 52,27 & 14,36 & 38,22 & 54,64 & 18,98 & 35,66 & 48,40 & 12,01 & 36,39 & 36,86 & 14,48 & 22,38 \\
\hline $\mathrm{Q}+\mathrm{F}$ & 52,27 & 14,36 & 38,22 & 120,72 & 55,68 & 65,04 & 97,31 & 29,39 & 67,93 & 61,36 & 22,27 & 39,09 \\
\hline Q-F & 52,27 & 14,36 & 38,22 & 82,11 & 21,30 & 60,81 & 63,05 & 13,42 & 49,64 & 50,83 & 14,00 & 36,83 \\
\hline $\mathrm{M}+\mathrm{F}$ & 52,27 & 14,36 & 38,22 & 104,58 & 53,90 & 50,68 & 59,70 & 22,81 & 36,89 & 60,89 & 19,46 & 41,43 \\
\hline \multirow[t]{2}{*}{$\mathrm{M}-\mathrm{F}$} & 52,27 & 14,36 & 38,22 & 80,04 & 26,48 & 53,55 & 54,67 & 12,48 & 42,19 & 43,81 & 11,82 & 32,00 \\
\hline & \multicolumn{12}{|c|}{$10-20 \mathrm{~cm}$} \\
\hline Controle & 88,97 & 10,39 & 78,58 & 79,80 & 16,10 & 63,70 & 65,54 & 9,19 & 56,36 & 56,98 & 13,17 & 43,81 \\
\hline $\mathrm{Q}+\mathrm{F}$ & 88,97 & 10,39 & 78,58 & 105,43 & 28,40 & 77,03 & 73,29 & 16,70 & 56,59 & 67,03 & 17,24 & 49,79 \\
\hline Q-F & 88,97 & 10,39 & 78,58 & 77,88 & 19,46 & 58,42 & 55,21 & 13,88 & 41,32 & 57,57 & 15,66 & 41,90 \\
\hline $\mathrm{M}+\mathrm{F}$ & 88,97 & 10,39 & 78,58 & 97,77 & 26,48 & 71,28 & 76,11 & 16,08 & 60,03 & 67,43 & 21,19 & 46,24 \\
\hline M-F & 88,97 & 10,39 & 78,58 & 106,87 & 20,79 & 86,08 & 52,16 & 11,07 & 41,09 & 56,38 & 13,82 & 42,56 \\
\hline
\end{tabular}


Tabela 24. Valores médios de P-total (Pt), P-inorgânico (Pi) e P-orgânico (Po), obtidos nas duas profundidades da área VS4a durante os quatro períodos de amostragem do solo.

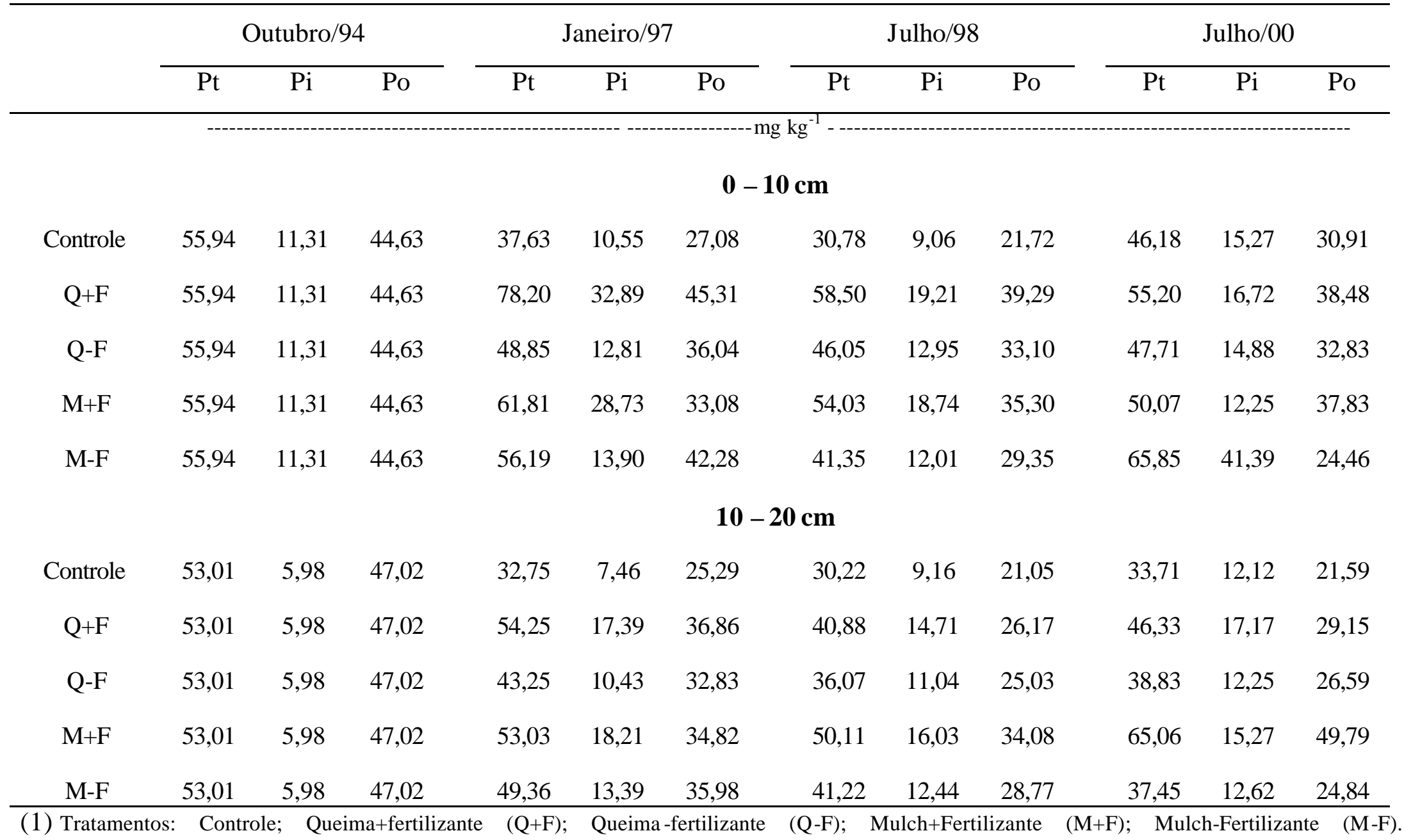


Tabela 25.Variação dos resultados de concentração de $\mathrm{P}$ orgânico estimados pelo método de ignição para área experimental que inicialmente apresentava vegetação secundária com 10 anos de idade.

\begin{tabular}{|c|c|c|c|c|}
\hline Tratamentos & $\begin{array}{l}\text { Valores mínimo e } \\
\text { máximo }\end{array}$ & Média & Desvio Padrão & $\mathrm{CV}$ \\
\hline & ------------------- & $\mathrm{mg} \mathrm{kg}^{-1}$ & ----------- & $(\%)$ \\
\hline & \multicolumn{4}{|c|}{ Profundidade 0 a $10 \mathrm{~cm}$} \\
\hline Controle & 18,28 a 49,17 & 33,16 & 9,18 & 27,70 \\
\hline Queima + Fertilizante & 30,79 a 71,91 & 52,57 & 16,86 & 32,08 \\
\hline Queima - Fertilizante & 32,29 a 69,79 & 46,37 & 11,89 & 25,65 \\
\hline Mulching + Fertilizante & 32,19 a 78,23 & 41,81 & 12,93 & 30,93 \\
\hline \multirow[t]{2}{*}{ Mulching - Fertilizante } & 30,79 a 80,89 & 41,49 & 13,64 & 32,88 \\
\hline & \multicolumn{4}{|c|}{ Profundidade 10 a $20 \mathrm{~cm}$} \\
\hline Controle & 42,93 a 83,66 & 60,61 & 13,29 & 21,93 \\
\hline Queima + Fertilizante & 48,65 a 86,64 & 65,49 & 13,82 & 21,11 \\
\hline Queima - Fertilizante & 39,78 a 83,66 & 55,06 & 16,50 & 29,97 \\
\hline Mulching + Fertilizante & 39,97 a 83,66 & 64,03 & 13,71 & 21,42 \\
\hline Mulching - Fertilizante & 37,94 a 92,00 & 62,07 & 21,86 & 35,22 \\
\hline
\end{tabular}


Tabela 26. Variação dos resultados de concentração de $\mathrm{P}$ orgânico estimados pelo método de ignição para área experimental que inicialmente apresentava vegetação secundária com 4 anos de idade.

\begin{tabular}{ccccc}
\hline Tratamentos & $\begin{array}{c}\text { Valores mínimo e } \\
\text { máximo }\end{array}$ & Média & Desvio Padrão & CV \\
\hline Controle & --------------------- mg kg $^{-1}$-------------------- & $(\%)$ \\
Profundidade 0 a 10 cm & \\
Queima + Fertilizante & 35,60 a 49,90 & 41,92 & 9,15 & 29,43 \\
Queima - Fertilizante & 29,72 a 45,10 & 36,65 & 4,49 & 10,70 \\
Mulching + Fertilizante & 27,95 a 56,54 & 37,70 & 5,64 & 15,38 \\
Mulching - Fertilizante & 19,86 a 45,50 & 35,17 & 8,88 & 23,55 \\
& & Profundidade 10 a 20 cm & 27,17 \\
Controle & 20,02 a 50,64 & 28,74 & 11,62 & 40,46 \\
Queima + Fertilizante & 25,97 a 50,64 & 34,80 & 8,66 & 24,89 \\
Queima - Fertilizante & 23,07 a 50,64 & 32,87 & 9,27 & 28,19 \\
Mulching + Fertilizante & 31,42 a 53,84 & 41,42 & 8,34 & 20,14 \\
Mulching - Fertilizante & 24,53 a 50,64 & 34,15 & 9,15 & 26,79 \\
\hline
\end{tabular}

Pela análise de variância dos resultados de Po total, não se verificaram interações significativas entre tratamentos e épocas de amostragem para a camada superficial da área com VS10a; no entanto, essas interações foram significativas, ao nível 1\%, para a camada subsuperficial dessa área e para as duas camadas estudadas da área VS4a.

Diante disso, foram avaliados pelo teste de Tukey os efeitos isolados dos tratamentos e das épocas de amostragens sobre os teores de Po total para a camada superficial $(0-10 \mathrm{~cm})$ da área VS10a (Tabelas 27 e 28). Os resultados evidenciaram aumentos significativos das quantidades de $\mathrm{P}$ orgânico para todos os tratamentos, quando comparados com as parcelas controle. $\mathrm{O}$ valor médio de Po mais significativo foi obtido para o tratamento $\mathrm{Q}+\mathrm{F}$ (queima com fertilizante), que só não diferiu do que 
envolvia Q-F (queima sem fertilizante). Esse último não diferiu significativamente daqueles que envolveram utilização da cobertura morta (Tabela 27).

Os valores médios de Po aumentaram significativamente da primeira para a segunda amostragem (Janeiro de 1997) e diminuíram nas demais, retornando aos níveis do início do experimento (Tabela 28).

Tabela 27. Médias de P orgânico, durante as 4 épocas de amostragens da profundidade 0-10 cm em função dos tratamentos aplicados na área experimental que inicialmente apresentava vegetação secundária com 10 anos de idade.

\begin{tabular}{cc}
\hline Tratamentos $^{(1)}$ & P orgânico \\
\hline Controle & $\mathrm{mg} \mathrm{kg}^{-1}$ \\
Queima + Fertilizante & $33,16 \mathrm{a}$ \\
Queima - Fertilizante & $52,57 \mathrm{c}$ \\
Mulching + Fertilizante & $46,37 \mathrm{bc}$ \\
Mulching - Fertilizante & $41,81 \mathrm{~b}$ \\
\hline
\end{tabular}

* Médias seguidas por mesma letra não diferem entre sí, ao nível de 5\%, pelo teste de Tukey; DMS =6,53 $\mathrm{m} \mathrm{kg}^{-1}$

Tabela 28. Médias de $\mathrm{P}$ orgânico nas 4 épocas de amostragens da profundidade $0-10 \mathrm{~cm}$ na área experimental que inicialmente apresentava vegetação secundária com 10 anos de idade.

\begin{tabular}{cc}
\hline Épocas de Amostragem & P orgânico \\
\hline & $\mathrm{mg} \mathrm{kg}^{-1}$ \\
Out./94 & $38,22 \mathrm{ab}$ \\
Jan./97 & $53,15 \mathrm{c}$ \\
Jul./98 & $46,61 \mathrm{bc}$ \\
Jul./00 & $34,35 \mathrm{a}$ \\
\hline * Médias seguidas por mesma letra não diferem entre sí, ao nível de $5 \%$, pelo teste de Tukey; DMS =9,60 $\mathrm{mg} \mathrm{kg}^{-1}$
\end{tabular}

* Médias seguidas por mesma letra não diferem entre sí, ao nível de 5\%, pelo teste de Tukey; DMS = 9,60 $\mathrm{mg} \mathrm{kg}^{-1}$ 
Para a camada subsuperficial $(10-20 \mathrm{~cm})$ da área VS10a os valores médios de Po não variaram significativamente da primeira para a segunda amostragem (Tabela 29); no entanto, verificaram-se reduções significativas a partir da terceira amostragem. De forma geral, não foram encontradas diferenças significativas entre os métodos de preparo do solo e as parcelas mantidas com vegetação natural, dentro da cada época de amostragem.

Esses resultados da área VS10a demonstram que a utilização dos tratamentos de preparo do solo sem queima (mulching) proporcionaram aumentos na quantidade de Po total na camada superficial, quando comparados com a parcela controle (Tabelas 27 e 28). Na subsuperficial, embora tenham sido observados decréscimos no teor de Po total em relação ao início do experimento, esses tratamentos proporcionaram resultados adequados durante o período avaliado, principalmente quando comparados com a parcela controle (Tabela 29).

Tabela 29. Valores médios de $\mathrm{P}$ orgânico $\left(\mathrm{mg} \mathrm{kg}^{-1}\right)$, na profundidade $10-20 \mathrm{~cm}$, em função dos tratamentos e épocas de amostragens da área experimental VS10a ${ }^{1}$.

\begin{tabular}{|c|c|c|c|c|}
\hline \multirow[t]{2}{*}{ Tratamentos } & \multicolumn{4}{|c|}{ Épocas de Amostragem } \\
\hline & Outubro/94 & Janeiro/97 & Julho/98 & Julho/00 \\
\hline Controle & $78,58 \mathrm{Aa}$ & $63,70 \mathrm{ABab}$ & $56,35 \mathrm{ABbc}$ & $43,80 \mathrm{Ac}$ \\
\hline Queima + Fertilizante & $78,58 \mathrm{Aa}$ & $77,03 \mathrm{BCa}$ & $56,59 \mathrm{Bb}$ & $49,79 \mathrm{Ab}$ \\
\hline Queima - Fertilizante & $78,58 \mathrm{Aa}$ & $58,42 \mathrm{Ab}$ & $41,33 \mathrm{Ac}$ & $41,90 \mathrm{Ac}$ \\
\hline Mulching + Fertilizante & $78,58 \mathrm{Aa}$ & $71,28 \mathrm{ACab}$ & $60,03 \mathrm{Bbc}$ & $46,24 \mathrm{Ac}$ \\
\hline Mulching - Fertilizante & $78,58 \mathrm{Aa}$ & $86,08 \mathrm{Cab}$ & $41,09 \mathrm{Ac}$ & $42,56 \mathrm{Ac}$ \\
\hline
\end{tabular}


Os resultados médios da quantidade de Po do solo, a partir dos tratamentos e das épocas de amostragens, para área VS4a estão apresentados nas Tabelas 29 e 30. De forma geral, os resultados da primeira amostragem da camada superficial (Tabela 30) são similares aos obtidos na mesma época na área VS10a. Em relação à primeira amostragem, houve redução significativa de Po somente no tratamento de mulching sem fertilizante, que apresentou um valor de $24,46 \mathrm{mg} \mathrm{kg}^{-1}$ na última amostragem (Tabela 30).

Na segunda e na terceira época de amostragem encontraram-se diferenças significativas nas médias de Po entre as parcelas controle e o tratamento de queima com fertilizante. Na última época de amostragem as médias de Po não diferiram entre os tratamentos (Tabela 30).

Para a profundidade $10-20 \mathrm{~cm}$ da área VS4a verificaram-se reduções significativas na concentração de Po após a primeira amostragem, exceto nos tratamentos queima + fertilizante e mulching + fertilizante, na segunda e última época de amostragem, respectivamente (Tabela 31). Quando se considerou cada época de amostragem notou-se que o valor médio de Po para o tratamento de mulching com fertilizante aumentou significativamente em relação aos demais tratamentos na última amostragem (Tabela 31).

Os resultados demonstram que o preparo do solo sem queima associado com a utilização de fertilizantes apresenta um grande potencial para a manutenção do Po total no solo na camada subsuperficial da área VS4a. No caso da área VS10a, houve decréscimo na quantidade de Po, mas ainda assim foram obtidos melhores resultados quando houve utilização do fertilizante.

De maneira geral, os resultados de Po encontrados nas duas áreas experimentais estão de acordo com os obtidos na avaliação da matéria orgânica e do Presina. Isso se deve à relação existente entre o Po e os teores de $\mathrm{MO}$ e de $\mathrm{P}$ disponível nos solos, conforme citado por Brams (1973), Fassbender \& Boernemisza (1994) e Linsquist et al. (1997).

Beck \& Sanchez (1994), trabalhando com fracionamento de P em amostras de solo que estavam sob cultivo contínuo durante 18 anos no Peru, verificaram 
que nos sistemas agrícolas que receberam fertilizantes fosfatados não houve alteração do Po, sendo nesse caso o Pi responsável pela variação do fósforo disponível. Nos sistemas sem utilização de fertilizantes, o Po foi o principal responsável pela variação do $\mathrm{P}$ disponível para as plantas. Linsquist et al. (1997), trabalhando com formas de manejo da aplicação de fertilizantes fosfatados em solo do Hawaii, também relataram que o Po é uma importante fonte de fósforo para as plantas em sistemas não fertilizados.

Beck \& Sanchez (1996), trabalhando com cultivo contínuo durante 13 anos, verificaram nas camadas subsuperficiais um decréscimo de $41 \%$ do Po nas parcelas não fertilizadas e um aumento de 50\% nas parcelas fertilizadas. Brito (1998), avaliando uma conversão de floresta para pastagem na Amazônia, observou aumentos de $\mathrm{P}$ disponível e total logo após a queima da vegetação, no entanto, com o passar do tempo ocorreu um decréscimo dos teores de Po, Pi e Pt, devido a diversos processos, entre os quais a retenção, a remoção pelas culturas e também a erosão.

Os resultados obtidos no presente trabalho, quando comparados com os de Beck \& Sanchez (1994), Linquist et al. (1997), Beck \& Sanchez (1996) e Brito (1998), demonstram a grande variabilidade no comportamento da fração de P orgânico do solo. Além disso, fica evidente a necessidade de estudos que procurem entender a dinâmica das diferentes frações da matéria orgânica e do $\mathrm{P}$ orgânico em solos submetidos a sistemas de cultivo que contemplem a utilização de materiais orgânicos. 
Tabela 30. Valores médios de $\mathrm{P}$ orgânico $\left(\mathrm{mg} \mathrm{kg}^{-1}\right)$, na profundidade $010 \mathrm{~cm}$, em função dos tratamentos e épocas de amostragens da área experimental VS4a $a^{1}$.

\begin{tabular}{|c|c|c|c|c|}
\hline \multirow[t]{2}{*}{ Tratamentos } & \multicolumn{4}{|c|}{ Épocas de Amostragem } \\
\hline & Outubro/94 & Janeiro/97 & Julho/98 & Julho/00 \\
\hline Controle & $44,63 \mathrm{Ab}$ & $27,08 \mathrm{Aa}$ & $21,72 \mathrm{Aa}$ & $30,91 \mathrm{Aab}$ \\
\hline Queima + Fertilizante & 44,63 Aa & $45,31 \mathrm{Ba}$ & $39,29 \mathrm{Ba}$ & $38,48 \mathrm{Aa}$ \\
\hline Queima - Fertilizante & 44,63 Aa & $36,04 \mathrm{ABa}$ & $33,10 \mathrm{ABa}$ & $32,83 \mathrm{Aa}$ \\
\hline Mulching + Fertilizante & 44,63 Аа & $33,08 \mathrm{ABa}$ & $35,30 \mathrm{ABa}$ & $37,83 \mathrm{Aa}$ \\
\hline Mulching - Fertilizante & $44,63 \mathrm{Ab}$ & $42,28 \mathrm{ABb}$ & 29,35 ABab & $24,46 \mathrm{Aa}$ \\
\hline
\end{tabular}

Tabela 31. Valores médios de $\mathrm{P}$ orgânico $\left(\mathrm{mg} \mathrm{kg}^{-1}\right)$, na profundidade $10-20 \mathrm{~cm}$, em função dos tratamentos e épocas de amostragens da área experimental $\mathrm{VS} 4 \mathrm{a}^{1}$.

\begin{tabular}{|c|c|c|c|c|}
\hline \multirow[t]{2}{*}{ Tratamentos } & \multicolumn{4}{|c|}{ Épocas de Amostragem } \\
\hline & Outubro/94 & Janeiro/97 & Julho/98 & Julho/00 \\
\hline Controle & $47,03 \mathrm{Ab}$ & $25,29 \mathrm{Aa}$ & $21,05 \mathrm{Aa}$ & $21,59 \mathrm{Aa}$ \\
\hline Queima + Fertilizante & $47,03 \mathrm{Ac}$ & $36,86 \mathrm{Bbc}$ & $26,17 \mathrm{ABa}$ & 29,15 Aab \\
\hline Queima-Fertilizante & $47,03 \mathrm{Ab}$ & $32,83 \mathrm{ABa}$ & $25,03 \mathrm{ABa}$ & $26,59 \mathrm{Aa}$ \\
\hline Mulching + Fertilizante & $47,03 \mathrm{Ab}$ & $34,82 \mathrm{ABa}$ & $34,08 \mathrm{Ba}$ & $49,69 \mathrm{Bb}$ \\
\hline Mulching - Fertilizante & $47,03 \mathrm{Ac}$ & $35,98 \mathrm{Bb}$ & $28,77 \mathrm{ABab}$ & $24,84 \mathrm{Aa}$ \\
\hline
\end{tabular}




\section{CONCLUSÕES}

Com base nos resultados obtidos neste trabalho, pode-se chegar às seguintes conclusões:

- Para todos os métodos de preparo do solo houve manutenção ou aumentos no nível de fertilidade do solo, avaliada pela matéria orgânica, P-resina, $\mathrm{pH}$ em $\mathrm{CaCl}_{2}$, saturação por bases e alumínio trocável, bem como redução da capacidade de adsorção de P.

- O método de preparo do solo que não utiliza a queima da vegetação (mulching) mostrou-se superior ao método tradicional de corte-queima, uma vez que não diminuiu a fertilidade do solo, reduziu a capacidade de adsorção de P e aumentou a quantidade de P orgânico total;

- A utilização do fertilizante NPK contribuiu para manter o teor de P-resina e de P orgânico total do solo ao longo dos seis anos de estudo, independentemente da utilização ou não do fogo no preparo do solo;

- A sustentabilidade do sistema foi maior na área com tempo de pousio de 10 anos e com maior quantidade de biomassa vegetal do que na área com 4 anos de pousio. 


\section{REFERÊNCIAS BIBLIOGRÁFICAS}

ABEKOE, M.K.; SAHRAWAT, K.L. Phosphate retention and extractability in soils of the humid zone in West África. Geoderma, v.102, p.175-187, 2001.

ACQUAYE, D.K. Some significance of soil organic phosphorus mineralization in the phophorus nutrition of cocoa in Ghana. Plant and Soil, v.19, p.65-80, 1963.

ADEPETU, J.A.; COREY, R.B. Organic phosphorus as a predictor of plant available phosphorus in soils of southern Nigeria. Soil Science, v.122, p.159-164, 1976.

AFIF, E.; BARRÓN, V.; TORRENT, J. Organic matter delays but does not prevent phosphate sorption by cerrado soils from Brazil. Soil Science, v. 159, n.3, p.207$211,1995$.

ALMEIDA NETO, J.X.de.; BRASIL SOBRINHO, O.C.do. Fixação de fósforos em três solos sob cerrado de Goiás. Revista Brasileira de Ciência do Solo, v.1, p.12-15, 1977.

ALVAREZ V., V.H.; NOVAIS, R.F.; DIAS, L.E.; OLIVEIRA, J.A. DE. Determinação e uso do fósforo remanescente. Sociedade Brasileira de Ciência do Solo - Boletim Informativo, v.25, n.1, p.27-32, 2000.

ALVES, M.C. SAS - Estatística básica. 2.ed. Piracicaba: CIAGRI. 53p. s. d.. 
ANGHINONI, I.; BALIGAR, V.C.; WRIGHT, R.J. Phosphorus sorption isoterm characteristics and availability parameters of appalachian acidic soils. Communications Soil Science Plant Analysis, v.27, n.9/10, p. 2033-2048, 1996.

AYANABA, A. The value of mulches in the management of organic matter in tropical soils. In: COLÓQUIO REGIONAL SOBRE MATÉRIA ORGÂNICA DO SOLO, Piracicaba, 1982. Anais. Piracicaba: PROMOCET, 1982. p.97-103.

BACHE, B.W.; WILLIAMS, E.G. A phosphate sorption index for soils. Journal Soil Science, v.22, p.289-301, 1971.

BARROW, N.J. Reaction of anions and cations with variable-charge soils. Advances in Agronomy, v.38, p.183-230, 1985.

BARROW, N.J. The description of phosphate adsorption curves. Journal of Soil Science, v.29, p.447-462, 1978.

BARROW, N.J.; BOLLAND, M.D.A.; ALLEN, D.G. Effect of previous additions of superphosphate on sorption of phosphate. Australian Journal Soil Research, v.36, p.359-372, 1998.

BAR-YOSEF, B.; KAFKAFI, U.; ROSENBERG, R.; SPOSITO, G. Phosphorus adsorption by kaolinite and montmorillonite. I. Effect of time, ionic strength and pH. Soil Science Society of America Journal, v.52, n.6, p.1580-1585, 1988.

BECK, M.A.; SANCHEZ, P.A. Soil phosphorus fraction dynamics during 18 years of cultivation on a typic paleudult. Soil Science Society America Journal, v.28, p.1424-1431, 1994.

BECK, M.A.; SANCHEZ, P.A. Soil phosphorus movement and budget after 13 years of fertilized cul tivation in the Amazon basin. Plant and Soil, v.184, p.23-31, 1996.

BECK, M.A.; SANCHEZ, P.A. Soil phosphorus movement and budget after 13 years of fertilized cultivation in the Amazon basin. Plant and Soil, v.184, p.23-31, 1996. 
BECK, M.A.; SANCHEZ, P.A. Soil phosphurus fraction dynamics during 18 years of cultivation on a Paleudult. Soil Science Society America Journal, v.58, p.14241431, 1994.

BIGHAM, J.M.; GOLDEN, D.C.; BUOL, S.W.; WEED, S.B.; BOWEN, L.H. Iron oxide mineralogy of well-drained ultisols and oxisols: II. Influence on color, surface area, and phsphate retention. Soil Science Society America Journal, v.42, p.825$830,1978$.

BORNEMISZA, E.; IGUE, K. A comparison of three methods for determining organic phosphorus in Costa Rican Soils. Soil Science, v.103, n.5, 347-354, 1967.

BOTSCHEK, J.; FERRAZ, J.; JAHNEL, M.; SKOWRONEK, A. Soil chemical properties of a toposequence under primary rain forest in the Itacoatiara vicinity (Amazonas, Brazil). Geoderma, v.72, p.119-132, 1996.

BOWMAN, R.A. A sequencial extraction procedure with concentrated sulphuric acid and dilute base for soil organic phosphorus. Soil Science Society America Journal, v.53, p.362-366, 1989.

BRADY, N.C. Alternatives to slash-and-burn: a global imperative. Agriculture Ecosystems and Environment, v.58, p.3-11, 1996.

BRAMS, E. Soil organic matter and phosphorus relationships under tropical forests. Plant and Soil, v.39, p.465-468, 1973.

BRASIL, E.C. Sistema de cultivo em faixas como alternativa ao sistema tradicional (shifting cultivation): primeiras experiências no nordeste paraense. In: MESA REDONDA SOBRE RECUPERAÇÃO DE SOLOS ATRAVÉS DO USO DE LEGUMINOSAS. Belém, 1992. Trabalhos e recomendações. Belém: EMBRAPA - CPATU - GTZ, 1992. p.9-26 (EMBRAPA . CPATU. Documentos, 67) 
BRASIL, E.C.; MURAOKA, T. Capacidade de adsorção fósforo em Latossolo Amarelo e Podzólico Vermelho-Amarelo da Amazônia Oriental. Boletim da FCAP, v.24, p.81-91, 1995.

BRENNAN, R.F.; BOLLAND, M.D.; JEFFERY, R.C.; ALLEN, D.G. Phosphorus adsorption by a range of western australian soils related to soil properties. Communications Soil Science Plant Analysis, v.25, n.15/16, p.2785-2795, 1994.

BRIENZA JUNIOR, S.; COSTA, V. de O.; SANTOS, W.E.S. et al. Enriquecimento de capoeira com árvores leguminosas contribuindo para o acúmulo de biomassa na agricultura familiar no nordeste do Pará, Brasil. In: SEMINÁRIO SOBRE MANEJO DA VEGETAÇÃO SECUNDÁRIA PARA SUSTENTABILIDADE DA AGRICULTURA FAMILIAR DA AMAZÔNIA ORIENTAL, Belém, 1999. Anais, Belém: Embrapa Amazônia Oriental/CNPq, 2000. p.83-84. (Embrapa Amazônia Oriental. Documentos, 69)

BRINKMANN, W.L.F.; NASCIMENTO, J.C. de. The effect os slash and burn agriculture on plant nutrients in the Tertiary region of Central Amazonia. Turrialba, v.23, n.3, p.284-290, 1973.

BRITO, M. de M.P. O fósforo dos solos de Rondônia: variabilidade espacial e temporal na conversão de floresta em pastagens. Piracicaba, 1998. 115p. Tese (Doutorado)Escola Superior de Agricultura “Luiz de Queiroz”, Universidade de São Paulo.

CASAGRANDE, J.C. Avaliação do um modelo de complexação de superfície para adsorção de fosfato em solos ácricos do norte paulista. Piracicaba, 1993. 160p. Tese (Doutorado) - Escola Superior de Agricultura "Luiz de Queiroz”, Universidade de São Paulo.

CASTRO, A.F. de; BARRETO, W.O.; ANASTÁCIO, M.L.A. Correlação entre pH e saturação de bases de alguns solos brasileiros. Pesquisa Agropecuária Brasileira, Sér. Agron., v.7, p.9-17, 1972. 
CATANI, R.A.; GALLO, J.R. Avaliação da exigência em calcário dos solos do Estado de São Paulo, mediante correlação entre o pH e a porcentagem de saturação em bases. Revista de Agricultura, v.30, n.1/3, p.49-60, 1955.

CHANG, S.C.; JACKSON, M.L. Fractionation of soil phosphorus. Soil Science, v.84, p.133-144, 1957.

CHEN, Z.; XING, B.; McGILL, W.B. A unified sorption variable for environmental applications of the freundlich equation. Journal Environmental Quality, v.28, p.1422-1428, 1999.

CONDRON, L.M.; MOIR, J.O.; TIESSEN, H.; STEWART, J.W.B. Critical evaluation of methods for determining total organic phosphorus in tropical soils. Soil Science Society America Journal, v.54, p.1261-1266, 1990.

DALAL, R.C. Soil organic phosphurus. Advances in Agronomy, v.29, p.83-113, 1977.

DAROUB, S.H.; ELLIS, B.G.; ROBERTSON, G.P. Effect of cropping and lowchemical input systems on soil phosphorus fractions. Soil Science, v.166, n.4, 281$291,2001$.

DYNIA, J.F.; CAMARGO, O.A. de. Efeitos da adubação fosfatada e da calagem sobre a adsorção de fósforo em um Latossolo Vermelho-escuro. Pesquisa Agropecuária Brasileira, v.32, n.8, p.865-868, 1997.

EGHBALL, B.; BINFORD, G.D.; BALTENSPERGER, D.D. Phosphorus movement and adsorption in a soil receiving long-term manure and fertilizer application. Journal Environmental Quality, v.25, p.1339-1343, 1996.

EMPRESA BRASILEIRA DE PESQUISA AGROPECUÁRIA. Sistema Brasileiro de Classificação de Solos. Brasília: Serviço de Produção de Informação/Embrapa Centro Nacional de Pesquisa de Solos, 1999. 412p. 
FEARSINDE, P.M. Amazonian deforestation and global warming: carbon stocks in vegetation replacing Brazil's Amazon forest. Forest Ecology and Management, v.80, p. 21-34, 1996.

FEARSINDE, P.M. Rethinking continuos cultivation in amazonia. BioScience, v.37, n.3, p.209-214, 1987.

FONTES, M.P.F.; WEED, S.B. Phosphate adsorption by clays from Brazilian Oxisoils: relationships with specific surface area and mineralogy. Geoderma, v.72, p.37-51, 1996.

FOX, R.L.; KAMPRATH, E.J. Adsorption and leaching of $\mathrm{P}$ in acid organic soils and high organic matter sand. Soil Science Society America Proceedings, v.35, p.154$156,1971$.

FUJISAKA, S.; WHITE, D. Pasture or permanent crops after slash-and-burn cultivation? Land-use choice in three Amazon colonies. Agroforestry Systems, v.42, p.45-59, 1998.

GAMA, M.A.P. Determinação da acidez potencial e da necessidade de calagem em solos do Nordeste Paraense. Piracicaba, 1998. 72p. Dissertação (Mestrado) - Escola Superior de Agricultura “Luiz de Queiroz”, Universidade de São Paulo.

GIARDINA, C.P.; SANFORD Jr., R.L.; DØCKERSMITH, I.C. Changes in soil phosphorus and nitrogen during slash-and-burn clearing of a dry tropical forest. Soil Science Society of America Journal , v.64, p.399-405, 2000.

HARRISON, A.F. Labile organic phosphurus mineralization in relation to soil properties. Soil Biology Biochemistry, v.14, p.343-351, 1982.

HARTER, R. Curve-fit errors in Langmuir adsorption maxima. Soil Science Society of America Journal, v.48, p.749-752, 1984. 
HAYNES, R.J. Lime and phosphate in the soil-plant system. Advances in Agronomy, v.37, p.249-315, 1984.

HEDLEY, M.J.; STEWART, W.B.; CHAUHAN, B.S. Changes in inorganic and organic soil fractions induced by cultivation practices and by laboratory incubations. Soil Science Society America Journal, v.46, p.970-976, 1982a.

HEDLEY, M.J.; WHITE, R.E.; NYE, P.H. Plant-induced changes in the rhizosphere of rape (Brassica napus var. emerald) seedlings. III. Changes in L value, soil phosphate fractions and phosphatase activity. New Phytologist, v.91, p.45-56, $1982 b$.

HERNANI, L.C.; SAKAI, S.; ISHIMURA, I.; LEPSCH, I.F. Influência de métodos de limpeza de terreno sob floresta secundária em Latossolo Amarelo do Vale do Ribeira, SP: I. Dinâmica de atributos químicos, físico e produção de milho. Revista Brasileira de Ciência do Solo, v.11, p.205-213, 1987.

HOLFORD, I.C.R.; MATTINGLY, G.E.G. Phosphate adsorption and availability plant of phosphate. Plant and Soil, v.44, p.377-389. 1976.

HOLFORD, I.C.R.; WEDDERBURN, R.W.M.; MATTINGLY, G.E.G. A Langmuir two-surface equation as a model for phsphate adsorption by soil. Journal of Soil Science, v.25, n.2, p.242-255, 1974.

HÖLSCHER, D.; LUDWING, B.; MÖLLER, R.F.; FÖLSTER, H. Dynamic of soil chemical parameters in shifting agriculture in the Eastern Amazon. Agriculture Ecosystems and Environment, v.66, p.153-163, 1997.

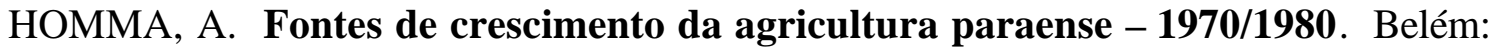
EMBRAPA - CPATU, 1981. 29p. (EMBRAPA - CPATU. Boletim de Pesquisa, 27). 
HSU, P.H. Adsorption of phosphorus by aluminum and iron in soils. Soil Science Society of America Proceedings, v.28, p.474-478, 1964.

HUE, N.V. Correcting soil acidity of a highly weathered ultisol with chicken manure and sewage sludge. Communications Soil Science Plant Analysis, v.23, p.241$264,1992$.

HUE, N.V. Effects of organic acids/anions on P sorption and phytoavailability in soils with different mineralogies. Soil Science, v.152, n.6, p.463-471, 1991.

HUE, N.V. Interaction of $\mathrm{Ca}\left(\mathrm{H}_{2} \mathrm{PO}_{4}\right)_{2}$ applied to an Oxisol and previous sludge amendment: soil and crop response. Communications Soil Science Plant Analysis, v.21, p.61-73, 1990.

IBGE//Cidadesat//http://www1.ibge.gov.br/cidadesat/default.php. (10/09/2001).

IYAMUREMYE, F.; DICK, R.P.; BAHAN, J. Organic amendments and phosphorus dynamics: I. Phosphorus chemistry and sorption. Soil Science, v.161, n.7, p.426$435,1996$.

IYAMUREMYE, F.; DICK, R.P.; BAHAN, J. Organic amendments and phosphorus dynamics: II. Distribution of soil phosphorus fractions. Soil Science, v.161, n.7, p.436-443, 1996.

JUO, A.S.R.; MANU, A. Chemical dynamics in slash and burn agriculture. Agriculture, Ecosystems and Environment, v.58, p.49-60, 1996.

KANASHIRO, M.; DENICH, M. Possibilidades de utilização e manejo adequado de áreas alteradas e abandonadas na Amazônia brasileira. Brasília: MCT/CNPq, 1998. 157p. (Estudos dos impactos humanos nas florestas e áreas inundadas nos trópicos). 
KATO, M.S.A., FREITAS, M.N.; DIAS, C.S.; KATO, O.R. Sistemas de produção de pequenos agricultores de mandioca no município de Bragança-Pará. Belém: EMBRAPA-CPATU, 1992. 22p. (Documentos, 66).

KATO, M.S.A; KATO, O.R.; DENICH, M.; VLEK, P.L.G. Fire-free alternatives to slash-and-burn for shifting cultivation in the eastern Amazon region: the role of fertilizers. Field Crops Research, v.62, p.225-237, 1999.

KER, J.C.; FONTES, M.P.F.; SOUZA, A.R.; RESENDE, M. Adsorção de fósforo em alguns solos latossólicos: relação entre mineralogia e efeito da calagem. Revista Ceres, v.43, n.246, p.216-226, 1996.

KLEINMAN, P.J.A.; BRYANT, R.B.; PIMENTEL, D. Assessing ecological sustainability of slash-and-burn agriculture through soil fertility indicators. Agronomy Journal, v.88, p.122-127, 1996.

KWARI, J.D.; BATEY, T. Effect of heating on phosphate sorption and availability in some north-est Nigerian soils. Journal of Soil Science, v.42, p.381-388, 1991.

LAL, R. Conservations of tropical rainforest: agronomic potential and ecological consequences. Advances in Agronomy, v.39, p.173-264, 1986.

LARSEN, S. Soil phosphorus. Advances in Agronomy, v.19, p.151-211, 1967.

LAVERDIÈRE, M.R.; KARAM, A. Sorptions of phosphorus by some surface soils from Quebec in relation to their properties. Communications in Soil Science and Plant Analysis, v.15, p.1215-1230, 1984.

LEAL, J.R.; VELLOSO, A.C.X. Adsorção de fosfato em latossolos sob vegetação de cerrado. Pesquisa Agropecuária Brasileira, v.8, p.81-88, 1973.

LEMARE, P.H.; PEREIRA, J.; GOEDERT, W.J. Effects of green manure on isotopically exchangeable phsphate in a dark-red latosol in Brazil. Journal of Soil Science, v.38, p.199-209, 1987. 
LINDSAY, W.L.; FRAZIER, A.W.; STEPHENSON, H.F. Identification of reaction products from phosphate fertilizers in soils. Soil Science Society of America Proceedings, v.26, p.446-452, 1962.

LINQUIST, B.A.; SINGLETON, P.W.; CASSMAN, K.G. Inorganic and organic phosphorus dynamics during a build-up and decline of available phosphorus in na ultisol. Soil Science, v.162, n.4, p.254-264, 1997.

LOPES, A.S.; COX, F.R. Relação de características físicas, químicas e mineralógicas com fixação de fósforo em solos sob cerrados. Revista Brasileira de Ciência do Solo, v.3, p.82-88, 1979.

LÓPEZ-HERNÁNDEZ, D.; NIÑO, M. Phosphorus mineralization during laboratory incubation in soils derived from different textured parent materials. Geoderma, v.56, p.527-537, 1993.

MACKENSEN, J.; HÖLSCHER, D.; KLINGE, R.; FÖLSTER, H. Nutrient transfer to the atmosfere by burning of debris in eastern Amazonia. Forest Ecology and Management, v.86, p.121-128, 1996.

MAPA, R.B.; GUNASENA, H.P.M. Effect of alley cropping on soil aggregate stability of a tropical Alfisol. Agroforestry Systems, v.32, p.237-245, 1995.

MARTINS, P.F. da SILVA. Utilização de leguminosas visando o cultivo contínuo de culturas alimentares. In: MESA REDONDA SOBRE RECUPERAÇÃO DE SOLOS ATRAVÉS DO USO DE LEGUMINOSAS. Belém, 1992. Trabalhos e recomendações. Belém: EMBRAPA - CPATU - GTZ, 1992. p.89-100 (EMBRAPA . CPATU. Documentos, 67)).

MARTINS, P.F.da S.; CERRI, C.C.; VOLKOFF, B.; ANDREUX, F. efeito do desmatamento e do cultivo sobre características físicas e químicas do solo sob floresta natural na amazônia oriental. Revista IG, v.11, n.1, p.21-33, 1990. 
MARTINS, P.F.da S.; CERRI, C.C.; VOLKOFF, B.; ANDREUX, F; CHAUVEL, A. Consequences of clearing and tillage on the soil of a natural amazonian ecosystem oriental. Forest Ecology and Management, v.38, p.273-302, 1991.

MEAD, J.A. A comparison of the Langmuir, Freundlich and Temkin equations to describe phosphate adsorption properties of soils. Australian Journal Soil Research, v.19, p.333-342, 1981.

MEHADI, A.A.; TAYLOR, R.W. Phosphate adsorption by two highly-weathered soils. Soil Science Society America Journal, v.52, p.627-632, 1988.

MEHADI, A.A.; TAYLOR, R.W.; SHUFORD, J.W. Prediction of fertilizer phosphate requirement using the Langmuir adsorption maximum. Plant and Soil, v.122, p.267-270, 1990 .

MESQUITA FILHO, M.V. de.; TORRENT, J. Phosphate sorption as related to mineralogy of a hydrosequence of soil from the Cerrado region (Brazil). Geoderma, v.58, p.107-123, 1993.

METHA, N.C.; LEGG, J.O.; GORING, C.A.I.; BLACK, C.A. Determination of organic phosphorus in soils. I. Extraction method. Soil Science Society America Journal, v.18, p.443-449, 1954.

MOLLER, M.R.F.; KLANT, E. Sorção de fósforo por colóides inorgânicos extraídos de dois solos da Amazônia. Belém: EMBRAPA - CPATU, 1984. 16p. (EMBRAPA . CPATU. Boletim de Pesquisa, 60).

MUNNS, D.N.; FOX, R.L. The slow reaction which continues phosphate adsorption: kinetics and equilibrium in some tropical soils. Soil Science Society America Journal, v.40, p.46-51, 1976.

MYERS, N. Tropical forests: present status and future outlook. Climate Change, v.19, p.3-32, 1991. 
NAKOS, G. Phosphorus adsorption by forest soils. Communications Soil Science Plant Analysis, v.18, n.3, p.279-286, 1987.

NICHOLAIDES, J.J., III; BANDY, D.E.; SÁNCHEZ, P.A.; BENITES, J.R.; VILLACHICA, J.H.; COUTU, A.J.; VALVERDE, C.S. Agricultural alternatives for the Amazon Basin. BioScience, v.35, p.279-285, 1985.

NZIGUHEBA, G.; PALM, C.A.; BURESH, R.J.; SMITHSON, P.C. Soil phosphorus fractions and adsorption as affected by organic and inorganic sources. Plant and Soil, v.198, p.159-168, 1998.

O'HALLORAN, I.P. Total and organic phosphorus. In: CARTER, M.R. (ed.) Soil Sampling and Methods of Analysis - part 2. Boca Raton: Lewis, 1993, p. 213229.

O'HALLORAN, I.P.; STEWART, J.W.; JONG, E. DE. Changes in forms and available as influenced by management practices. Plant and Soil, v.100, p.113-126, 1987.

OBERSON, A.; FARDEAU, J.C.; BESSON, J.M.; STICHER, H. Soil phosphurus dynamics in cropping systems managed according to conventional and biological agricultural methods. Biology and Fertility of Soils, v.16, p.111-117, 1993.

OHNO, T.; CRANNELL, B.S. Green and animal manure-derived dissolved organic matter effects on phosphorus sorption. Journal Environmental Quality, v.25, p.1137-1143, 1996.

OLSEN, S.R.; SOMMERS, L.E. Phosphorus. In: PAGE, A.L.; MILLER, R.H. \& KEENEY, D.R. (Ed.), Methods of Soil Analysis - part 2. Madison: American Society of Agronomy, 1982. p.403-431.

OLSEN, S.R.; WATANABE, F.S. A method to determine a phosphous adsorption maximum of soils as measured by the Langmuir isotherm. Soil Science Society America Proceedings, v.24, p.144-149, 1957. 
O'RELLY, S.E.; SIMS, J.T. Phosphorus adsorption and desorption in a sandy soil amended with high rates of coal fly ash. Communications Soil Science Plant Analysis, v.26, n.17/18, p.2983-2993, 1995.

PADOCH, C.; CHOTA INUMA, J.; De JONG, W.; UNRUH, J. Amazonian agroforestry: a market-oriented system in Peru. Agroforestry Systems, v.3, p.4758, 1985.

PARFITT, R.L. Anion adsorption by soils and soil materials. Advances in Agronomy, v.30, p.1-50, 1978.

PARFITT, R.L.; ATKINSON, R.J.; SMART, R.S.T.C. The mechanism of phosphate fixation by iron oxides. Soil Science Society of America Proceedings, v.39, p.837$841,1975$.

PAVAN, M.A.; FILHO, A.A. Fracionamento de fósforo em um experimento de manejo da fertilidade do solo para produção de café no noroeste do Paraná. Arquivos de Biologia e Tecnologia, v.38, n.1, p.157-165, 1995.

PAVAN, M.A.; LEAL, A.C. Utilização de uma técnica de fracionamento para caracterizar formas de fósforo em solo incubado com resíduos de leucena. Arquivos de Biologia e Tecnologia, v.38, n.2, p.375-383, 1995.

RAIJ, B. van. Fertilidade do solo e adubação. Piracicaba: POTAFOS, 1991. 343p.

RAIJ, B. van.; QUAGGIO, J.A.; CANTARELlA, H. et al. Análise química do solo para fins de fertilidade. Campinas: Fundação Cargill, 1987. 170p.

RAIJ, B. van; SACCHETTO, M.T.D. Correlações entre o pH e o grau de saturação em bases nos solos com horizonte B textural e horizonte B latossólico. Bragantia, v.27, n.17, p.193-200, 1968.

RAINTREE, J.B.; WARNER, K. Agroforestry pathways for the intensification of shifting cultivation. Agroforestry Systems, v.4, p.39-54, 1986. 
RAJAN, S.S.S.; FOX, R.L. Phosphate adsorption by soils: II. Reactions in tropical acid soils. Soil Science Society America Journal, v.42, p.846-851, 1975.

RAVEN, K.P.; HOSSNER, L.R. Soil phosphorus desorption kinetics and its relationship with plant grwth. Soil Science Society of America Journal, v.58, p. 416-423, 1994.

RODER, W.; PHONGCHANH, S.; MANIPHONE, S. Dinamics of soil and vegetation during crop and falow period in slash-and-burn fields of northern Laos. Geoderma, v.76, p.131-144, 1997.

SÁ, T.D. de A.; VIELHAUER, K.; KANASHIRO, M.; DENICH, M.; VLEK, P.L.G. Towards improving natural resources use in Eastern Amazonia through a modified sequential agroforestry system. In: CONGRESSO BRASILEIRO EM SISTEMAS AGROFlORESTAIS, 2., Belém, 1998. Resumos Expandidos. Belém: Embrapa Amazônia Oriental, 1998. p.95-100.

SAMPLE, E.C.; SOPER, R.J.; RACZ, G.J. Reactions of phosphate fertilizers in soils. In: KHASAWNEH, F.E.; SAMPLE, E.C.; KAMPRATH, E.J. (Ed.) The role of phosphorus in agriculture. Madison: American Society of Agronomy, 1980. p.263-310.

SANCHEZ, P.A. Properties and Management of soils in the tropics. New York:John Wiley. 1976. 618p.

SANCHEZ, P.A.; BANDY, D.E.; VILLACHICA, J.H.; NICHOLAIDES, J.J. Amazon Basin Soils: management for continuos crop production. Science, v.216, p.821-827, 1982.

SANCHEZ, P.A.; BENITES, J.R. Low-input cropping for acid soils of the Humid Tropics. Science, v.238, p.1521-1527, 1987 
SANCHEZ, P.A.; BUOL, S.W. Soils of the tropics and the food crisis. Science, v.188, p.598-603, 1975.

SANCHEZ, P.A.; SALINAS, J.G. Low-input technology for managing oxisols and ultisols in tropical america. Advances in Agronomy, v.34, p.279-406, 1981.

SANCHEZ, P.A.; UEHARA, G. Management considerations for acid soils with high phosphorus fixation capacity. In: KHASAWNEH, F.E.; SAMPLE, E.C.; KAMPRATH, E.J. (Ed.) The role of phosphorus in agriculture. Madison: American Society of Agronomy, 1980. p.471-514.

SAS INSTITUTE. SAS: Procedures Guide, Release 6.03 Edition. Cary, 1988. 441p.

SAUNDERS, W.M.; WILLIAMS, E.G. Observations on the determination of organic phosphorus in soils. Journal of Soil Science, v.6, p.254-267, 1955.

SCHROEDER, P. Organic matter cycling by tropical agroforestry systems: A review. Journal of Tropical Forest Science, v.7, n.3, p.462-474, 1995.

SERRÃO, E.A. Possibilites for sustainable agriculture development in the Brazilian Amazon: An EMBRAPA proposal. In: M. CLÜSENER-GODT; I. SACHS (Ed.) Brazilian perspectives on sustainable development of the Amazon region. Pearl River, New York: Parthernon, 1995. p.259-285 (Man \& the Biosphere Series 15).

SEUBERT, C.E.; SANCHEZ, P.A.; VALVERDE, C. Effects of land clearing methods on soil properties of na ultisol and crop perfomance in the Amazon jungle of Peru. Tropical Agriculture, v.54, n.4, p.307-321, 1977.

SILVA, L.F.da. Alterações edáficas em "Solos de Tabuleiro" (Haplorthoxs) por influência do desmatamento, queima e sistemas de manejo. Revista Theobroma, v.11, n.1, p.5-19, 1981. 
SILVA, M.L.N.; CURI, N.; BLANCANEUX, P.; LIMA, J.M. de; CARVALHO, A.R. de. Rotação adubo verde - milho e adsorção de fósforo em Latossolo VermelhoEscuro. Pesquisa Agropecuária Brasileira, v.32, n.6, p.649-654, 1997.

SING, B.B.; JONES, J.P. Phosphorus sorption and desorption characteristics of soil as affected by organic residues. Soil Science Society of America Journal, v.40, p.389-394, 1976.

SINGH, R.; MOLLER, M.R.F.; FERREIRA, W. de A. Características da sorção do fósforo relacionadas com propriedades selecionadas de solos dos trópicos úmidos da Amazônia. Revista Brasileira de Ciência do Solo, v.7, p.233-241, 1983.

SMECK, N.E. Phosphurus dynamics in soils and landscapes. Geoderma, v.36, p.185$199,1985$.

SMYTH, T.J.; BASTOS, J.B. Alterações na fertilidade de um Latossolo Amarelo álico pela queima da vegetação. Revista Brasileira de Ciência do Solo, v.8, p.127-132, 1984.

SMYTH, T.J.; SANCHEZ, P.A. Effects of lime, silicate and phosphorus application to na Oxisol on phosphorus sorption and íon retention. Soil Science Society of America Journal, v.44, n.3, p.500-505, 1980.

SOMMER, R.; VLEK, P.L.G.; FÖLSTER, H.; SÁ, T.D. de A. Slash and mulch to reduce nutrient losses in shifting cultivation in the Eastern Amazon. In: SEMINÁRIO SOBRE MANEJO DA VEGETAÇÃO SECUNDÁRIA PARA SUSTENTABILIDADE DA AGRICULTURA FAMILIAR DA AMAZÔNIA ORIENTAL, Belém, 1999. Anais, Belém: Embrapa Amazônia Oriental/CNPq, 2000. p.80-81. (Embrapa Amazônia Oriental. Documentos, 69).

SPARKS, D.L.; JARDINE, P.M. Comparison of kinetic equations to describe potassium-calcium exchange in purê and in mixed systems. Soil Science, v.138, n.2, p.115-122, 1984. 
STEWART, J.W.B.; TIESSEN, H. Dynamics of soil organic phosphurus. Biogeochemistry, v.4, p.41-60, 1987.

SZOTT, L.T.; PALM, C.A. Nutrients stocks in managed and natural humid tropical fallows. Plant and Soil, v.186, p.293-309, 1996.

TAYLOR, R.W.; BLEAM, W.F.; TU, S. On the Langmuir phosphate adsorption Maximum. Communications Soil Science Plant Analysis, v.27, n.13/14, p.2713$2722,1996$.

THOMAS, G.W.; PEASLEE, D.E. Testing soils for phosphorus. In: WALSH, L.M.; BEATON, J.D. (Ed.) Soil testing and plant analysis. Madison: Soil Science Society of America, 1973. p.115-129.

THOMPSON, E.J.; BLACK, C.A. Change in extractable organic phosphorus in soil in the presence and absence of plants - III. Phosphatase effects. Plant and Soil, v.32, p.335-348, 1970 .

TIESSEN, H.; MOIR, J.O. Char acterization of available P by sequential extraction. In: CARTER, M.R. (ed.) Soil Sampling and Methods of Analysis part 2. Boca Raton: Lewis, 1993, p. 75-86.

TIESSEN, H.; SALCEDO, I.H.; SAMPAIO, E.V.S.B. Nutrient and soil organic matter dynamics under shifting cultivation in semi-arid northeastern Brazil. Agriculture Ecosystems and Environment, v.38, p.139-151, 1992.

TIESSEN, H.; STEWART, J.W.B.; COLE, C.V. Pathways of phosphurus transformations in soils of differing pedogenesis. Soil Science Society America Journal, v.48, p.853-858, 1984.

TURRIÓN, M.B.; GLASER, B.; SOLOMON, D. Effects of deforestation on phosphorus pools in mountain soils of the Alay Range, Khyrgyzia. Biology and Fertility of Soils, v.31, p.134-142, 2000. 
UDO, E.J.; UZU, F.O. Charac teristics of phosphorus adsorption by some Nigerian soils. Soil Science Society of America Proceedings, v.36, p.879-883, 1972.

VIEIRA, L.S. Formas de fósforo em solos amazônicos. Boletim da FCAP, v.17, p.17$30,1988$.

VIEIRA, L.S.; SANTOS, P.C.T. Amazônia: seus solos e outros recursos naturais. São Paulo: Agronômica Ceres, 1987. 416p.

WALBRIDGE, M.R. Phosphurus availability in acid organic soils of the lower North Carolina coastal plain. Ecology, v.72, p.2083-2100, 1991.

WALKER, T.W.; ADAMS, A.F.R. Stuies on soil organic matter. I. Influence of phosphorus content of parent materials on accumulations of carbon, nitrogen, sulfur and organic phosphorus in glassland soils. Soil Science, v.85, p.307-318, 1958.

WALKER, T.W.; SYERS, J.K. The fate of phosphorus during pedogenesis. Geoderma, v.5, p.1-19, 1976.

WIERSUM, K.F. Tree gardening and taungya on Java: Examples de agroforestry techniques in the humid tropics. Agroforestry Systems, v.1, p.53-70, 1983. 